\title{
THE AIR POLLUTION CONTRIBUTIONS OF A LARGE-SCALE SUBURBAN DEVELOPMENT
}

\author{
by
}

Victoria Grace Di Poce

BASc., Ryerson University, Toronto, Ontario, 2007

BSc., University of Toronto, Toronto, Ontario, 2005

\author{
A thesis \\ presented to Ryerson University \\ in partial fulfillment of the \\ requirements for the degree of \\ Master of Applied Science \\ in the Program of
}

Environmental Applied Science and Management

Toronto, Ontario, Canada, 2009

() Victoria Grace Di Poce 2009 
I hereby declare that I am the sole author of this thesis or dissertation.

I authorize Ryerson University to lend this thesis or dissertation to other institutions or individuals for the purpose of scholarly research.

I further authorize Ryerson University to reproduce this thesis or dissertation by photocopying or by other means, in total or in part, at the request of other institutions or individuals for the purpose of scholarly research. 


\begin{abstract}
The Air Pollution Contributions of a Large-scale Suburban Development, Master of Applied Science 2009,

Victoria Grace Di Poce, Environmental Applied Science and Management, Ryerson University.
\end{abstract}

In 2007, Toronto Public Health found that air pollution from traffic causes as many as 440 premature deaths and 1,700 hospitalizations annually in the city. Many researchers have demonstrated the links between urban design and vehicle use, however little research has been done to address the air pollution contributions of vehicle-dependent, large-scale suburban developments. To address this deficiency, this study estimated the air pollution contributions of a 6,755 unit approved subdivision, to be built in the Town of Richmond Hill, Ontario. Using the Canadian Mortgage and Housing Corporation's Tool for Evaluating Neighbourhood Sustainability and Transportation Canada's Urban Transportation Emissions Calculator the quantity of vehicle-produced criteria air contaminants were estimated for the development in the years 2010 and 2030. The quantity of CAC emissions estimated for both 2010 and 2030 suggest that the forecast emissions from the development are non-trivial and that further study should be conducted to estimate the health impacts of this development. 


\section{ACKNOWLEDGEMENTS}

I would really like to thank Prof. Ron Pushchak for his encouragement and his advice. Without his guidance and support this thesis would have never been possible. Thank you for your kindness and confidence in me.

I would also like to thank my husband, Pat, for his love, support and patience. I could not thank him enough for putting up with my paper tornadoes and endless worrying. Thank you for your tolerance and your computer formatting savvy. I love you.

Finally, I want to thank my mom and little sister, who inspire me to keep achieving my goals. Thank you for your endless encouragement. 


\section{TABLE OF CONTENTS}

Table of Contents $\mathbf{v}$

List of Figures........................................................................................................................... ix

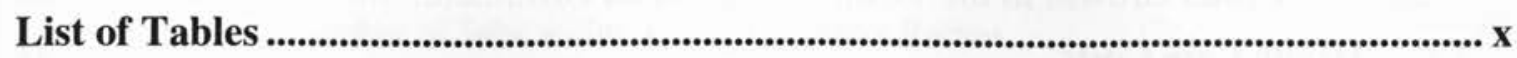

List of Backup Figures/Tables in Appendix 1 ............................................................. xi

1 Introduction ........................................................................................................... 1

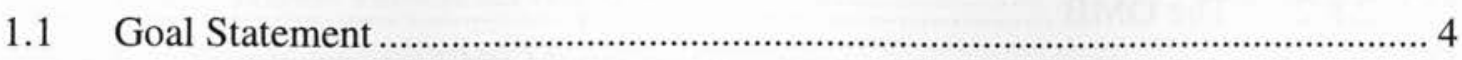

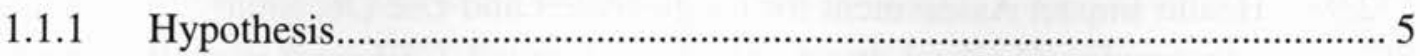

1.2 Objectives

2 Background Literature Review....................................................................... 7

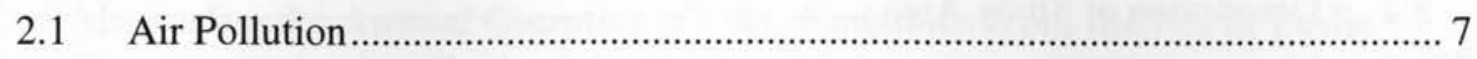

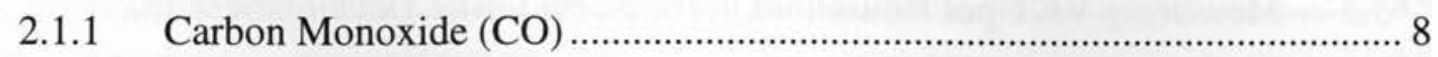

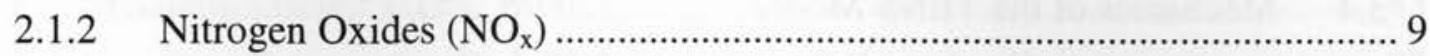

2.1.3 Volatile Organic Compounds (VOCs) …………………........................... 10

2.1.4 Particulate Matter (PM) ........................................................................ 10

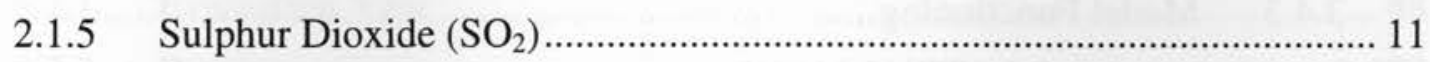

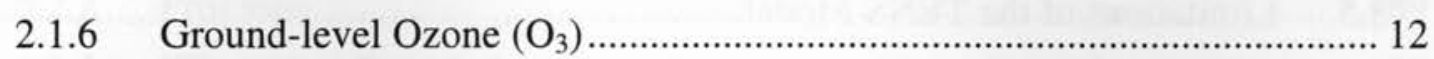

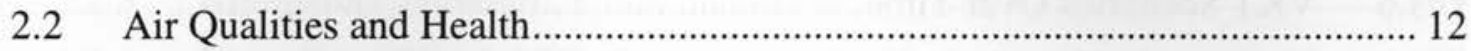

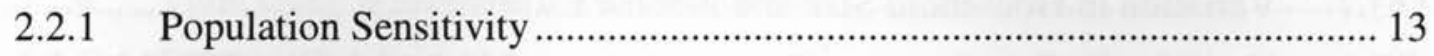

2.2.2 Linking Air Quality to Health Impacts ................................................... 13

2.2.3 Respiratory Disease and Air Pollution..................................................... 14

2.2.4 Cardiovascular Disease and Air Pollution ……........................................ 15

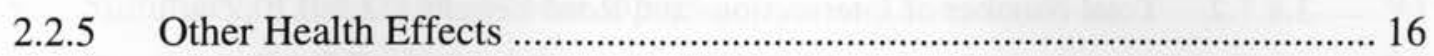

2.3 Vehicle Emissions, Air Pollution and Health..................................................... 16

2.3.1 Exposure to Vehicle Emissions ........................................................... 17

2.3.2 Overall Morbidity and Mortality from Traffic in Toronto........................... 19

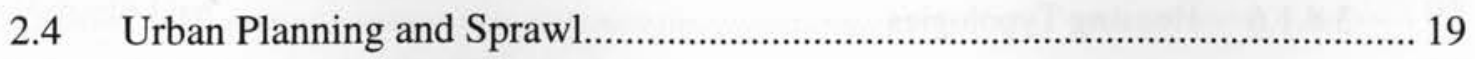

2.5 Linking the Built Environment and Travel Behavior........................................ 21

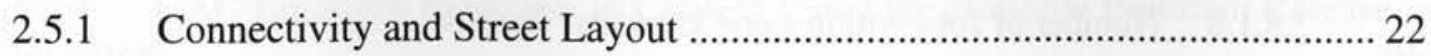

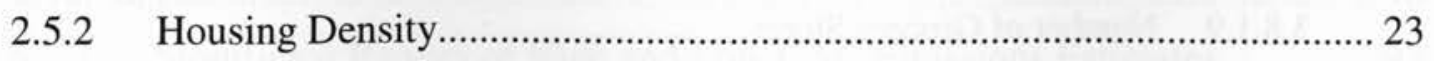

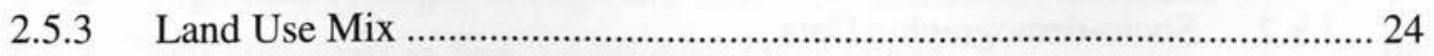


2.5.5 Transportation Infrastructure ................................................................ 25

2.6 Growth in the Greater Golden Horseshoe Area and the Town of Richmond Hill 26

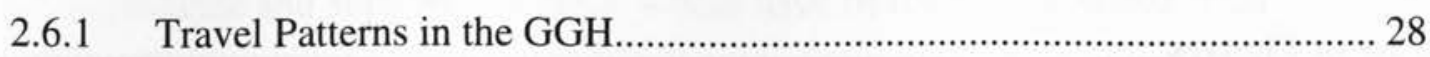

2.6.2 Urban Growth in the Town of Richmond Hill........................................... 28

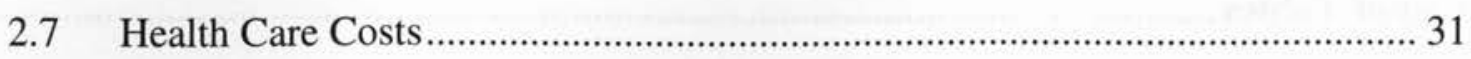

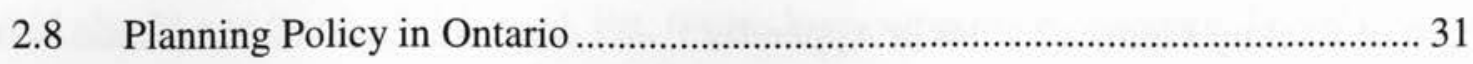

2.8.1 Shortcomings of Provincial Policies and Legislation ................................. 32

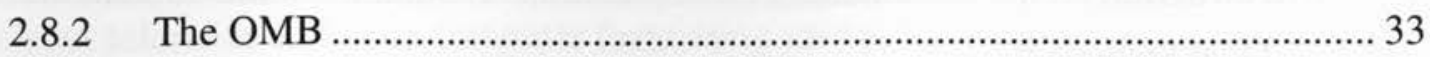

2.9 Health Impact Assessment for Large-scale Land Use Decisions....................... 34

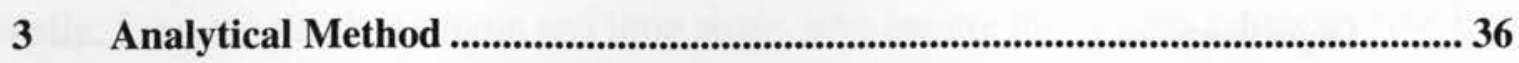

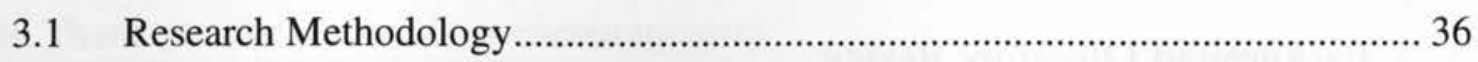

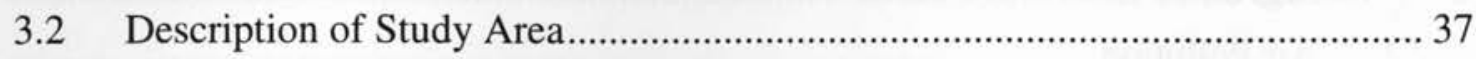

3.3 Measuring VKT per Household in the North Leslie Development ................... 40

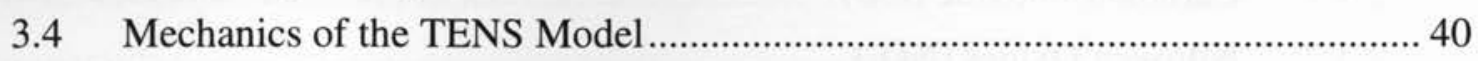

3.4.1 The Data Used in the TENS Model's Development.................................... 41

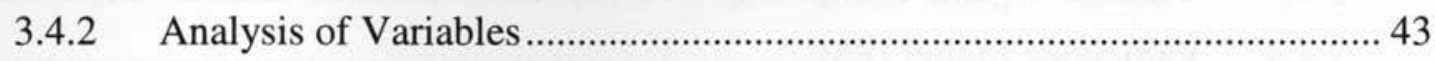

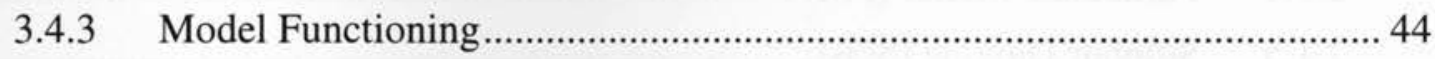

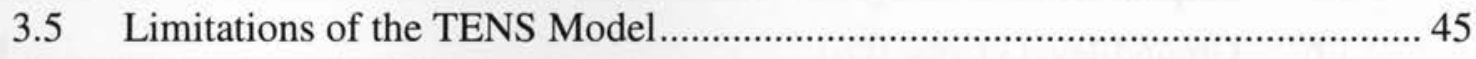

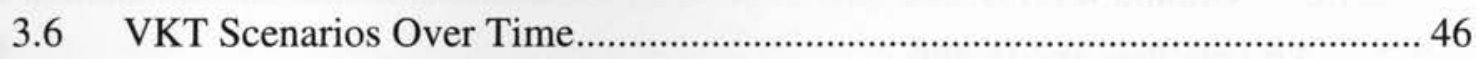

3.7 Variation in Household Size and Income Estimates ......................................... 47

3.8 North Leslie Development Characteristics and Values for the TENS Model.... 48

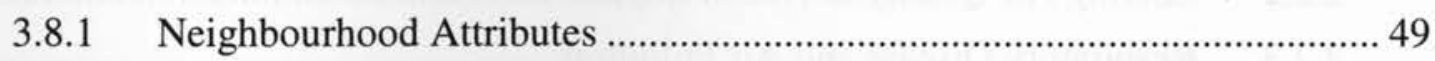

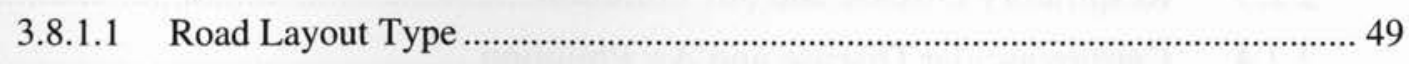

3.8.1.2 Total Number of Intersections and Road Length ............................................. 49

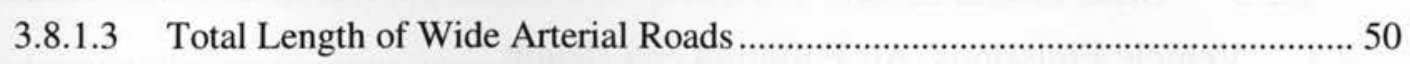

3.8.1.4 Total Length of Bike Routes .................................................................... 51

3.8.1.5 Land Area and Number of Housing Units ................................................... 53

3.8.1.6 Housing Typologies................................................................................... 54

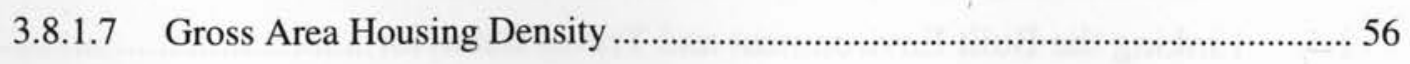

3.8.1.8 Number of Jobs within a one kilometer Radius............................................... 56

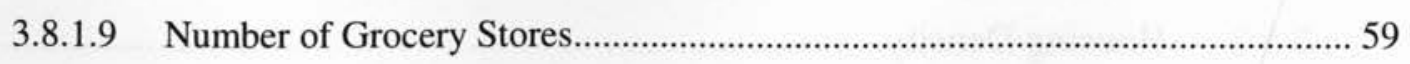

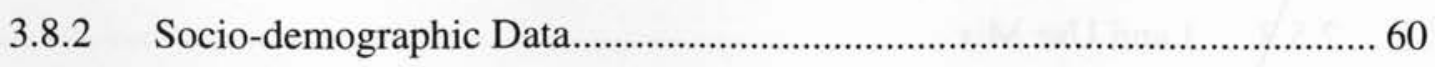




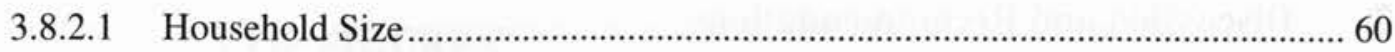

3.8.2.2 Percentage of the Population Under 16 Years Old............................................. 63

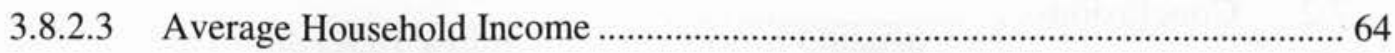

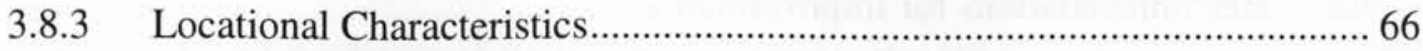

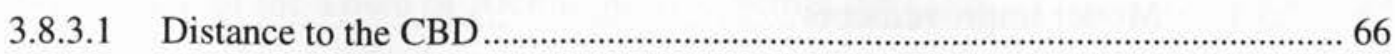

3.8.3.2 Number of Jobs within Five Kilometers Radius ............................................. 67

3.8.3.3 Distance to Nearest Rapid Transit Station........................................................ 70

3.8.3.4 Distance to the Nearest Commuter Rail Station.............................................. 71

3.8.3.5 Transit Vehicle Service Hours..................................................................... 72

3.8.4 Summary of TENS Model Inputs …………….......................................... 77

3.8.5 Results from VKT Estimations for the North Leslie Development............ 78

4 Measuring Annual VKT for the North Leslie Development ............................... 83

5 Measuring the Annual Quantity of CAC Emissions from the North Leslie

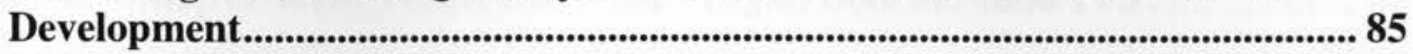

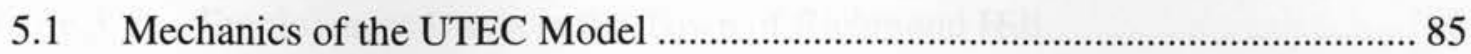

5.1.1 Data Sources for the UTEC Model CAC Emission Factors ....................... 87

5.2 UTEC Variables for the North Leslie Development......................................... 88

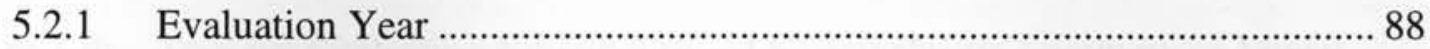

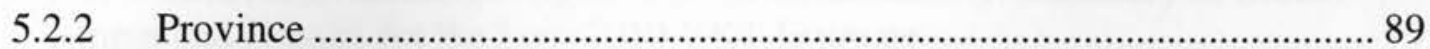

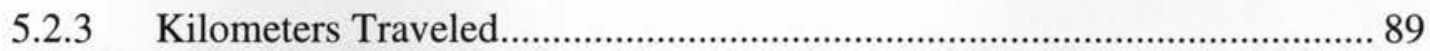

5.2.4 Time Over Which VKT was measured........................................................ 89

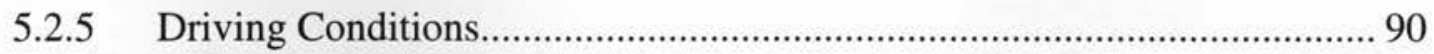

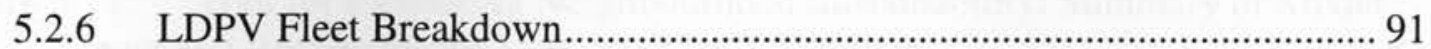

5.2.7 Fleet Breakdown by Fuel Technology …….......................................... 92

5.3 Summary of the UTEC Model Inputs ............................................................. 93

5.4 Resulting CAC Emissions from the UTEC Model ………............................... 94

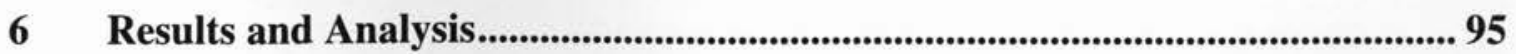

6.1 Estimating the VKT of a Large-scale Urban Development from Personal

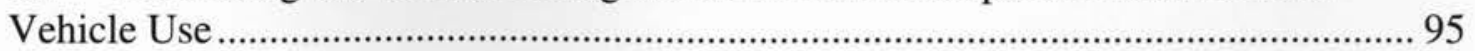

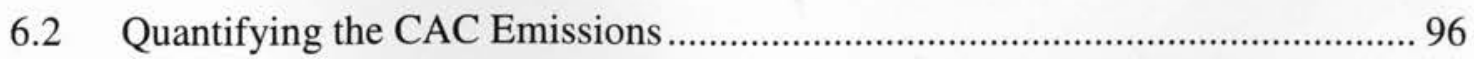

6.2.1 CAC Emission Estimates in Context Using the National Pollutant Release

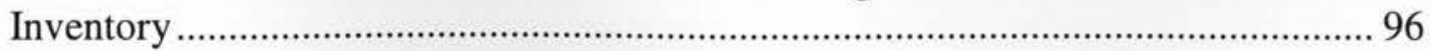

6.2.2 Significant Ranges of High and Low CAC Emissions Estimates .............. 97

6.2.3 Improvements in Fuel Technology Over Time........................................... 98 
7 Discussion and Recommendations ...........................................................................99

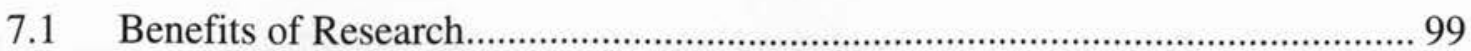

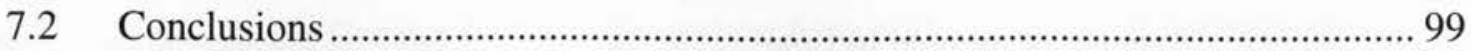

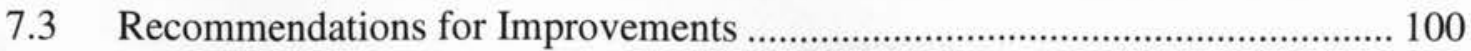

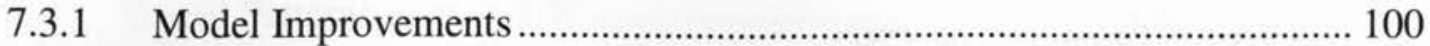

7.3.2 Data Collection Improvements ………................................................... 101

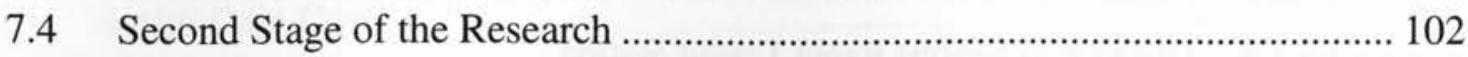

7.4.1 Quantifying the Human Health Impact of Large-scale Urban Development from Vehicle Use 102

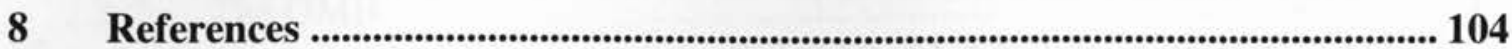

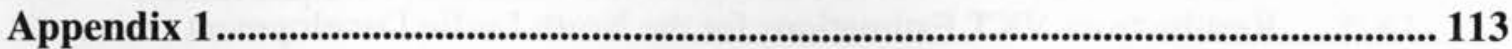

Glossary of Terms ................................................................................................................... 132 


\section{LIST OF FIGURES}

Figure 2-1: Map of the GGH within the Province of Ontario ……………………........ 27

Figure 2-2: $\quad$ Map of the Town of Richmond Hill within the GTA ................................. 29

Figure 3-1: Map of the North Leslie Development, Richmond Hill, Ontario ............... 39

Figure 3-2: 1996 Travel Survey Summary Area for the TTS ....................................... 42

Figure 3-3: Map of Toronto CMA used in the TENS Model ........................................ 43

Figure 3-4: Richmond Hill Transportation Master Plan Map of Recommended

Improvements to Municipal Road Networks........................................................ 52

Figure 3-5: Map of Retail Stores in RIOCAN Elgin Hills Crossing Retail Park, Richmond Hill, Ontario ................................................................................ 57

Figure 3-6: Map of Ward 3 (left) and Ward 5 (right) from the 2006 TTS .................... 62

Figure 3-7: Employment Lands in the Town of Richmond Hill..................................... 68

Figure 3-8: Map of the Area Used to Determine the Future Bus Service Network and Transit Service Hours for the North Leslie Development in 2030 .................... 75

Figure 3-9: Tool for Evaluating Neighbourhood Sustainability: Summary of Model Input and Results for the Low 2010 VKT Estimate ............................................. 79

Figure 3-10: Tool for Evaluating Neighbourhood Sustainability: Summary of Model Input and Results for the High 2010 VKT Estimate............................................ 80

Figure 3-11: Tool for Evaluating Neighbourhood Sustainability: Summary of Model Input and Results for the Low 2030 VKT Estimate

Figure 3-12: Tool for Evaluating Neighbourhood Sustainability: Summary of Model Input and Results for the High 2030 VKT Estimate. 82 


\section{LIST OF TABLES}

Table 2-1: New/Revised Ontario Planning Legislation and Policy Pieces 32

Table 3-1: Household Sizes and Household Income Distribution into the Four VKT Estimate Scenarios. 48

Table 3-2: Breakdown of the North Leslie Development by Dwelling Unit Type 55

Table 3-3: RIOCAN Elgin Hills Crossing Retail Park Employment Numbers, 2009. 58

Table 3-4: Percentage of the Population Under 15 Years Old Averaged Across Three Census Tracts.

Table 3-5: Median Household Income Values Used for the 2010 and 2030 VKT Estimates. 66

Table 3-6: Richmond Hill Employment Distribution. 69

Table 3-7: Current Public Transit Bus Routes Serving the North Leslie Development Used for the 2010 VKT Estimate

Table 3-8: Public Transit Bus Routes Used to Estimate the Public Transit Vehicle Service Hours of the North Leslie Development in the 2030 VKT Estimate .... 76

Table 3-9: Summary of the TENS Model Inputs for the North Leslie Development .. 77

Table 3-10: Weekday VKT per Household Estimates by the TENS Model for the North Leslie Development. .78

Table 4-1: Annual VKT for the Entire North Leslie Development................................ 84

Table 5-1: Summary of the UTEC Model Inputs for the North Leslie Development.. 93

Table 5-2: $\quad$ Summary of the Annual CAC Emission Outputs from the North Leslie Development Data (Tonnes).

Table 6-1: $\quad$ NPRI Threshold Reporting Levels for CAC Emissions Compared to the North Leslie Development CAC Emissions Estimates (Tonnes). 


\section{LIST OF BACKUP FIGURES/TABLES IN APPENDIX 1}

Table A-1: Road Layout/Configuration Descriptions from the TENS Model

Table B-1: Calculations of the Total Number of Employees in the RIOCAN Elgin Hills Crossing Retail Park

Table B-3: Sample of School Employment Numbers, 2009.

Table B-4: Calculation of the Total Number of Employees within one kilometer of the

North Leslie Development in 2030 ................................................................ 118

Figure C-1: Map of Census Tract 0422.03, Toronto, Ontario …................................... 119

Figure C-2: Map of Census Tract 0424.04, Toronto, Ontario ………………................ 120

Figure C-3: Map of Census Tract 0424.05, Toronto, Ontario ……………………......... 121

Figure D-1: Map of Bus Route No. 82 Valleymede-Spadina......................................... 122

Figure D-2: Map of Bus Route No. 83/83A Trench ..................................................... 123

Figure D-3: Map of Bus Route No. 90 Leslie South ....................................................... 124

Figure D-4: Map of Bus Route No. 91/91A/91E Bayview South ................................... 125

Figure D-5: Map of Bus Route No. 589 Richmond Hill Community Bus ...................... 126

Figure D-6: Map of Bus Route No. 86 Weldrick-Newkirk ………………..................... 127

Figure D-7: Map of Bus Routes No. 98 Yonge North and 99 Yonge South .................. 128

Table E-1: 2006 and 2031 CAC Emission Factors Used in the UTEC Model for LDPV

Vehicle Classes

Table F-1: 2006 Fuel Efficiency by Vehicle Class Used in the UTEC Model................ 130

Table F-2: 2030 Fuel Efficiency by Vehicle Class Used in the UTEC Model............... 131 
Air pollution is a growing public health concern in Canada. In 2008, it was reported by the Canadian Medical Association (2008) that over 21,000 Canadians die prematurely from air pollution-related illnesses. Despite the impact across the country, nowhere has this problem received as much attention as in the province of Ontario. It was the Ontario Medical Association that developed the Illness Cost of Air Pollution model in 2000 to estimate the impact that air pollution was having on public health and the health care system in Ontario (Ontario Medical Association, 2005). Through better scientific understanding of air pollution, the model was improved in 2005 and it established that approximately 5,800 premature deaths in Ontario were caused by air pollution in a single year, a number that would rise to 10,000 by 2026. It also reported air pollution would cost the province $\$ 7.8$ billion in health care costs.

While there are many sources of air pollution, vehicle emissions are a major source of air pollution and illness in Ontario. Vehicle emissions are responsible for 58 per cent of carbon monoxide $(\mathrm{CO})$ pollutants, 33 per cent of nitrogen oxides $\left(\mathrm{NO}_{\mathrm{x}}\right)$ pollutants, 20 per cent of particulate matter and 18 per cent of volatile organic compounds (VOCs) (Bray et al., 2005). In addition, they largely account for the production of ground-level ozone $\left(\mathrm{O}_{3}\right)$ formed by a mixture of VOCs and $\mathrm{NO}_{\mathrm{x}}$ in the presence of sunlight. These pollutants have major impacts on both the respiratory and cardio-vascular systems, contributing to the first and fourth leading causes of death in Ontario, heart and lung disease respectively (Chan and Young, 1999). In order to quantify the health impacts of vehicle use in Toronto, Toronto Public Health conducted a study in 2007 and found that air pollution from traffic alone gives rise to 440 premature deaths and 1,700 hospitalizations per year in Toronto (Toronto Public Health, 2007). This study helped to highlight the local health impact of vehicle emissions and the importance of reducing the production of vehicle emissions.

It has however long been known that vehicles emissions cause air pollution. Recognizing that cars and light trucks are responsible for 35 per cent of Ontario's greenhouse gas 
(GHG) emissions and a significant amount of air pollution, the government began to regulate the production of emissions per vehicle kilometer traveled (VKT) (Burda, 2008). This was accomplished by legislating the use of emission control technology and the chemical composition of fuel. The government also established initiatives such as the Drive Clean program in 1999, which is an automobile emission control program that ensures proper vehicle maintenance. Unfortunately, in recent years the ever-increasing number of vehicles on the road and greater distances traveled has outweighed any progress made by these initiatives and this has caused the focus of study to turn towards urban planning and vehicle use (Bray et al., 2005; Donnan, 2008).

Through multiple studies, the frequency with which an individual or family travels by car and their trip duration has been found to be influenced by the design and location of their neighbourhood. Results from many studies comparing neighbourhood design have found that low density, single purpose land use and poorly-connected street networks are associated with much greater vehicle dependence (Ewing \& Kreutzer, 2006; Ewing \& Cervaro, 2001; Frank et al., 2000). For example, a characteristic such as low-density housing results in inadequate ridership to support public transit or, lack of street connectivity along with single use zoning decreases a community's level of walkability. In fact, in 2008 , it was found that while the average commute was only 9.2 kilometers in the Greater Toronto and Hamilton Area, a mere 4.6 per cent of people walked to work, and 0.8 per cent of people cycled (Canzi, 2008). As neighbourhoods are designed for automobile use, community amenities and employment gradually move further and further from the city centre.

Urban growth with these sprawling characteristics, common to the suburban developments on the periphery of the metropolitan areas in Ontario, has been termed 'urban sprawl'. In the 2006 Canadian Census, it was reported that almost two thirds of the metropolitan growth occurred on the periphery of metropolitan areas and almost 60 per cent of household dwellings were single-family detached houses in Canada. Compounding the problem, there has been a 173 per cent increase in number of private dwellings, but only a 73 per cent increase in population, and the number of persons per 
household has fallen to 2.5, down 36 per cent since the 1961 (Donnan, 2008). In addition, the increase in population and expansion of urban sprawl has doubled the number of cars in Canada over the last twenty years (Pim \& Ornoy, 2005).

These numbers are particularly concerning in Ontario since over the next 30 years Ontario's population is expected to grow by another 3.8 million to 15.4 million people, with 7.5 million or 49 per cent of Ontarians calling the Greater Toronto Area their home. If urban development in Southern Ontario continues to follow 'business-as-usual' patterns, another 260,000 acres of rural land will be converted to low-density, automobile-dependent, urban sprawl development. This is expected to increase automobile trips during peak hours in the GTA by approximately 50 per cent over the next twenty years. Consequently, hours of delay experienced by drivers will increase by 300 per cent and $\mathrm{CO}$ emissions are expected to increase by 42 per cent per capita (IBI Group \& Dillon Consulting, 2002).

In recent years the Government of Ontario has attempted to curtail urban sprawl through the imposition of new planning policy and the enactment of planning legislation, such as revising the Provincial Policy Statement and enacting the Places to Grow Act, 2005. However, they are largely unable to affect individual development decisions. Municipal and provincial officials often face convincing economic incentives to approve less than suitable development applications that promise to generate jobs and investments in their communities.

Ontario's planning approval process, whether at the provincial or the local level, has no requirements to evaluate the impact that these individual residential developments have on public health and the resultant healthcare costs. One reason for this is the lack of assessment tools applied to private developments and the need to effectively relate specific developments to environmental outcomes. Although many researchers have either studied the impact of air pollution on health or the influence that urban sprawl has on personal vehicle travel, little work has been done to quantify the health impact that vehicle emissions resulting from individual developments have on regional communities. 
As with many of the environmental initiatives, such as the reduction of the sulphur content of fuels, planning decisions require impact numbers, not general goals of better air quality. The planning process demands numbers and the current information gap allows the potential health impact to be ignored. This is particularly true for major large suburban developments that receive approval at the Ontario Municipal Board (OMB) as the health impacts are assumed to be minor without an estimate of the actual health effects of each development. With little empirical evidence that links new major development approvals to increased morbidity and mortality, the health consequences will remain a factor outside of the decision making process.

\subsection{Goal Statement}

The study undertaken in this thesis is the first part of a two part study to estimate the health outcomes of a single large-scale suburban development. The first part of this study, conducted in this thesis, was to quantify the criteria air contaminants (CAC) resulting from an increase in vehicular emissions from a recently approved large-scale suburban development common in Southern Ontario. The second part, yet to be completed, will input the air contaminant quantities into an area dispersion model to estimate the predictable health outcomes of the contaminants added.

The study focused narrowly on a 620 -hectare residential development located in the town of Richmond Hill, Ontario, known as the North Leslie Development. Having already been approved by the local and provincial OMB planning authorities, the development will contain approximately 6,755 dwellings, most of which are low-density and all of which are within a development with limited street connectivity and land use zoning, thereby fitting the urban sprawl definition.

This thesis was broken down into two phases. The first phase of this study required quantifying the VKT of every household in the future neighbourhood with the use of the Canadian Mortgage and Housing Corporation's (CMHC) Tool for Evaluating Neighbourhood Sustainability (TENS). The key goal of this phase was to estimate the 
total number of VKT produced by residents in the entire North Leslie Development on an annual basis.

The second phase of the study involved converting the annual VKT from the development into the weight of additional CACs that would be released into the airshed annually from the additional vehicular emissions. This conversion was conducted using Transport Canada's Urban Transportation Emissions Calculator (UTEC). The goal of this phase was to estimate the weight of additional CAC emission in order to provide the information required for a future investigation to estimate the increases in morbidity and mortality-related health impacts that are related to land-use decisions and urban sprawl developments.

\subsubsection{Hypothesis}

This study is expected to find that the North Leslie Development will produce non-trivial levels of CAC emissions annually from the increase in vehicular traffic from the development's new residents. It is also expected to identify an increase in the amount of

CACs produced over time. Currently, large-scale urban land use decisions are assumed to have trivial impacts on their contribution of pollutants to the airshed. It is anticipated that this assumption is wrong and that large-scale urban developments should be evaluated to determine their impact on air pollution before being approved for development.

\section{$1.2 \quad$ Objectives}

This thesis has the following objectives:

1) To conduct a literature review examining the chemical components of air pollution, the health impacts of these pollutants, the contribution of air pollutants from vehicle emissions, the link between the built environment and travel behavior, the urban development trends in Southern Ontario, and the current planning policies in Ontario. 
2) To calculate the approximate total quantity of household-generated VKT for a suburban development immediately after it is built and twenty years into the future.

3) To estimate the quantity of CAC emissions that will be added to the airshed annually from the additional VKT produce by the development after it is built and twenty years into the future. 
Air pollution causes illness, automobiles are major contributors to air pollution and urban sprawl encourages vehicle dependency. The background section of this thesis will help to establish a correlation between public health and the built environment, specifically the potential health consequences of large-scale developments at the urban periphery. It will begin by reviewing the components of air pollution from fossil-fuel combustion and demonstrate the relationship between vehicles and air pollution. It will then present research highlighting the large impact that air pollution has on public health and discuss the literature that correlates land use to vehicle dependence and driving patterns.

This section will also shed light on urban planning policy in the Province of Ontario. It will discuss the current policy tools used to diminish urban sprawl projects and the criticism they have received for not being adequate. This discussion will help indicate where there are policy gaps regarding public health and sprawling urban developments.

Together, this background information will help to demonstrate the need to investigate the air pollution contribution and ensuing health impacts of large-scale, suburban developments, which is necessary if provincial planning processes are ever to account for the broader human health consequences of each individual development.

\section{1}

\section{Air Pollution}

Air is composed of four main gases: nitrogen, oxygen, argon and carbon dioxide. To sustain life, these four gases plus trace amounts of other chemicals must maintain a relatively stable ratio to one another. However, a multitude of undesirable gases and particles derived from both natural sources and human activities are constantly being released into the atmosphere as air pollutants threatening the health of humans, animals and damaging plants. While many human activities create pollution, the most significant activity contributing to air pollution is the combustion of fossil fuels. This includes activities such as personal transportation, heating and cooling of buildings, operating 
industries, transporting goods and making electricity (Pollution Probe, 2002). The noxious mixture of vapours, gases and particles created by these activities is commonly referred to as "smog" (NSIDC, n.d.).

Smog is composed of a group of primary and secondary pollutants. This group of pollutants is commonly referred to as 'criteria air contaminants' (CAC). The CACs that are primary pollutants are: $\mathrm{CO}, \mathrm{NO}_{\mathrm{x}}$, sulphur dioxide $\left(\mathrm{SO}_{2}\right)$, VOCs, and airborne particulate matter (PM). These products are emitted directly into the atmosphere from sources that burn fossil fuels. The CACs that are secondary pollutants, on the other hand, are produced in the atmosphere. Unlike primary pollutants, secondary pollutants do not come directly out of the stack or tail pipe. Instead, they are formed by reactions that take place in the atmosphere between primary pollutants, water vapour and sunlight. These include toxins such as ground-level ozone $\left(\mathrm{O}_{3}\right)$, some kinds of airborne PM, and acid aerosols (sulfuric and sulfurous, and nitrous and nitric acids) (Pollution Probe, 2002; David Suzuki Foundation, 1998).

The following is a listing of CAC emitted by cars and light trucks, and their role in the atmospheric pollution process. The CACs discussed will later be quantified in the study using the VKT from the North Leslie Development, therefore it is important to understand their physical characteristics and impact on human health.

\subsubsection{Carbon Monoxide (CO)}

$\mathrm{CO}$ is a coulourless, odourless, tasteless and poisonous gas which has both anthropogenic and natural sources. Man-made CO sources include vehicle engines and energy generation through the burning of fuel (Ministry of the Environment, 2009a). Emitted

directly into the atmosphere, $\mathrm{CO}$ production is the result of a low fuel-to-air ratio during the fuel combustion process, which occurs most often in vehicles during start-up and when cars are not properly tuned. It is also influenced by weather, with $\mathrm{CO}$ emission levels worsening in the cold winter months (Pollution Probe, 2002; U.S. EPA, n.d.). 
Eighty-five per cent of $\mathrm{CO}$ emissions in Ontario are from transportation, 45 per cent of which are the result of road vehicles (Ministry of the Environment, 2009a). Personal vehicles are responsible for 85 to 90 per cent of $\mathrm{CO}$ emissions in cities, and $\mathrm{CO}$ levels increase dramatically during traffic congestion (U.S. EPA, 2009a) Fortunately, CO emissions have been targeted for reduction through government legislation. The U.S. Environmental Protection Agency reports that between 1980 and 2008, CO levels have fallen by 79 per cent following the introduction of the catalytic converter (U.S. EPA, 2009b). Unfortunately, the technological improvements have been offset by the increased demand for automobiles.

\subsubsection{Nitrogen Oxides $\left(\mathrm{NO}_{\mathrm{x}}\right)$}

$\mathrm{NO}_{\mathrm{x}}$ are a group of compounds that include nitric oxide (NO), nitrogen dioxide $\left(\mathrm{NO}_{2}\right)$ and nitrous oxide $\left(\mathrm{N}_{2} \mathrm{O}\right)$. Some come from natural sources; however, anthropogenic activity has strongly increased the amount of nitrogen compounds in the environment. The most common forms of nitrogen which pollute the air are $\mathrm{NO}, \mathrm{NO}_{2}$, and $\mathrm{NH}_{3}$. (WHO Regional Office for Europe, 2000). Approximately 94 per cent of the $\mathrm{NO}_{\mathrm{x}}$ gases are from vehicles, industry, production of electrical power and home heating (David Suzuki Foundation, 1998). $\mathrm{NO}$ and $\mathrm{NO}_{2}$ are precursors for tropospheric $\mathrm{O}_{3}$ and $\mathrm{N}_{2} \mathrm{O}$ contributes to the depletion of stratospheric $\mathrm{O}_{3}$, also known as the ozone layer (WHO Regional Office for Europe, 2000).

While catalytic converters have helped to reduce some of the $\mathrm{NO}_{\mathrm{x}}$ from vehicle emissions, there has been an overall increase of nitrogen gases in the atmosphere due to an increased number of vehicles on the road and a trend towards larger, less efficient vehicles. From 2 to 5 per cent of $\mathrm{NO}_{\mathrm{x}}$ emissions from gasoline engines are emitted in the form of $\mathrm{NO}_{2}$ under normal driving conditions and up to 30 per cent under idling conditions (Soltic and Weilenmann, 2002). This is an important public health consideration as $\mathrm{NO}_{2}$ is more toxic that $\mathrm{NO}$ and has the potential to create more $\mathrm{O}_{3}$ (Soltic and Weilenmann, 2002). There have been studies done on the effects of $\mathrm{NO}_{2}$ on the respiratory system which have concluded that elevations of $\mathrm{NO}_{2}$ in the air have lead 
to increases in hospitalizations for respiratory illness and mortality (Burnett, 1998; Anderson, 1996).

\subsubsection{Volatile Organic Compounds (VOCs)}

VOCs are organic gases that are released from certain solids or liquids (U.S. EPA, 2009e). Five times more VOCs come from natural sources than from man-made sources (David Suzuki Foundation, 1998). Nonetheless, in urban areas anthropogenic VOCs are much more common and contribute significantly to the production of smog (Environment Canada, 1997). VOCs react with $\mathrm{NO}_{\mathrm{x}}$ in the presence of sunlight to form $\mathrm{O}_{3}$ and also contribute to the formation of secondary PM through complex chemical processes. VOCs are found in gasoline and diesel vehicle emissions due to incomplete combustion, evaporative emissions from vehicle refueling stations and fumes from solvents, including oil-based paints and household cleaning products (U.S. EPA, 2009e; Pollution Probe, 2002).

\subsubsection{Particulate Matter (PM)}

Airborne particulates are very small particles found suspended in the atmosphere. While they can be solid or aerosols, it is their size that defines their behavior and influences the impact they have on the environment and human health (U.S. EPA, 2009d). Particulates are measured by their diameter. Generally, when discussing air pollution, two groups of particulates receive the most attention. The first group is particulates under 10 microns $(\mu \mathrm{m})\left(\mathrm{PM}_{10}\right)$, and the second is particulates under $2.5 \mu \mathrm{m}\left(\mathrm{PM}_{2.5}\right)$. They can both come from natural and man-made sources. Natural sources include forest fires and volcanoes. Anthropogenic sources include mechanical processes, such as mining and drilling, the burning of biomass, and the combustion of fossil fuels, which includes vehicle emissions, power generation, and industrial processes (U.S. EPA, 2009d). Primary particles are those emitted directly from the source, whereas secondary particles are formed in the atmosphere through chemical reactions, often involving $\mathrm{NO}_{\mathrm{x}}, \mathrm{SO}_{2}, \mathrm{VOCs}$ and $\mathrm{NH}_{3}$. The primary particles can also become secondary particles by adhering to other pollutants, 
such as heavy metals, increasing their toxicity (Pollution Probe, 2002; David Suzuki Foundation, 1998).

Particle size often dictates the length of time the particle will remain suspended in the atmosphere. This can range from minutes for $\mathrm{PM}_{10}$ to weeks for $\mathrm{PM}_{2.5}$ (Pollution Probe, 2002). Size also determines how far the particle can penetrate in the lung when it is inhaled. $\mathrm{PM}_{10}$ or larger will usually never get to the lungs since it gets caught in the nose or throat when inhaled. PM smaller than $10 \mu \mathrm{m}$ however is considered "inhalable" and has the ability to penetrate deep into the lung tissue even so far as reaching the blood stream (Brook et al., 2004). Recently, significant research has been done to understand the impacts of $\mathrm{PM}_{2.5}$ and smaller on the cardio-respiratory system. This will be discussed in further detail in Section 2.2 of the thesis.

\subsubsection{Sulphur Dioxide $\left(\mathrm{SO}_{2}\right)$}

Sulfur dioxide $\left(\mathrm{SO}_{2}\right)$ belongs to a group of gases called sulfur oxides $\left(\mathrm{SO}_{\mathrm{x}}\right)$. It is a colorless gas that smells like burnt matches and is toxic to human health. $\mathrm{SO}_{2}$ is a precursor to sulphates which contribute to the formation of respirable PM (Ministry of the Environment, 2009b). $\mathrm{SO}_{2}$ is one of the most persistent pollutants as it is very soluble in water. It is responsible for the formation of sulfuric acid mist when oxidized in the presence of water vapour, which contributes to acid rain, snow and fog (Ministry of the Environment, 2009b).

The principal source of $\mathrm{SO}_{2}$ is human activity as it is formed when fuel-containing sulfur is burned. This includes fuel sources such as coal and oil often used in smelters, pulp and paper mills and power generation plants. The gases are also formed when gasoline is extracted from oil. The emission of $\mathrm{SO}_{2}$ from gasoline and diesel combustion is relatively small, approximately four per cent; however, it is a concern due to its concentration in urban environments (Ministry of the Environment, 2009b; Pollution Probe, 2002). 
Ozone is an odourless, colourless gas that is the primary constituent of smog (U.S. EPA, 2009c). Unlike the natural occurring 'ozone layer' that protects the earth from ultraviolet rays, ground-level $\mathrm{O}_{3}$ is located in the lower troposphere and is a highly reactive chemical that is toxic to human health. While both layers are the same chemicals, the ozone formed near the surface of the earth is largely the result of local $\mathrm{NO}_{\mathrm{x}}$ gases, VOCs emissions and sunlight reacting together in a stagnant air mass. There tends to be high levels of ground-level ozone in large cities, however rural areas can also experience elevated levels due to the wind carrying it several hundred kilometers (U.S. EPA, 2009c).

The Canadian Smog Advisory Program, after reviewing available studies, concluded that the current levels of ground-level $\mathrm{O}_{3}$ exposure are responsible for cases of lung inflammation, decreased lung function, airway hyper-reactivity, respiratory symptoms, possible increased medication use and physician/emergency room visits among individuals with heart or lung disease, reduced exercise capacity, increased hospital admissions and possible increased mortality (Stieb et al., 1995).

\section{2}

\section{Air Qualities and Health}

A few episodes of dramatically increased mortality rates during extreme elevations in urban pollution initiated the study of air pollution and health. These events include the London fog incident in 1952, linked with 4,000 deaths, the Meuse Valley incident in Belgium, which killed 63 people and made hundreds ill, and the Donora, Pennsylvania incident in 1948, which 1000s fell ill and 20 were killed (Pollution Probe, 2002).

Today, there is little doubt that air pollution causes increased risks of death and illness. Stieb et al. (2002) conducted a meta-analysis of 109 studies and found that $\mathrm{PM}_{10}, \mathrm{CO}$, $\mathrm{NO}_{2}, \mathrm{O}_{3}$, and $\mathrm{SO}_{2}$ were all positively and significantly associated with all-cause mortality. Similar studies conducted in Canada found positive associations between air pollutants and mortality (Burnett et al., 1998a; Burnett et al., 2000). In Ontario, the Ontario Medical Association (2005) recently estimated that smog was the cause of 5,800 
premature deaths, 16,800 hospital admissions and 59,700 emergency rooms visits in 2005 in Ontario. They also projected that by 2026, smog would be the cause of over 10,000 premature deaths per year.

\subsubsection{Population Sensitivity}

Every day, each adult breathes in 15,000 to 20,000 liters of air (Pollution Probe, 2002). This air can contain many pollutants that are toxic to human health and for the most part, do not have threshold levels at which no health effects are observed. Having said this, the health effect that air pollution has on each individual can vary greatly. It can range from mild effects such as an eye irritation to very severe consequences, such as death. The impact that air pollution has on each individual depends on the exposure, but also varies greatly from person to person depending on individual sensitivities to the pollutants and pre-existing physical conditions. Factors such as age and physical health often influence a person's vulnerability to air pollution (Toronto Public Health, 2007). For example, children under 15 years old inhale more air proportional to their body weight than adults, exposing them to more pollutants per kilogram of body weight. Also, persons that are very physically active outdoors are more exposed to air pollutants and may be at higher risk (Pollution Probe, 2002). Therefore, the effects of air pollution are not distributed evenly across the population and the severe health consequences are most often seen in the more vulnerable groups in society.

\subsubsection{Linking Air Quality to Health Impacts}

Due to the scattered nature of air pollution and the individuality of human sensitivities, it is difficult to establish definitive correlations between pollution exposure and human illness. While this link has now been clearly established through research, the variable mixture of individual reactions, air pollutant concentrations, pollutant types, exposure times and human behavior has made finding the relationship very difficult. As such, most evidence comes from studies that have observed: increases in disease morbidity and mortality during and immediately after pollution episodes; associations between daily 
changes in pollutants and hospitalizations and deaths; and increased health risks linked with spatial and temporal differences in ambient pollution levels.

\subsubsection{Respiratory Disease and Air Pollution}

Respiratory morbidity and mortality have been the most frequently studied health effects associated with air pollution. The results of these studies have demonstrated that the health consequences of air pollution on the respiratory system can range from coughing and wheezing, to asthma and chronic obstructive pulmonary disease (COPD), which includes chronic bronchitis and emphysema. $\mathrm{PM}, \mathrm{O}_{3}$ and $\mathrm{NO}_{2}$ are the pollutants most often linked with these respiratory conditions (Toronto Public Health, 2007). Both $\mathrm{PM}_{10}$ and $\mathrm{PM}_{2.5}$ were found to have a significant associations with upper and lower respiratory tract disease (Chardon et al., 2007).

Asthma is one of the conditions that have been strongly associated with short-term exposure to elevated pollution levels. Air pollution has been shown to not only worsen symptoms in asthmatics, but can also induce asthma in people that have never had the condition before (Sunyer et al., 2006). One of the most cited and well-known pieces of evidence demonstrating the connection between air pollution, vehicles and asthma is a study that took place during the 1996 Olympics hosted in Atlanta, Georgia, one of the most geographically sprawling cities in the United States. During the Olympics, the City of Atlanta provided a 24-hour public transportation system, added 1,000 buses for park and ride services, encouraged alternative work hours and telecommuting, prohibited cars in the downtown sector and altered downtown delivery services. This led to a 28 per cent drop in one-hour peak ozone and between 11 and 44 per cent drop in acute asthma events (Friedman et al., 1998).

Reduced lung function and chronic respiratory effects, such as COPD, have also been associated with air pollution through chronic exposure. In two studies, it was found that groups living close to roadways with elevated pollution levels were at increased risk for respiratory conditions. In one of the studies, healthy university students in Korea living 
near a main roadway were found to have decreased lung function (Hong et al., 2005). In the other study, a group of 4757 women exposed for at least 5 years to $\mathrm{PM}_{10}$ and $\mathrm{NO}_{2}$ from a major road were found to be at increased risk for decreased pulmonary function and COPD (Schikowski et al. 2005). Chronic exposure to air pollution has also been related to bronchitis (Sunyer et al., 2006).

\subsubsection{Cardiovascular Disease and Air Pollution}

Cardiovascular disease is an extensive category of conditions that affect the heart and circulatory system. It is also the leading cause of death in Ontario. It is currently responsible for 30.4 per cent of all deaths in Ontario and the number of deaths from cardiovascular disease is expected to double by 2018 (Chan \& Young, 1999). In an effort to understand the causes of cardiac disease and help reduce the number of cardiac-related illnesses and deaths, many researchers have been studying the relationship between environmental air pollutants and cardiac disease. While heart health is not typically associated with air pollution, the results of these recent studies have yielded many interesting findings about the biological mechanisms linking air pollution and heart disease.

PM has been identified as one of the major culprits. Several studies have shown that both long-term PM exposure and short-term PM increases are the cause of heart disease and stroke. Some $\mathrm{PM}_{2.5}$ can cross the pulmonary epithelium and directly penetrate the circulatory system (Brook et al. 2004). A study conducted by Pope et al. (2004) observed the correlation between long-term exposure to particulate air pollution and cardiovascular

disease. They found that a $10 \mu \mathrm{g} / \mathrm{m}^{3}$ elevation in fine PM was associated with an 8 to 18 per cent increase in cardiovascular mortality risk. This included mortality attributable to ischemic heart disease, dysrhythmias, heart failure, and cardiac arrest. The biological mechanisms involved included pulmonary and systemic inflammation, accelerated atherosclerosis and altered cardiac autonomic function. Many similar studies demonstrating the links between PM and cardiovascular disease have been done resulting in similar conclusions (Hoffman, 2007; Kunzli et al., 2005; Johnson, 2004; Pope et al., 
2002). PM is not however the only pollutant that affects the cardiovascular system. CO and $\mathrm{NO}_{2}$ have also been associated with emergency room visits due to strokes (Villeneuve et al., 2006).

\subsubsection{Other Health Effects}

Cancer and reproductive effects have also been linked to air pollution exposure. With regard to cancer, lung cancer is the type most frequently associated with air pollution; however, other cancers, like childhood leukemia and breast cancer, have also been implicated (Nie et al., 2007; Pearson et al., 2000). In a large study of 4000 people in Europe, the association between lung cancer and vehicle-related pollution was investigated. It was found that people living near heavy-traffic roads or who had high exposure rates to $\mathrm{NO}_{2}$ were at increased risk for lung cancer (Vineis et al., 2006). Similar results were also found in many other studies (Parent et al., 2007; Nafstad et al., 2003; Pope et al., 2002; Nyberg et al., 2000).

As for reproductive effects, there is evidence that air pollution affects fertility in men and increases the risk of adverse pregnancy outcomes. In one study, the sperm quality of men who work at highway tollgates was found to be inferior in motility compared to controls (De Rosa et al., 2003). Also, low birth weights in infants were associated in several studies with maternal exposure to vehicle emissions during pregnancy (Bell et al. 2007; Salam et al. 2005; Sram et al. 2005; Wilhelm and Ritz. 2005).

\section{3}

\section{Vehicle Emissions, Air Pollution and Health}

In Canada, transportation accounts for 26 per cent of total GHG emissions from all sectors and is responsible for 28 per cent of emissions growth since 1990 (CMHC, 2007). While this includes all modes of transportation, including trains, boats and planes, light trucks and cars account for 50 per cent of the emissions from transport. Personal vehicle transportation also constitutes, on average, 50 per cent of the GHG produced by each household (CMHC, 2007). 
In Ontario, the largest proportion of GHG emissions are also transportation-related and personal vehicle use is the component where the largest forecast growth of GHG emissions is expected to occur (Burda, 2008). This trend is especially significant in the urban areas of the Province, such as Toronto, where personal vehicles contribute substantially to the quantity of criteria air pollutants found in the local and regional atmosphere. The criteria pollutants found in vehicle emissions include $\mathrm{NO}_{\mathbf{x}}, \mathrm{SO}_{2}, \mathrm{CO}$, $\mathrm{PM}_{10}, \mathrm{PM}_{2.5}$, and VOCs. The percentage of pollutants in Toronto derived from vehicles is as follows:

- 85 per cent of $\mathrm{CO}$

- 69 per cent of $\mathrm{NO}_{\mathrm{x}}$

- 39 per cent of $\mathrm{PM}_{10}$

- 16 per cent of $\mathrm{PM}_{2.5}$

- Less than 5 per cent $\mathrm{SO}_{2}$ (Toronto Public Health, 2007).

Being a secondary pollutant, $\mathrm{O}_{3}$ is not directly emitted from a vehicle's tailpipe; however, it is formed with the precursor chemicals emitted from the tailpipe such as VOCs and $\mathrm{NO}_{\mathrm{x}}$ (Toronto Public Health, 2007).

The quantity and composition of air pollution emitted from a vehicle depends on four variables: the type of vehicle being driven, the type and length of the vehicle trip, the characteristics of the particular pollutants in the area and weather conditions (Ewing \& Kreutzer, 2006). While the description of how vehicles pollute is beyond the scope of this thesis, it is important to note that the many characteristics that impact the way vehicles pollute, such as vehicle type, vehicle speed, VKT and vehicle trip duration are closely determined by the built environment (Ewing \& Kreutzer, 2006).

\subsubsection{Exposure to Vehicle Emissions}

People are exposed to traffic-related pollution in many different ways. Many studies have investigated the health effects associated with being a driver, both professionally (truck, bus and taxi drivers) and non-professionally. Lung cancer and increased levels of 
respiratory conditions were found to be associated with professional driving in many studies (Jones et al., 2006; Jakobsson et al., 1997; Borgia et al., 1994; Guberan et al., 1992; Steenland et al., 1990). A study conducted in Denmark found that of 28,744 men with lung cancer, the increased risk was associated with those who were taxi drivers or truck drivers compared to other men living under similar socioeconomic conditions (Hansen et al., 1998). Another study in Shanghai found that taxi and bus drivers were also at increased risk for respiratory symptoms and chronic respiratory disease compared to unexposed controls (Zhou et al., 2001).

Commuters in cars or on buses were also a group found to be at increased risk due to elevated exposure rates (Gee \& Raper, 1999). A study in Los Angeles found that exposure to $\mathrm{CO}$ levels was three times higher in a commuter's vehicle than at their home or work (Ziskind et al., 1997). Also, in another study, levels of $\mathrm{PM}_{2.5}$ were found to be twice as high in London's on-road vehicles during commutes (Adams et al., 2001). Due to greater traffic density during the morning and evening commutes, higher concentrations of pollutants were found during these times. This is due to a greater number of vehicles and lower traveling speeds that emitted larger concentrations of pollutants (Kaur et al., 2005).

Those living close to roadways were also at risk of exposure to traffic-related air pollution. Research conducted by Finkelstein et al. (2004) found that living close to a major road was associated with a mortality rate advancement period of 2.5 years. Many other studies have found similar associated with living near busy roadways and increases in morbidity and mortality rates due to traffic-related pollution exposure (Hoek, 2002; Hoffman, 2007; Schikowski, 2005). Some of these studies have been discussed earlier in this thesis.

Finally, pedestrians, cyclists and those with an increased level of physical activity in urban areas have also been found at risk for increased exposure (Toronto Public Health, 2004). This has been studied most frequently in cyclists (O'Donoghue et al., 2007; Van Wijnen et al., 1995). Due to increases in pulmonary ventilation during physical activity, 
an increased number of inhaled particles are deposited into the lungs (Sharman et al., 2004) putting them at higher risk. Ironically, research by Campbell et al. (2005) suggests that vigorous outdoor activity should be limited during the rush hours and in high traffic areas, which discourages traveling to work by foot or by bicycle, both emission-free commuting methods.

\subsubsection{Overall Morbidity and Mortality from Traffic in Toronto}

Recently, Toronto Public Health (2007) conducted a study to determine the burden of illness from traffic pollution in Toronto. They found that traffic pollution was, on average, the cause of 257 acute exposure mortalities and 183 chronic exposure mortalities each year in Toronto. In addition, traffic pollution was found to be responsible for 1,700 respiratory and cardiovascular hospitalizations. While the large majority of these hospitalizations occur in the elderly (96 per cent), children experienced 1,300 episodes of acute bronchitis every year due to traffic-related air pollution. Overall, 200,000 restricted activity days are caused per year due to vehicle usage, highlighting the urgency of reducing vehicle use in urban areas (Toronto Public Health, 2007).

\section{$2.4 \quad$ Urban Planning and Sprawl}

The built environment is a key determinant of public health. This was well established during the $19^{\text {th }}$ century when industrialization led many to crowd into cities and live in unsanitary conditions in order to find work. The conditions of the built environment facilitated the spread of infectious diseases and contributed to many epidemics.

Due to the threat of infectious diseases, population decentralization and the establishment of single purpose land uses became a public health priority. This led to the creation of zoning ordinances in the 1920s, which separated the residential neighbourhoods from commercial and industrial areas. Families that could afford to move away from the city did so and established in low density housing far from the city. As this became more affordable and increasing affluence permitted widespread private vehicle ownership, the average family also began moving to the suburbs. This move to the suburbs by the middle 
class was also accelerated by the fact that as cities became more and more concentrated with low-income households it created undesirable conditions for those who could afford to move (Downs, 1997). As the incidence rate of infectious disease decreased, public health officials largely abandoned the role they played in urban planning. They chose instead to focus on chronic diseases and human behavior, such as tobacco smoking (Collins Perdue et al., 2003; Gurin, 2003; Mieszkowski \& Mills, 1993).

Today, the built environment is once again at the centre of another large public health crisis. Ironically, it is due to the excessive low-density urban growth away from the city centers over the last 50 years across North America. Commonly known as "urban sprawl", it is the result of years of scattered urban growth that is now being identified as a large urban planning problem with major direct and indirect consequences on the environment and on human health.

Many scholars have defined the term "urban sprawl". When summarized, the characteristics of urban sprawl always include: low density, separation of land uses, automobile dependence, pedestrian unfriendliness, leapfrogging development, employment decentralization, greenfield consumption and fragmented government responsibility and oversight (Bray et al., 2005). From a more layman's perspective, they are large developments of practically identical single detached homes on curvilinear street networks, with little accessibility to shopping or employment centers without using a vehicle.

In Canada, these sprawling low-density developments are now the norm. Nearly half of Canadians living in metropolitan areas live in low-density areas. In fact, between 1991 and 2001, 60 per cent of new dwellings were low density, single-detached homes (Turcotte, n.d.). Characteristic of sprawl, these new developments have been rapidly consuming rural land in Canada. Between 1971 and 2001 there had been a 96 per cent increase in urban land and a rural land loss of $15,200 \mathrm{~km}^{2}$ in Canada. During the same period, Ontario saw the same trend as urban land grew by 80 per cent or $4,300 \mathrm{~km}^{2}$ (Donnan, 2008). 
Developers argue that urban sprawl is a consumer choice. In the United States, a survey was conducted which asked whether respondents favoured single-family homes with a yard and attached garage and 80 per cent of respondents said that they did (Burchell et al., 1998). However, others argue that lower purchase prices of homes and the low costs of automobile travel are the attraction (Ewing, 1997). Either way, low-density residential developments, widespread strip commercial parks, and segregation of land uses have forced the population into private vehicles to carry out every daily task and the public health consequences are very apparent.

\subsection{Linking the Built Environment and Travel Behavior}

One of the most characteristic features of urban sprawl is automobile ownership, highlighting the relationship between low-density developments and the need to drive. Connectivity, density and mix of land uses have been identified as the key characteristics that influence vehicle dependence in a neighbourhood. More specifically, in 'The Cost of Sprawl - Revisited', Burchell et al. (1998) identified five elements that link travel behavior with the notion of sprawl. They are:

1. Low density development

2. Spatially segregate land uses

3. Leapfrog development

4. Transport dominance of motor vehicle

5. Widespread commercial strip development.

These features are all common to urban sprawl developments, which explain why urban sprawl has been blamed for increase in vehicle dependence. While many studies have demonstrated the connection between the built environment and travel behavior, Ewing and Cervero (2001) found that the built environment had the largest impact on trip length, VKT and vehicle hours traveled (VHT). Mode choice was determined to be influenced by both the built environment and individual characteristics, while the number of trips taken daily depends more on economic status. Because urban characteristics are often studied 
together, it is difficult to separate confounding variables; however, many clear conclusions have been made.

The following subsections discuss elements of urban design that influence vehicle travel behavior and therefore contribute to the generation of air contaminants in the development under study.

\subsubsection{Connectivity and Street Layout}

Street networks are described by their connectivity, directness of routing, block size, sidewalk continuity, and by many other features. These features impact travel decisions and therefore have a large influence on vehicle use. Conventional suburban developments typically have curvilinear, poorly-connected road networks that limit transportation methods to the automobile. Curvilinear and cul-de-sac street patterns lengthen the distance between residences and local amenities, thereby reducing the likelihood of people walking, cycling or taking transit, contributing to the fact that 4 out of 5 vehicle trips in Ontario are for non-work travel (Donnan, 2008). Alternatively, streets with good connectivity have many intersections, many route choices and can often be described as a street grid network. They impact the use of transit by improving transit access through relatively direct routes and by offering alternatives to major arterial, high traffic roadways (Ewing \& Cervero, 2001).

Studies of street networks have shown that compact networks influence vehicle use and reduce criteria pollutants. Cervero and Kockelman (1997) found that VKT for non-work trips was related to the number of four-way intersections and the number of blocks with quadrilateral shapes. In two other studies, it was found that better street connectivity was found to have an inverse relationship with the number of VOCs and $\mathrm{NO}_{\mathrm{x}}$ produced per household (Ewing \& Kreutzer, 2006). 


\subsection{2 Housing Density}

Density is described by the compactness of a neighbourhood. It is usually a measure of the number of households found per hectare. It measures intensity of residential development and can be an indicator of how close non-work trip ends are found to be from their starting points (homes). Housing density influences trip behavior in three main ways: it reduces trip length, it reduces the need to own a vehicle and it increases the opportunity for alternative mode choice. Many studies have demonstrated that as density rises, trips get shorter, and therefore vehicle trip rates drop and the shares in transit, walking and cycling modes increase (Ewing, 1997; Frank and Pivo, 1994; Kitamura et al., 1995).

A number of studies have found that increasing densities can reduce VKT. A study by Holtzclaw (1994) concluded that VKT could be reduced by 25 to 30 per cent if urban densities were doubled. Some research, however, has demonstrated that the relationship between VKT and density is not linear. Dunphy and Fisher (1994) found that in rural areas, where density is generally very low, significant increases in density do not influence VKT. However, in suburban regions an increase in density dramatically decreases VKT, trip duration and trip length.

By reducing vehicle dependence, increasing urban density also reduces the amount of pollution created. Frank et al. (2000) studied the relationship between housing, employment density, land use mix, street connectivity and commute length to the quantity of household emissions. It was found that levels of $\mathrm{CO}, \mathrm{NO}_{\mathrm{x}}$ and $\mathrm{VOCs}$ were all found to decrease as density increased. Another study by Golob and Brownstone (2005) found that when controlling for all other factors, a lower density of 1,000 housing units per square mile increased yearly fuel usage by 170 liters, which would inherently impact emission rates. 
As with density, research indicates that greater land use mix in a neighbourhood can influence travel behavior for the better. Land use mixing has been associated with reduced VKT and VHT. A more varied area allows residents to access more facilities and amenities by walking, cycling or riding transit, thereby reducing vehicle trips and reducing emissions (Cervero, 1996). Studies have not yet come to a conclusion about the perfect combination of land uses; however, proximity between commercial centers and residential areas has been shown to increase a neighbourhood's 'walkability' (Ewing \& Kreutzer, 2006). In one study conducted in Seattle, Washington, it was found that vehicle trip distance was found to be half as long for those living in mixed-use neighbourhoods. They were also found to take non-motorized trips three times more often than those living in single use communities (Rutherford et al., 1996).

While still up for debate, designing a community with a job and housing balance at a subregional level could reduce VMT and VHT. Research done in California found that residents who lived in a community with a balance of employment and residential uses traveled two thirds less in distance during their commute than did workers living where there was more housing than employment (Ewing, 1994). Another study found that, by doubling accessibility to jobs in the San Francisco area, a 7.5 per cent decrease occurred in the number of vehicles owned (Kochelman, 1997). However, there are still too few studies in this field to determine what could be considered a satisfactory employmenthousing mix.

\subsubsection{Regional Location}

As discussed, density, connectivity and land use mix are important factors that influence travel behavior. However, dense, mixed-use developments that are not connected to the greater urban environment may not see the travel benefits associated with these features (Ewing \& Cervero, 2001). Another important piece of the puzzle is the regional location of the development. Unfortunately, suburban developments are often developed in 
greenfields far from established urbanized areas and therefore the residents must travel long distances to reach work and non-work locations.

The U.S. Environmental Protection Agency (EPA) compared the transportation and environmental impacts of building a development in two different locations. One location was a potential greenfield site, while the other was an infill site ${ }^{1}$ (brownfield) that would be redeveloped. It was found that the infill site would generate significantly lower VKT and emissions than the greenfield site (Anderson \& Schroeer, 1999). Another study by the EPA estimated the difference between the emissions produced from a development located on an infill site in a town to one that would be located on a site located outside of the metropolitan area. It was found that the infill site would result in 15 to 25 per cent fewer VKT, 37 to 81 per cent less $\mathrm{NO}_{\mathrm{x}}$ emissions and 293 to 316 per cent less VOC emissions (Bailey, 1999). It is assumed that due to the lack of proximity to employment areas and commercial areas, not only does the VKT by residence increase but so do the levels of emissions (Ewing \& Kreutzer, 2006).

\subsubsection{Transportation Infrastructure}

Transportation infrastructure supports urban sprawl, while public transit is practically incapacitated by low-density sprawl. Public transit is often very limited or simply not a feasible option for low-density developments. Bus service requires a minimum housing density of 37 units per hectare and rail service requires 64 units per hectare (CMHC, 2007). To demonstrate the strides that still need to be made, the Town of Richmond Hill currently has 5.1 dwellings per hectare (SHS Consulting \& Centre for Spatial Economics, 2008). Developments at such low densities have little expectation of transit service in the foreseeable future.

In order to deal with increased transportation needs and growing congestion from urban sprawl, the Province of Ontario decided to invest $\$ 1.7$ billion in the provincial highway

\footnotetext{
${ }^{1}$ Infill development involves developing on parcels of land that are located in existing residential areas but are vacant or underutilized. This includes both brownfields (previously industrial or commercial) and greyfields (previously commercial centers).
} 
system and $\$ 1.2$ billion through the MoveOntario 2020 program (Ontario Ministry of Finance, 2007). Unfortunately, funding road expansion will not reduce congestion. In fact, road expansion has been demonstrated in many studies to induce travel demands (Cervero, 2003; Hansen \& Huang, 1997; Goodwin, 1996). In other words, the more highways are built, the more traffic there will be to fill them. This is due to the benefits that lane miles confer to the driver in the form of increased speeds and travel times. Cervero (2003) studied 24 California freeway projects and potential travel increases. He concluded that not only did highways induce travel in the long and short run, but they also induced growth and investment in real estate developments surrounding the new or improved freeways. While transportation plans would seem to support new highways in Ontario, the cliché "you can't pave your way out of traffic congestion" has been shown to hold true.

\section{6}

\section{Growth in the Greater Golden Horseshoe Area and the Town of Richmond Hill}

The Greater Golden Horseshoe (GGH) region was identified in 2005 by the Environmental Health Committee of the Ontario College of Family Physicians, as the region most affected by urban sprawl in Ontario (Bray et al., 2005). With over six million residents, the GGH area is the fastest growing and sprawling area in Canada and is expected to grow by 8.6 million people and consume an additional 260,000 acres by 2031. It is composed of a handful of regional municipalities, including the Cities of Toronto and Hamilton and the regions of York, Peel, Durham, Halton, Niagara, that surround lake Ontario (Bray et al., 2005). A map of the GGH within the Province of Ontario can be found in the Figure 2-1. 


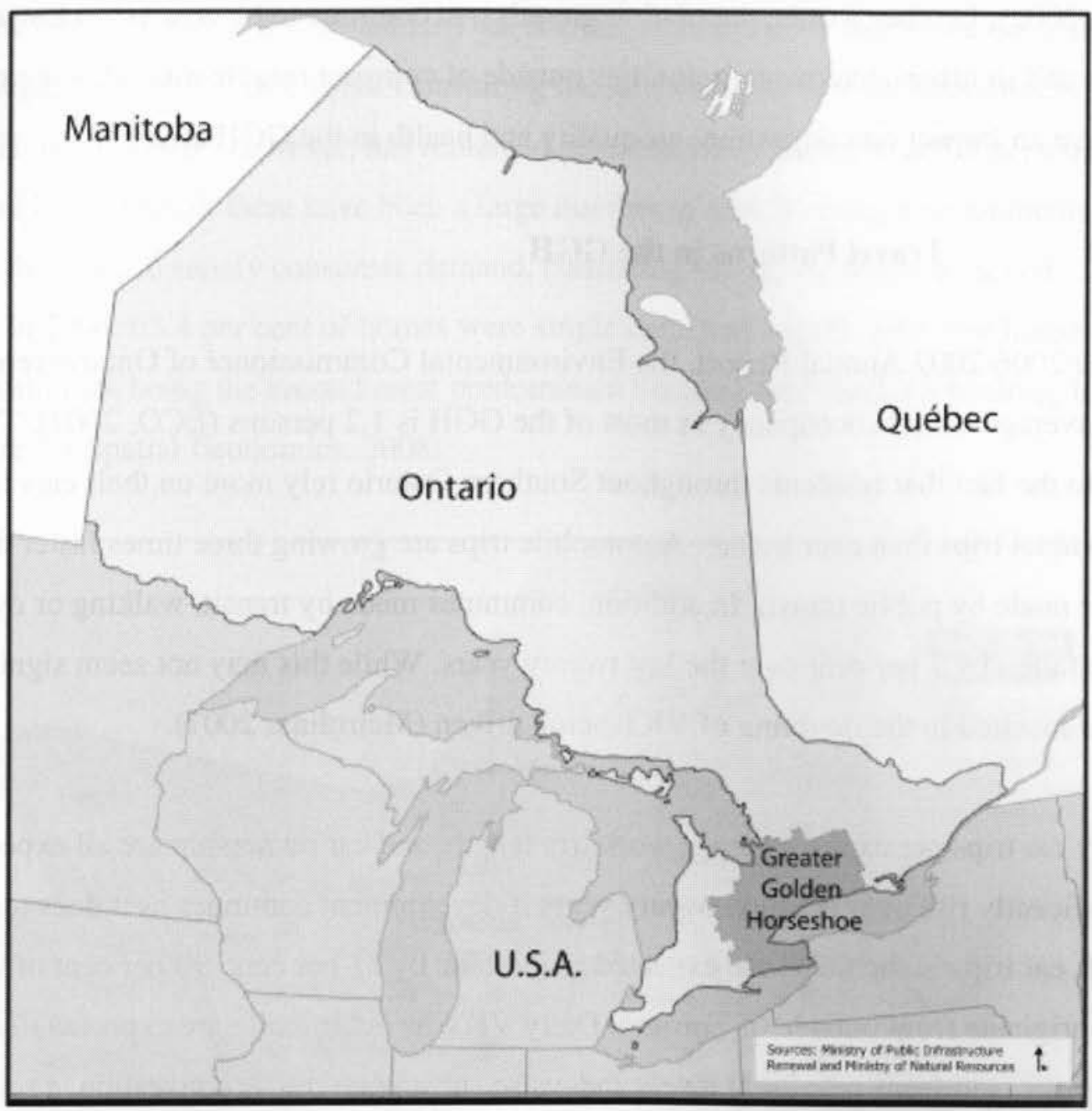

Figure 2-1: Map of the GGH within the Province of Ontario

Source: (Ministry of Public Infrastructure Renewal, 2008)

Over the last two decades 80 per cent of the GGH area's population growth has been in the suburban regions of Durham, Peel, York and Halton. Land consumption per capita in these regions is occurring approximately three times faster $(2,500$ square feet per person and job) in newly urbanized areas compared to already urban areas (IBI Group \& Dillon Consulting Ltd., 2002). With new provincial legislation, the GGH area is expected to see residential densities rise in new suburban developments over the next 20 years; however, the population and employment density across the region is expected to increase very little (IBI Group \& Dillon Consulting Ltd., 2002). This is due to the fact that population growth will occur in areas where density is rising; however, those areas will remain below the average density of the GGH area as a whole (IBI Group \& Dillon Consulting 
Ltd., 2002). In other words, population growth will continue to be greatest in low-density areas and in urban shadow communities outside of compact rural towns. This is expected to have an impact on congestion, air quality and health in the GGH area.

\subsubsection{Travel Patterns in the GGH}

In the 2006-2007 Annual Report, the Environmental Commissioner of Ontario reported that average vehicle occupancy in most of the GGH is 1.2 persons (ECO, 2007). This is due to the fact that residents throughout Southern Ontario rely more on their cars for individual trips than ever before. Automobile trips are growing three times faster than those made by public transit. In addition, commutes made by transit, walking or cycling have fallen by 7 per cent over the last twenty years. While this may not seem significant, it has resulted in the doubling of VKT being driven (Metrolinx, 2007).

Daily car trips per capita, average work trip length, and car ownership are all expected to significantly rise over the next twenty years if development continues as it does today. By 2031, car trips in the GGH are expected to increase by 51 per cent, 90 per cent of which will originate from outside of Toronto. Daily VKT by automobile are expected to grow by 64 per cent from year 2000 levels and cause substantial traffic congestion, a source of additional contaminant emissions. It has been projected that, even with a 30 per cent increase in highway lane-kilometers, a 6 per cent increase in arterial road lane-kilometers, and an overall increase of 9 per cent for highways plus arterial roads, congestion will increase by 67 per cent on highways and 51 per cent on arterial roads within the urban and suburban areas in the GGH (IBI Group \& Dillon Consulting Ltd., 2002).

\subsubsection{Urban Growth in the Town of Richmond Hill}

Richmond Hill is one of the fastest growing towns in Ontario. It is located in the center of York Region, which is in the northern part of the GGH. A map of Richmond Hill within the GTA is presented in Figure 2-2. 
Between 1991 and 2006, Richmond Hill has seen its population double while the rest of York Region grew by $76.8 \%$ (SHS Consulting Inc. \& Centre for Spatial Economics, 2008). Household size, however, has remained approximately the same at 3.2 persons per household. As a result there have been a large number of new housing developments built in the town to satisfy consumer demand, consisting mainly of single detached homes. In 2006, 63.4 per cent of homes were single detached homes, with row houses and townhouses being the second most predominant housing type (SHS Consulting Inc. \& Centre for Spatial Economics, 2008).

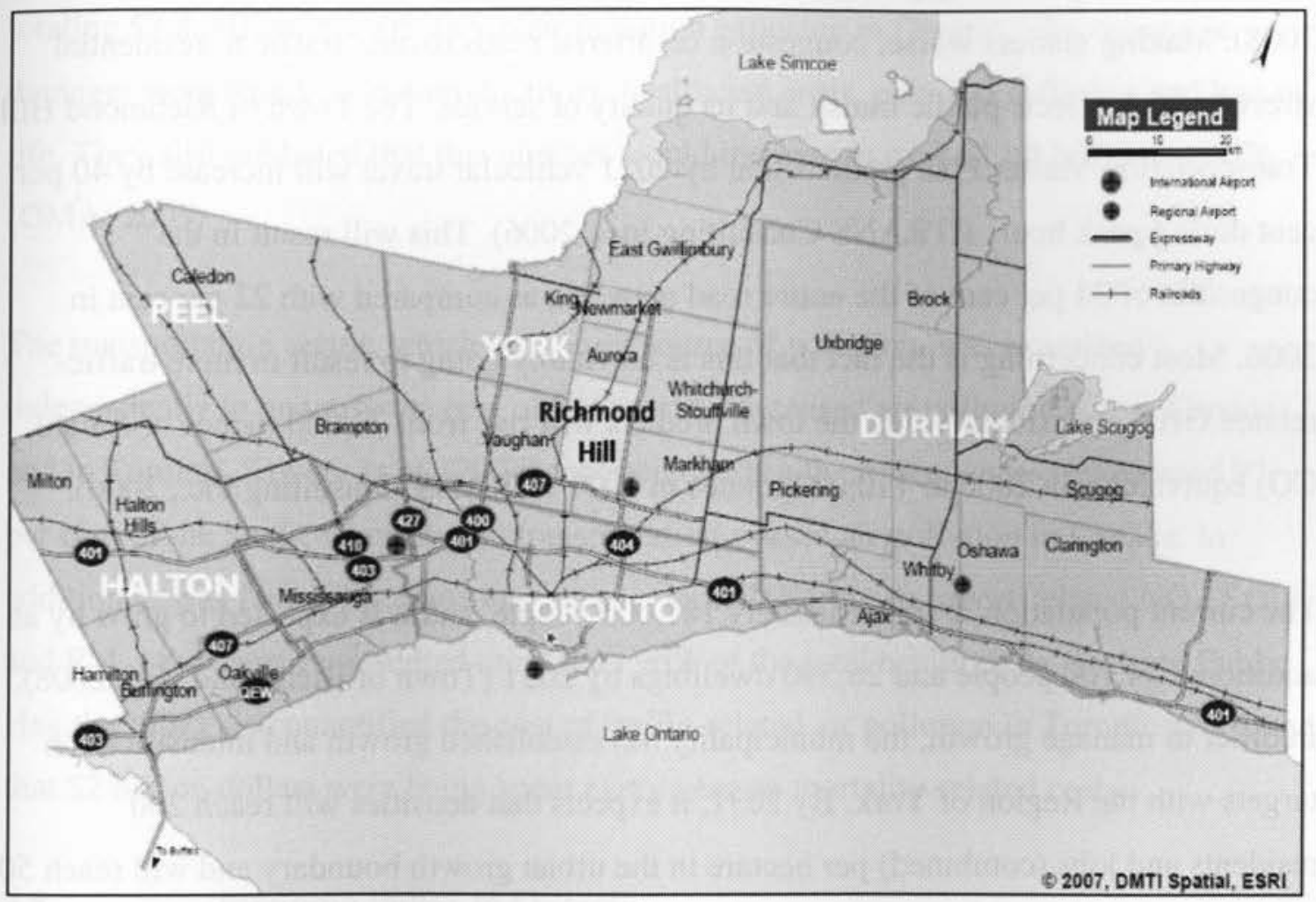

Figure 2-2: Map of the Town of Richmond Hill within the GTA Source: (SHS Consulting \& Centre for Spatial Economics, 2008, p. 161).

Another consequence of the increased population and low-density housing developments has been the population's reliance on personal vehicles. Richmond Hill is currently experiencing a severe problem with traffic congestion due to the travel patterns of residents. The 2001 Transportation Tomorrow Study found that 80 per cent of the trips made during the morning peak period in Richmond Hill were by car and that the number 
of vehicle trips per household and vehicle trips per person had gone up from 1996 to 2001. Of the trips made by Richmond Hill residents, 60.4 per cent of all trips were less than 10 kilometers, which demonstrates vehicle dependence and lack of alternative modes of transport for even short trips (SHS Consulting \& Centre for Spatial Economics, 2008).

Unsurprisingly, this has led to a serious congestion problem which has resulted in approximately 30 per cent of all arterial roads and 12 per cent of all collector roads congested during morning peak hours (SHS Consulting \& Centre for Spatial Economics, 2008). Making matters worse, congestion on arterial roads diverts traffic to residential streets, which affects public transit and its quality of service. The Town of Richmond Hill Transportation Master Plan predicts that by 2021 vehicular travel will increase by 40 per cent during peak hours (iTRANS Consulting Inc., 2006). This will result in the congestion of 34 per cent of the entire road network, as compared with 22 per cent in 2006. Most concerning is the fact that this is inevitably going to result in more trafficrelated GHG emissions, which the town predicts will rise from 73,000 tonnes of annual $\mathrm{CO}_{2}$ equivalents in 2006 to 110,000 tonnes in 2021 (iTRANS Consulting Inc., 2006).

The current population is approximately 181,000 people, and it is expected to grow by an additional 54,700 people and 26,590 dwellings by 2031 (Town of Richmond Hill, 2008). In order to manage growth, the municipality has established growth and intensification targets with the Region of York. By 2031, it expects that densities will reach 200 residents and jobs (combined) per hectare in the urban growth boundary and will reach 50 residents and jobs (combined) per hectare in the designated Greenfield Area of the municipality. These goals, however, seem very optimistic considering the fact that current density rates are 16.1 persons per hectare and 5.1 dwellings per hectare (SHS Consulting \& Centre for Spatial Economics, 2008). 
In Canadian society, all taxpayers contribute to financing the health care system through tax contributions. Moreover, when individuals fall ill and lose their income, social mechanisms, such as disability insurance serve to redistribute the burden of the economic loss from the individual to the entire society. Unfortunately, large amounts of health care resources are consumed curing and manage diseases that are cause by air pollution.

The Ontario Medical Association (2005) concluded that there were economic losses totaling $\$ 7.8$ billion in 2005 due to air pollution exposure in Ontario. The economic damages were based on lost productivity, healthcare costs, pain and suffering and loss of life. They also predicted that this number would increase to over $\$ 12.9$ billion by 2026 . (OMA, 2005)

The transportation sector, which is a major source of pollution, was examined independently to quantify the cost of transportation-caused air pollution across Canada and in Toronto. Sawyer et al. (2007) reported that health consequences represented 97 per cent of the total cost of overall transportation-caused air pollution in Canada. In addition, it was found that acute and chronic mortality from transport-related $\mathrm{NO}_{\mathrm{x}}, \mathrm{SO}_{2}$ and $\mathrm{PM}_{2.5}$ exposure represented more than $96 \%$ of the total health costs. Toronto Public Health (2007) also quantified the cost of traffic-related air pollution in Toronto and found that $\$ 2$ billion dollars were being spent every year on mortality-related costs.

\section{$2.8 \quad$ Planning Policy in Ontario}

In Ontario, municipalities are given authority over land use planning through the provincial Planning Act, 1990 and the Provincial Policy Statement (PPS), and are overseen by the provincially-appointed OMB. It is the Province that sets the directive through legislation and policies, which largely influences the development patterns across the province. Recently, the provincial legislative and policy framework for land use planning has undergone many changes. The Government of Ontario has introduced a number of pieces of major legislation and policies with regard to urban sustainability. 
This list includes: the new Greenbelt Act, 2005, the new Places to Grow Act, 2005, the revised Provincial Policy Statement, the Strong Communities Act, 2004, and the Greater Golden Horseshoe Growth Plan (Burda, 2008). A description of these policy documents and legislation is given in Table 2-1.

\section{Table 2-1: New/Revised Ontario Planning Legislation and Policy Pieces}

\begin{tabular}{ll}
\hline Legislation/Policy & Description \\
\hline Greenbelt Act, 2005 & $\begin{array}{l}\text { Legislation that protects 240,000 hectares } \\
\text { from urban development in the GGH. }\end{array}$ \\
\hline Place to Grow Act, 2005 & $\begin{array}{l}\text { Legislation that coordinates planning and } \\
\text { decisions making for growth management in } \\
\text { Ontario. It allows the Province to choose } \\
\text { growth intensification nodes and requires } \\
\text { municipalities to bring their official plans } \\
\text { into conformity with the growth plan for } \\
\text { their area. }\end{array}$ \\
\hline Provincial Policy Statement (PPS) & $\begin{array}{l}\text { This piece of legislation was revised to only } \\
\text { allow development in areas where there is } \\
\text { adequate infrastructure to sustain and } \\
\text { support it. }\end{array}$ \\
\hline Strong Communities Act, 2004 & $\begin{array}{l}\text { Legislation that new planning applications } \\
\text { conform to the new policies in the PPS. It } \\
\text { also gives the public more time and } \\
\text { opportunity to examine the planning process. }\end{array}$ \\
& $\begin{array}{l}\text { Sets policies on where and how urban } \\
\text { growth can occur in the GGH. It directs the } \\
\text { identification of growth areas, build-up } \\
\text { areas, settlement lands, greenfield areas and } \\
\text { employment lands. }\end{array}$ \\
\hline Greater Golden Horseshoe Growth Plan &
\end{tabular}

Source: (Burda, 2008, p. 6).

\subsubsection{Shortcomings of Provincial Policies and Legislation}

While the provincial planning initiatives are well-intentioned and aim to protect land, promote intensification and integrate transit, sprawl continues to occur in municipalities and the nurturing of smart growth in Ontario is uncertain. In the report "Getting Tough on Sprawl: Solutions to meet Ontario climate change targets" put out by the Pembina Institute, Burda (2008) reported that the changes in legislation are not rigorous enough to combat urban sprawl. She suggested that there are too few concrete regulations and too 
few incentives or disincentives to curb greenfield development. The new changes to legislation give the municipalities greater decision-making power, but do not ensure that they will use this authority to reduce sprawl. The Environmental Commissioner of Ontario (2007), Gord Miller, in the 2006-2007 Annual Report, echoed the same feeling of inadequate urban sprawl prevention by the Growth Plan. He suggested that Ontario's Growth Plan (a plan stemming from the Places to Grow Act, 2005) would need additional intensification and density targets, as well as further improvement to the quality and use of the public transit system if the Province's planning objectives are ever to be met (ECO, 2007).

\subsubsection{The OMB}

In addition to inadequate legislation and policies, some argue that it is the $\mathrm{OMB}, \mathrm{a}$ provincially-appointed hearing panel unique to Ontario that allows urban sprawl to continue by taking the power to control sprawl away from the municipalities through a right of appeal for the development industry. Critics argue that the trial-like adversarial approach of the OMB has become a developer-friendly system since the expense of the OMB process puts citizens groups, municipalities and non-governmental organizations at a great disadvantage (Burda, 2008). This process has also been blamed for intimidating municipalities into approving development projects that would have otherwise been rejected for fear that decisions will be appealed to the OMB and cost the municipality a large sum of money to fight.

With regard to health, the OMB historically has not evaluated the health consequences of urban developments because it is not a component of the planning process or in the Planning Act, 1990. It is assumed if the requirements of "good planning" (services, zoning, schools and open space) are met, the development is acceptable. This understanding is perhaps largely due to the fact that there has been little study done to quantify the social and economic impacts of individual developments. While the OMB may be a "good planning" body, the lack of empirical evidence linking an individual development to human health losses or costs has meant that general evidence supporting 
this issue has largely been ignored. The OMB has no intent or self-perceived authority to take into account the broader human health cost of each additional development.

The Environmental Assessment Act, 1990, introduced in the 1975s, was established to examine and evaluate the planning of public sector projects before the approval of any project. This applies to provincial and municipal projects such as power generation, transmission lines, highways and wastewater facilities. The legislation was put in place to ensure that the planning process was conducted thoughtfully and that consideration was given to the long-term impacts of the projects on the public good. Public sector plans could be rejected if they did not satisfy the EAA list of requirements. This legislation also encouraged transparency and gave the public new opportunities to participate in the planning process $(E C O, 2008)$.

While today some would argue that the EAA has been gutted by a long list of reforms to accelerate and lower the cost of project approval, there still are many benefits to having such legislation. By requiring proponents to scrutinize their own development proposals and put forward an explanation to rationalize their project selection, projects are at least put through the process of evaluation by their developers.

The health consequences of vehicle emissions associated with urban sprawl suggest that a similar assessment process is required for the health impacts of urban developments. As was previously touched on, urban sprawl continues to take place in Ontario regardless of new planning policies and legislation. Not unlike EAAs conducted on public projects, health impact assessments could provide the information and evidence needed to reconsider the construction of many urban residential developments. It is assumed that if health consequences were evaluated and quantified prior to the approval of the urban residential developments, municipalities and the public would have the leverage required to turn down project approvals on the basis of health impacts or at least require 
compensation to offset the health costs of such developments. This would reduce the occurrence and profitability of the greenfield, low-density developments.

Recently, some researchers have begun to study the use of health impact assessment to evaluate land use decisions (De Ridder et al., 2008; Corburn, 2007; Willis \& Keller, 2006). In one study by Willis \& Keller (2006) a modeling framework was created to evaluate the health risk implications of alternative land use scenarios on a regional and sub-regional scale. Their model considered the community health impacts of industrial versus commercial zoning decisions. Despite this new research, there has been little done to evaluate the health consequences of large-scale land use decisions such as in the case of individual residential developments. This thesis will therefore help to fill this information gap by estimating the quantity of additional CAC emissions from the residential vehicle emissions of the North Leslie Development. Its contribution to CAC emission production through vehicle use will provide the initial information necessary for the future investigation of the health impacts of large-scale, suburban developments and specifically the expected morbidity and mortality directly attributable to the development. 
3.1 Research Methodology

The objectives that were presented in Section 1.2, are presented below along with a breakdown of tasks required to accomplish these objectives:

1) To conduct a literature review examining the chemical components of air pollution, the health impacts of these pollutants, the contribution of air pollutants from vehicle emissions, the link between the built environment and travel behavior, the urban development trends in Southern Ontario, and the current planning policies in Ontario.

a. Provide a background of air pollution chemistry, specifically as it relates to human health.

b. Introduce the relationship between the built environment, vehicle use and health consequences.

c. Discuss how provincial planning policy and legislation has affected the built environment in Southern Ontario.

2) To calculate the approximate total quantity of household-generated VKT for an entire suburban development immediately after it is built and twenty years into the future.

a. Define the study area by size, location and planning characteristics;

b. Using the CMHC's TENS model, determine the weekday VKT per household in the year 2010 and 2030.

c. Using appropriate expansion factors, determine the annual VKT for the entire development in the year 2010 and 2030. 
3) To estimate the quantity of CAC that will be added to the airshed annually from the VKT produce by the development once it is built and twenty years into the future.

a. Using Transport Canada's UTEC model, convert the development's annual VKT into annual quantities of $\mathrm{CO}, \mathrm{NO}_{\mathrm{x}}, \mathrm{SO}_{2}, \mathrm{VOCs}, \mathrm{PM}_{10}$ and $\mathrm{PM}_{2.5}$ in tonnes.

\subsection{Description of Study Area}

The study area is a 620-hectare future residential development known as the North Leslie Development. It will be located in the Town of Richmond Hill, bounded by Bayview Avenue, Highway 404, Elgin Mills Road and $19^{\text {th }}$ Avenue. This development was selected because of its large size, its typical suburban low-density characteristics, and the way in which it demonstrates the continuation of business-as-usual land consumption without a health impact assessment as part of the OMB's approval process. A map of the North Leslie Development can be found in Figure 3-1.

The North Leslie Development is expected to contain approximately 6,755 new units, the majority of which will be low-density. This means that 21 to 32 homes will be built per hectare, far below the specific intensity targets set by the Growth Plan and density required to support local transit (Hemson Consulting Inc., 2009). ${ }^{2}$ Located approximately 10 kilometers from the closest employment hub and 20 kilometers from the nearest subway station, the community will naturally rely on individual car trips to commute to work and get around town. Based on Richmond Hill averages from the 2006 Transportation Tomorrow Study, this will mean another 13,500 additional drivers and automobiles in the community (Data Management Group, 2008). With the development also flanking Highway 404, it is almost certain that this development will further aggravate the traffic congestion problems in York Region and neighbouring areas, and contribute to the ongoing polluting of the air shed (iTRANS Consulting Inc., 2006).

\footnotetext{
${ }^{2}$ The Region of York is directed by the Growth Plan to plan for a density of 50 residents and jobs combined per hectare in new greenfield areas (Hemson Consulting Inc., 2009).
} 
As one would expect, approval for such a large development was highly controversial. In order to establish the North Leslie Planning District and implement a Secondary Plan for the new district, the urban boundary of the Town of Richmond Hill required expansion. This required an amendment to Richmond Hill's Official Planning Area. The landowners of the North Leslie Development Area, who organized themselves as the Bayview East Landowners Group, made applications to extend the urban boundary and after many appeals, were eventually permitted to develop the land based on decisions made at the OMB.

While some government agencies fought for the land to be developed as employment lands, local environmental groups were the only ones who fought against the land being urbanized. The Save the Rouge Valley System group opposed the boundary extension due to concerns over the natural heritage system and the groundwater resources found in the North Leslie Development area. The physical features of the land include three major tributaries of the Rouge River, which cross the North Leslie Development area, along with considerable wetlands and woodlots (OMB Decision/Order No. 3289, November 23, 2006). The north-west quadrant of the development area passes over the Ontario Greenbelt and over the south edge of the Oak Ridges Moraine.

Located in one of the fastest growing regions in Canada, Richmond Hill has seen its population soar over the last 25 years (SHS Consulting Inc. \& Centre for Spatial Economics, 2008). This growth has come at the cost of dwindling rural land. Despite changes to Ontario's planning policy, the approval of this development helps to demonstrate the continuation of greenfield consumption for low-density urban growth, designed to facilitate personal vehicle use. While it is evident that environmental concerns did not prevent this development from sprawling across another 620 hectares of rural land, estimates of the negative health impacts of this development and others like it could perhaps be the information needed to bring to an end to low-density, vehicledependent developments in Southern Ontario. 


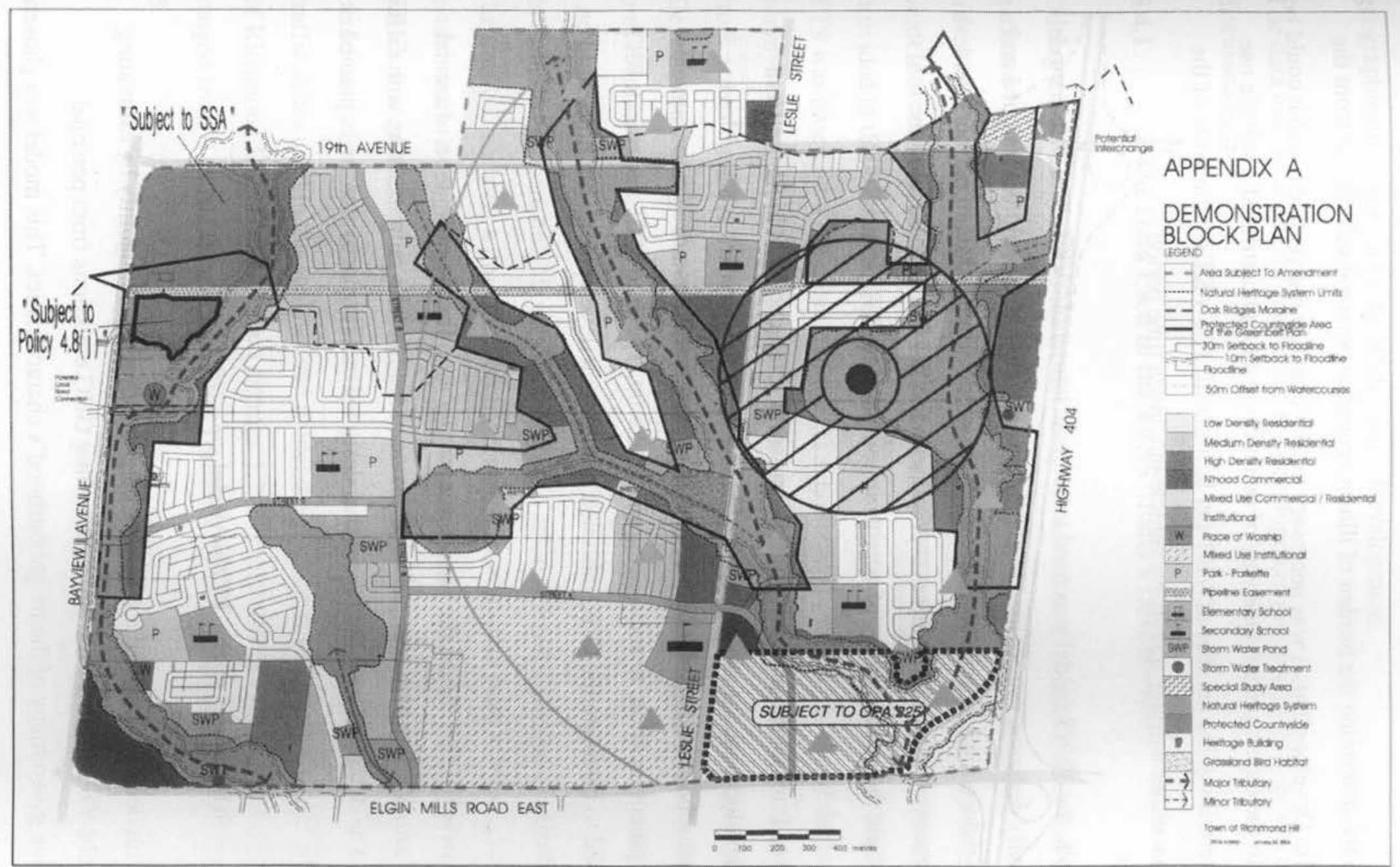

Figure 3-1: Map of the North Leslie Development, Richmond Hill, Ontario

*Note: The two circular maps superimposed on the map are in regards to local heron rookeries and are not pertinent to this thesis. Source: (Town of Richmond Hill, 2006) 
In order to the determine the burden of illness related to personal vehicle use from the North Leslie Development, it was necessary to first quantify the vehicle use that could be attributed to the development. One way of quantifying a neighbourhood's vehicle use was by determining the number of VKT per household. The VKT is a measure of the distance that either a driver travels by vehicle in a given time period.

In this thesis, the TENS model was used to estimate household VKT. The TENS model was originally designed to provide insight on how communities could be designed and planned to reduce their vehicle use and GHG emissions. The CHMC in partnership with the Department of Natural Resources worked with the IBI Group to develop the tool to help determine the sustainability of neighbourhood design (IBI Group, 2000).

Developed to forecast the amount of GHG emissions produced by vehicle use from proposed developments, it uses many neighbourhood characteristics as variables to calculate household VKT and transit PKT. These vary from urban design components and development location, to socio-economic make-up. The auto VKT and transit PKT are then used to calculate the GHG emission rate for that development, per household on an annual basis.

For the purposes of this thesis, the model was simply used for the estimation of annual household auto VKT, which was provided as one of the model's outputs along with GHG emissions. The details of how the model was designed and its mechanics are explained in Section 3.4 .

\section{4}

\section{Mechanics of the TENS Model}

The TENS model was designed to evaluate neighbourhood sustainability by estimating the household VKT, transit PKT and determining GHG emissions from personal transportation given many of the neighbourhood's characteristics. This model was chosen 
for this thesis due to its unique capability of modeling large-scale, residential developments, and due to the fact that the model was developed using data geographically pertinent to the North Leslie Development.

The data used to create the model and the development processes of the model are discussed next.

\subsubsection{The Data Used in the TENS Model's Development}

During the development of the model, a significant amount of information had to be gathered by the designers to build a framework that would quantify the links between travel behavior and neighbourhood characteristics. In the TENS model, the data on vehicle ownership, automobile VKT and transit PKT were based on the information provided in the 1996 Transportation Tomorrow Survey (TTS) (IBI Group, 2000). The TTS was based on a 5\% sample of the GTA households, making it one of the largest surveys of its kind in North America. The 1996 TTS area included transportation data from across the GTA, including Richmond Hill, the town in which the North Leslie Development area is found. A map of the travel survey summary area for the TTS is presented in Figure 3-2.

In order to compare neighbourhood features to determine the variables used in the model, the traffic zone level within the Toronto Census Metropolitan Area (CMA) was used to establish the level of aggregation for the development of the tool. The traffic zone level, which was on average an area of $6 \mathrm{~km}^{2}$, was found to be a level at which comparisons could easily be made between neighbourhoods and VKT. There were 795 Toronto CMA traffic zones used in the analysis and model development, which also included the Town of Richmond Hill. There were on average 1,290 households per traffic zone, but they ranged from 0 to 10,000 . A map of the Toronto CMA boundary is presented in Figure 33. 


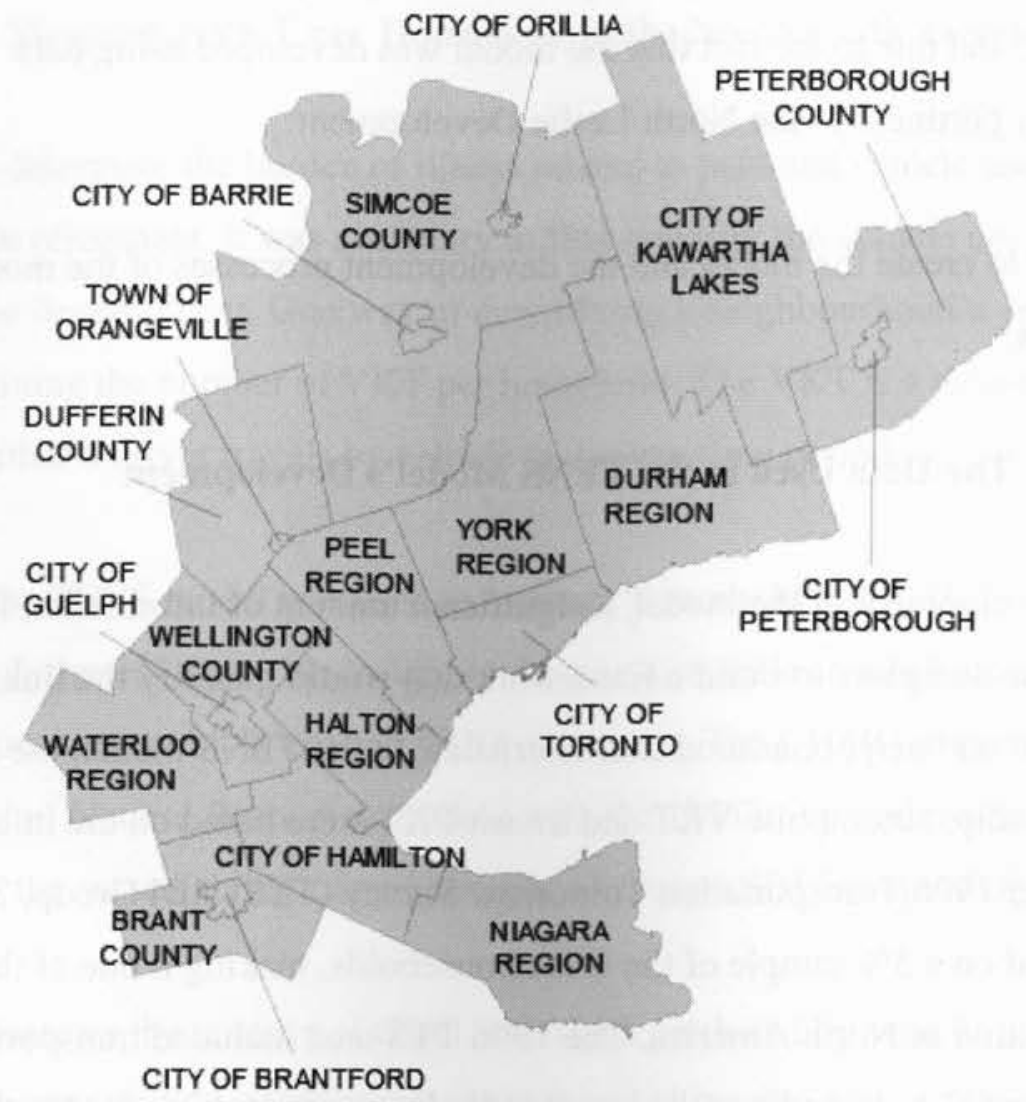

Figure 3-2: 1996 Travel Survey Summary Area for the TTS Source: (Data Management Group, n.d.).

The data used to develop this model, which used a geographical area that included the Town of Richmond Hill and the future North Leslie Development, were determined to be an appropriate measurement in estimating auto VKT for the development. By using data collected in the Toronto CMA to develop to model it can be assumed that, with accurate variable values, the TENS model would produce an accurate estimation of neighbourhood auto VKT for the North Leslie Development. 


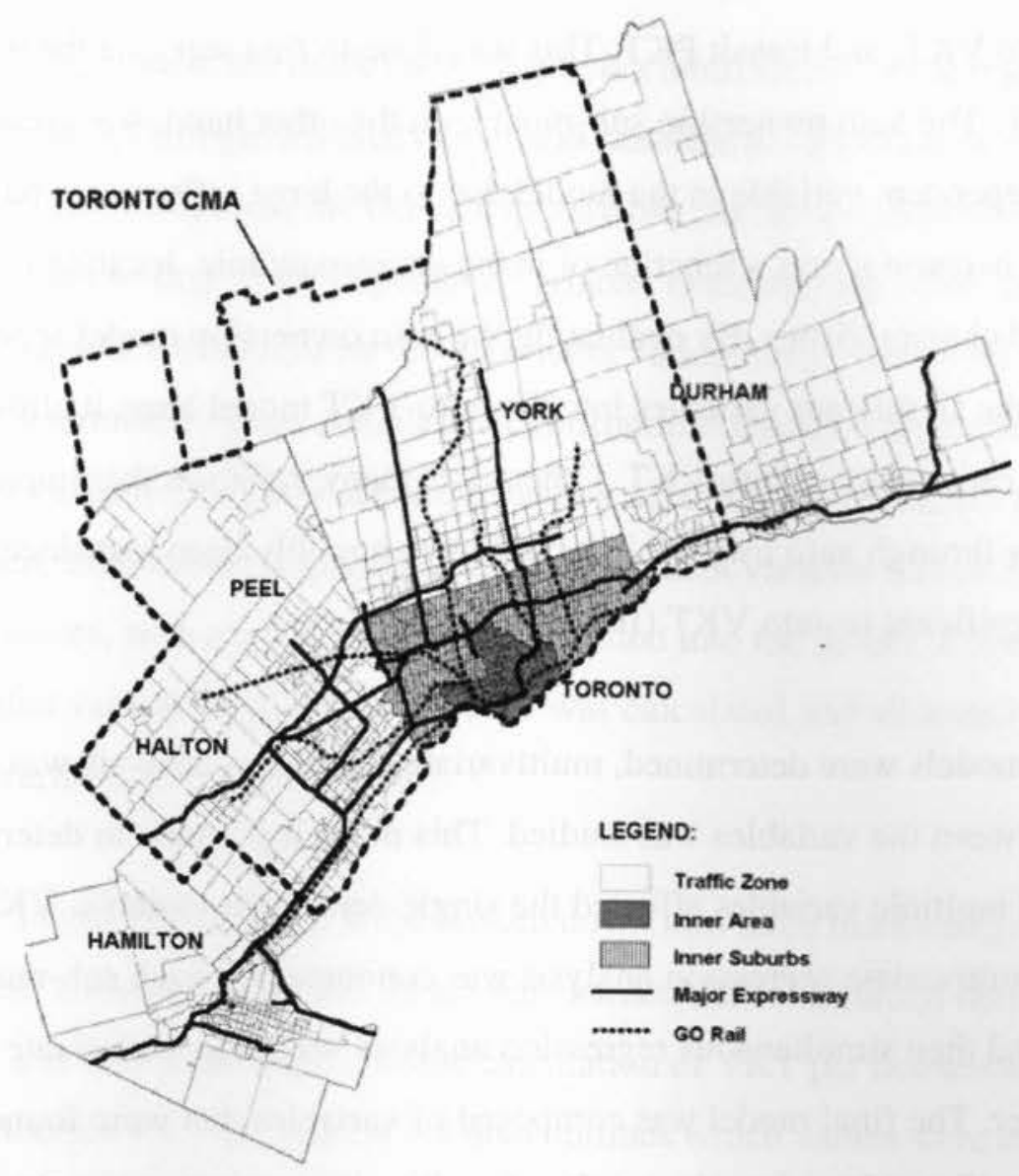

Figure 3-3: Map of Toronto CMA used in the TENS Model Source: (IBI Group, 2000, p. 5).

\subsubsection{Analysis of Variables}

Within the model, the dependent variable was VKT. It was defined by creating a standard measure of VKT using a "trip chaining approach" where all the daily travel by one individual was joined together as one long travel chain. All of the daily travel chains, or entire daily VKT, by individuals in one traffic zone were then summed and subsequently normalized (IBI Group, 2000).

As part of the development of the explanatory variables, or independent variables, a univariate analysis was first conducted to establish an understanding of how individual variables impact auto VKT and transit PKT, and whether the variable should be 
considered for inclusion. The model was then divided into three sub-models: auto ownership, auto VKT, and transit PKT. This was done to first separate the transit PKT from auto VKT. The auto ownership sub-model, on the other hand, was treated as an intermediate dependent variable in the model due to the large influence it has on auto VKT, but also because it was a function of many socioeconomic, locational and neighbourhood characteristics. By evaluating the auto ownership model separately and incorporating the significant variables into the auto VKT model later, it allowed for a more accurate estimation of auto VKT. Otherwise, many variables that impacted auto VKT indirectly through auto ownership would have possibly been lost since they were not directly significant to auto VKT (IBI Group, 2000).

Once the sub-models were determined, multivariate regression analysis was used and the covariance between the variables was studied. This made it possible to determine how individual and multiple variables affected the single dependent variable, VKT. During this process, multivariate regression analysis was conducted on each sub-model individually and then simultaneous regression analysis was used to evaluate the submodels together. The final model was composed of variables that were found to be statistically significant based on the results of multivariate regression analysis (IBI Group, 2000).

\subsection{3}

\section{Model Functioning}

The basic equation used by the model was:

$$
Y=a+b_{1} X_{1}+b_{2} X_{2}+b_{3} X_{3}+\ldots+b_{n} X_{n}
$$

where,

$$
\begin{aligned}
& Y=\text { the dependent variable } \\
& X=\text { the independent variable } \\
& a=\text { the constant term } \\
& b=\text { the coefficient term }
\end{aligned}
$$


As previously mentioned, the model was based on a multivariate linear regression analysis approach. Through this analysis, it was possible to identify how each independent variable impacted the dependent variable, and how independent variables interacted together to impact the dependent variable. Once the degree of each independent variable's influence on the dependent variable was quantified, the dependent variable was determined by the cumulative contribution of each independent variable to the dependent variable. This was accomplished by according a coefficient to each variable, which reflected the impact that that independent variable had on the dependent variable. Therefore, with each variable value inputted into the model, a coefficient determining that variable's influence on VKT was calculated and allocated to that independent variable (IBI Group, 2000).

The variables in the TENS model were broken down into three main categories: neighbourhood, socioeconomic and locational characteristics. Detailed descriptions of each variable and their contribution to the calculation of VKT per household are discussed in Section 3.8. The Section 3.8 also outlines which values were chosen for each variable and why. Variables that were not found to be statistically significant, and therefore not included in the sub-models, were not described in this thesis.

\subsection{Limitations of the TENS Model}

The model is largely limited by the data used in the development of the model. As was previously mentioned, the data on vehicle ownership and VKT per household came primarily from the 1996 TTS. Since 1996 there may have been changes in vehicle ownership data and VKT per household in Southern Ontario. Consequently, this could influence the outputs of the model. It is assumed however that the changes to vehicle ownership and regional VKT per household have not changed significantly.

The analysis used to develop the model was based on aggregating data at the zonal level within the Toronto CMA. While this seemed appropriate to the developers of the TENS 
model due to the focus on neighbourhoods and their performance, this approach could mask some of the behavioural relationships that could be observed at the household level. The outputs of this model must therefore be understood in the context of an entire neighbourhood and not used to describe individual household activities.

The model also considers all trip purposes together and consequently, it assumes that trips made for different purposes can be modeled using the same variables. This model can therefore not distinguish between the amount of VKT to work and the VKT for leisure.

\section{6}

\section{VKT Scenarios Over Time}

The physical design of a residential development does not change significantly over time, but the surroundings often do. The presence of a new urban development can lead to the expansion of transit routes, the addition of retail parks, and changes in other neighbourhood features. Time can also influence the socioeconomic factors important to vehicle use, such as employment availability and age distribution. Due to the evolution of communities over time, two VKT scenarios were created to demonstrate how time might influence vehicle dependence and consequently the quantity of CAC emissions arising from the North Leslie Development.

One scenario was developed to reflect the state of the development when it is first built. This scenario was named the 2010 VKT Estimate. The goal of this scenario was to estimate the quantity of CAC emissions produced by VKT if the development was built in the present. Therefore, no forecasting was done in this model. The 2010 VKT Estimate was calculated based on the Secondary Plan of the North Leslie Development within the present neighbourhood. In other words, neighbourhood characteristics such as bus routes and number of retail parks were assumed to remain unchanged.

The second scenario was designed to forecasts the VKT for the North Leslie Development in 2030. This scenario was named the 2030 VKT Estimate. The 2030 VKT 
Estimate was calculated based on the physical design of the North Leslie Development and neighbourhood changes that have been planned, proposed or estimated to take place over the next 20 years. The planned and proposed changes were based on a series of new provincial, regional or municipal planning and policy documents, which have been written, for the most part, within the last five years to address new provincial policy directions on growth. In order to take into account changes in socio-economic characteristics, demographics and other changes not forecast in planning documents, assumptions were made. As they are unique to each variable, the assumptions made are discussed as the variables are presented in the thesis, beginning in Section 3.8.

\section{7}

\section{Variation in Household Size and Income Estimates}

Within the TENS model, some variables have a greater impact than others on the output, or annual household VKT. Examples include distance to the central business district (CBD), household income and household size. It is important that the variables that have a large influence on the output be as accurate as possible. In most cases the variable values could be readily estimated; however, household size and household income did pose a problem when trying to establish an accurate estimate for the North Leslie Development.

Both household size (number of persons per dwelling) and household income are variables that have a great influence on VKT within the model; however, they also vary greatly within the Town of Richmond Hill from one development to another. This made it difficult to accurately select one value that would adequately represent the North Leslie Development. In order to manage this problem, it was decided that a high and low range VKT estimate would be determined using the highest and lowest household income and household size values found locally around the development. In other words, a high range VKT estimate for the North Leslie Development was modeled using the highest household income and highest household size estimates. Similarly, a low range VKT estimate for the North Leslie Development was modeled using the lowest household income and the smallest household size estimates. While the details of these values are 
explained in more detail later in Section 3.8, together these two VKT estimates established the range in which the future number of VKT could be found for the North Leslie Development.

Therefore, within both the 2010 VKT estimate and the 2030 VKT estimate, there was a high and low range VKT estimate calculated. A breakdown of the household size and household income were divided into the four scenarios which are presented in Table 3-1.

Table 3-1: Household Sizes and Household Income Distribution into the Four VKT Estimate Scenarios

\begin{tabular}{|c|c|c|c|c|}
\hline & $\begin{array}{l}\text { Low Range } \\
2010 \text { VKT } \\
\text { Estimate } \\
\text { (Scenario 1) }\end{array}$ & $\begin{array}{l}\text { High Range } \\
\text { 2010 VKT } \\
\text { Estimate } \\
\text { (Scenario 2) }\end{array}$ & $\begin{array}{l}\text { Low Range } \\
\text { 2030 VKT } \\
\text { Estimate } \\
\text { (Scenario 3) }\end{array}$ & $\begin{array}{l}\text { High Range } \\
2030 \text { VKT } \\
\text { Estimate } \\
\text { (Scenario 4) }\end{array}$ \\
\hline Year & 2010 & 2010 & 2030 & 2030 \\
\hline $\begin{array}{l}\text { Household } \\
\text { Size Value }\end{array}$ & $\begin{array}{l}\text { Smallest } \\
\text { Household Size }\end{array}$ & $\begin{array}{l}\text { Largest } \\
\text { Household Size }\end{array}$ & $\begin{array}{l}\text { Smallest } \\
\text { Household Size }\end{array}$ & $\begin{array}{l}\text { Largest } \\
\text { Household Size }\end{array}$ \\
\hline $\begin{array}{l}\text { Household } \\
\text { Income } \\
\text { Value }\end{array}$ & $\begin{array}{l}\text { Smallest } \\
\text { Household } \\
\text { Income } \\
\end{array}$ & $\begin{array}{l}\text { Largest } \\
\text { Household } \\
\text { Income }\end{array}$ & $\begin{array}{l}\text { Smallest } \\
\text { Household } \\
\text { Income } \\
\end{array}$ & $\begin{array}{l}\text { Largest } \\
\text { Household } \\
\text { Income }\end{array}$ \\
\hline
\end{tabular}

*Note: Household size is determined by the number of persons per dwelling. Model

This section presents the characteristics of the North Leslie Development necessary to determine the VKT estimate of the North Leslie Development using the TENS model. Variable by variable, the values used in the TENS model are discussed for both the 2010 VKT Estimate and the 2030 VKT Estimate. Any assumptions made are also described. The values are broken down by theme, as was done in the tool. Section 3.8.1 includes the neighbourhood attributes, Section 3.8.1 includes the socio-demographic data, and Section 3.8.3 includes the locational characteristics. A summary of all the TENS model inputs can be found in Table 3-9. 


\subsubsection{Road Layout Type}

During the estimation runs in the TENS model, the road layout variable was found, by the model's designers, to have a significant impact on VKT per household (IBI Group, 2000). This was evaluated by first manually classifying each traffic zone in the GTA and then comparing it to the local household VKT. A high degree of correlation was found by the designers between household VKT and road layout, with the lowest household VKT corresponding to grid networks and the highest household VKT corresponding with curvilinear and rural road layouts. After selecting the most statistically significant data, the auto VKT sub-model included a binary variable denoting a rural grid road type and the auto-ownership sub-model included a binary variable denoting a curvilinear road type, which included both the random and regular options.

Selecting the most appropriate road pattern for the North Leslie development was done by referring to a map of the future road layout produced by the Town of Richmond Hill (2006). It is represented in Figure 3-1. Of the possible seven options, the "mix of rectangular and curvilinear" was chosen to best describe the neighbourhood's future road network as the development has a predominance of curvilinear streets along with a significant grid network. The seven possible road layout options along with their descriptions can be found Appendix 1, Table A-1.

In regard to the 2010 and 2030 VKT forecasts, the same road layout was selected for all scenarios, as the road infrastructure is not expected to change over time.

\subsubsection{Total Number of Intersections and Road Length}

While estimating VKT using the TENS model, the number of intersections per roadkilometer was found to be a significant indicator of travel behavior. Designers of the model found a negative correlation between the number of intersections per roadkilometer and VKT. It was assumed that neighbourhoods with fewer intersections 
facilitated travel by vehicle, while developments with many intersections increased the connectivity for pedestrians and in turn increased the neighbourhood's walkability. While the ratio of intersections per kilometer had no statistically significant influence on auto ownership or transit PKT when evaluated through multiple regression analysis, it did significantly affect vehicle use and as a result was only used in the auto VKT sub-model of the tool.

The tool required the input of both the number of intersections and the length of the road within the development to calculate the number of intersections per road-kilometer ratio. The model specified that the total number of intersections be measured by including any intersection that connected two or more streets within the neighbourhood and only half of the intersections found on the periphery of the development. Total road length included all roads except for expressways and only one half of the length of roads on the periphery of the development.

For the 2010 VKT Estimate, both variables were manually measured using the map in Figure 3-1, produced by the Town of Richmond Hill (2006). The total road length was measured at 37 kilometers and the total number of intersections was found to be 121 intersections.

As for the 2030 VKT Estimate, both the road length and the number of intersections were assumed to remain consistent with the 2010 VKT Estimate values. It was assumed that neither variable would change significantly over time.

\subsubsection{Total Length of Wide Arterial Roads}

The ratio of wide arterial road length to total road length was found by the TENS model designers to have a statistically significant influence on auto VKT in the development of the model and was retained in the auto VKT sub-model. As is the case with the intersections to road-kilometer ratio, the presence of wide arterial roads was found to encourage vehicle use since it was assumed that wide arterial roads are not pedestrian 
friendly since people walking or cycling would prefer to use narrower, slower moving roads than high-speed, wide arterial roads.

To measure the ratio of wide arterial roads to total road length in the North Leslie Development, the model specified that only arterial roads with a width of at least three lanes found either in the development or on its periphery could be included in the measurement. The arterial roads in the development were wholly included, while those located on the boundaries would only be counted as half. Expressways were not included.

The Town of Richmond Hill Transportation Master Plan indicated that there were no wide arterial roads either within or surrounding the development presently (iTRANS Consulting Inc., 2006). These data were also verified by an on-site visit. Therefore, the value was set as zero kilometers for the 2010 VKT Estimate.

The Master Plan did however outline recommended improvements that included plans to widen Bayview Avenue, the western boundary of the development, to a three-lane road in both directions by 2021 (iTRANS, 2006). A map of the recommended road improvements is in Figure 3-4. As a result, the 2030 VKT Estimate included 1.9 kilometers of wide arterial road length, which accounted for the length of Bayview Avenue bordering the development.

\subsubsection{Total Length of Bike Routes}

In the model, bike routes were found by the designers to be statistically significant predictors of vehicle ownership and transit use. As the ratio of bike routes to total road length increased, vehicle ownership decreased and transit use increased. It was assumed that neighbourhoods that encouraged cycling by providing bike routes were expected to reduce automobile use. Total length of bike routes was therefore included as a variable in the auto ownership sub-model and the transit PKT sub-model. 
The total lengths of bike routes were accounted for by finding bike routes on and off streets, and park paths where bikes were permitted. It is important to note that unlike some of the measurements, which only accounted for one half of the values on the periphery, the entire lengths of the bike routes on the periphery were included in the measurement.

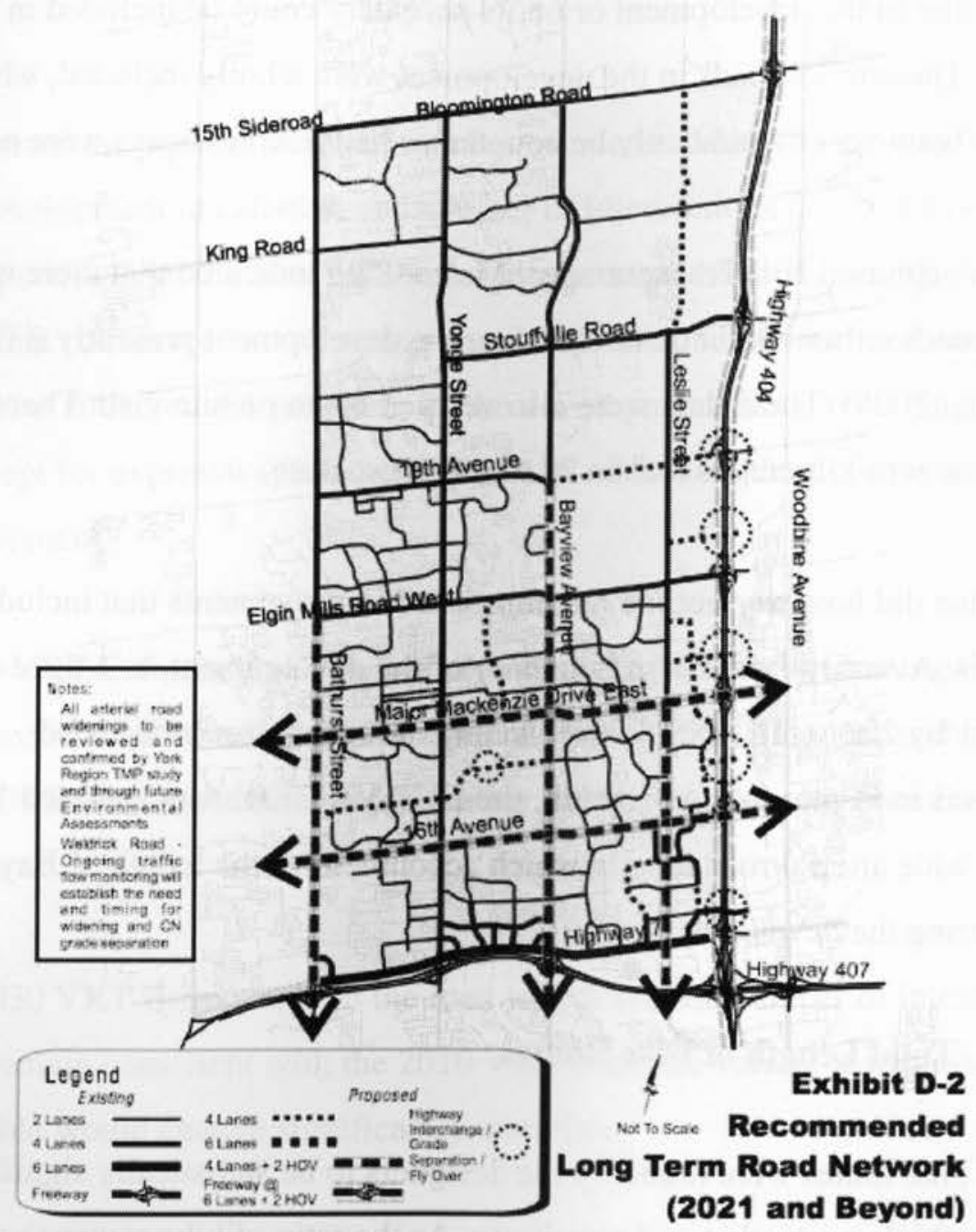

Figure 3-4: Richmond Hill Transportation Master Plan Map of Recommended Improvements to Municipal Road Networks

Source: (iTRANS Consulting Inc., 2006, p. 14).

For the 2010 VKT Estimate, no bike routes were included. While there was a small multi-purpose path within the Richmond Green Sports Centre and Park located in the development area on the southern border, it was not included. This decision was made due to the purpose of the path, which was to facilitate getting from one sports field (i.e. 
baseball diamond, soccer field) to another within the park. It did not facilitate personal transportation by bicycle outside of the park and therefore was disregarded.

For the 2030 VKT Estimate, the York Region Pedestrian and Cycling Master Plan was used to forecast the location of future bike paths (MMM Group Limited, Go for Green, \& Decima Research Inc., 2008). The document outlined the proposed long-term plan for bike paths in York Region over the next 25 years. As such, these proposals were only to be used as network concepts, which may or may not come into fruition. Nevertheless, these proposed paths were used to conservatively estimate the location and length of bike paths in the 2030 VKT Estimate. They included 2.83 kilometers on Elgin Mills Road, 1.9 kilometers on Bayview Avenue, 2.86 kilometers on $19^{\text {th }}$ Avenue and 2 kilometers on Leslie Street. Together these routes totaled 9.59 kilometers of bike paths.

\subsubsection{Land Area and Number of Housing Units}

In the model, the quantity of land area and the number of housing units was used to calculate the overall neighbourhood housing density. It was found by the designers of the model that the denser a neighbourhood is, the more likely people are to take public transit and not own a vehicle. The result reinforces the understanding that a certain level of density is required to provide adequate transit service.

The land area for the North Leslie Development was based on latest information provided in the documentation provided by the OMB (OMB Decision/Order No. 20080018, June $\left.18^{\text {th }}, 2008\right)$. The documentation stated that the entire development was approximately 620 hectares. As mentioned previously, specific areas of the development continued to be appealed to the OMB and therefore by the time the development would be built there could be changes to the size of the development. However, for the purposes of this thesis the 620-hectare value in the original proposal was use for both the 2010 VKT Estimate and the 2030 VKT Estimate. 
The total number of housing units that would likely be built in the North Leslie development was 6,755. This number was retrieved from the North Leslie Developers Group Secondary Plan (November 15, 2005). The number of housing units was not expected to change dramatically over time and therefore the same value was used for the 2010 and 2030 VKT Estimate. The breakdown of how these units would be developed is described in Table 3-2.

\subsubsection{Housing Typologies}

Housing typology consisted of two variables: the mix of housing types and the average number of rooms per dwelling. The housing mix was calculated by categorizing the development into the percentage of each dwelling type. That is, either single detached, semi-detached, townhouses/row houses, low-rise apartments or high-rise apartments. During the development of the tool, it was assumed that any link between housing type and VKT would be attributable to a difference in demographics. That is, younger families would be more likely to live in rented or smaller dwellings than older, well-established families. It was discovered by the designers of the model that when auto VKT was plotted against housing mix, there was an inverse correlation between housing mix and household VKT.

The average number of rooms per dwelling, also known as average dwelling size, was calculated by associating a certain number of rooms to each dwelling type. The model sould then calculate the average number of rooms per unit based on the number of rooms per dwelling type and the percentage of each dwelling type. As is expected, this variable was assumed to clearly reflect housing type. When VKT was plotted against the average house size for the neighbourhood, a trend of increasing VKT with increasing house size was found.

While the variables that described housing mix and average numbers of rooms per household were found to be insufficiently robust for the auto VKT sub-model and the transit PKT sub-model, they were found by the designers of the model to be a statistically 
significant indicator of auto ownership, and therefore were included in the auto ownership sub-model.

The housing mix for the North Leslie Development was obtained from the North Leslie Developers Group Secondary Plan (November 15, 2005). See Table 3-2 for the housing mix breakdown. Over half of the units in the development were classified as single detached homes demonstrating the low-density characteristics of the development.

Table 3-2: Breakdown of the North Leslie Development by Dwelling Unit Type

\begin{tabular}{lll}
\hline & Number of Units & Percentage of Total \\
\hline Single Detached & 3,540 units & $52.4 \%$ \\
\hline Semi-Detached & 640 units & $9.5 \%$ \\
\hline Townhouses / Row Houses & 1,065 units & $15.7 \%$ \\
\hline Low-rise Apartments & 235 units & $3.5 \%$ \\
\hline High-rise Apartment & 1,275 units & $18.9 \%$ \\
\hline Total & 6,755 units & $100 \%$ \\
\hline
\end{tabular}

Due to a lack of specific information regarding the number of rooms per dwelling within the North Leslie Development, the average dwelling size was determined using the average number of rooms per dwelling across the GTA. During the development of the model, the IBI Group (2000) determined that the average number of rooms per dwelling in the GTA was:

- 8.5 rooms per fully-detached home;

- 7 rooms per semi-detached home;

- 6 rooms per town/row house;

- 5 rooms per low-rise apartment; and,

- 3.5 rooms per high-rise apartment.

The number of rooms included all rooms in the unit, excluding bathrooms and hallways.

Using the percentage of each dwelling type and the average number of rooms per dwelling, the average dwelling size for the entire development was determined to be seven rooms per unit. The housing mix was determined by the model to be 0.80 . 
Both the 2010 and 2030 VKT Estimates contained the same values for housing mix and average number of rooms per dwelling as these variables were not expected to change over time.

\subsubsection{Gross Area Housing Density}

In some communities the density of the neighbourhood area might vary from the density of the local housing area within the neighbourhood being studied. In order to standardize the density value, regardless of the size of the development, the model used the gross area housing variable to determine the density within one kilometer of the center of the development. When tested by the tool's developers, the natural logarithm of the number of housing units within the one kilometer of the neighbourhood centroid proved to be a statistically significant indicator of automobile ownership and transit use. Therefore, the gross area housing density variable was included in the automobile ownership and transit PKT sub-models.

The default value for this variable uses the same value as the neighbourhood density, based on land area and number of housing units, as previously discussed. However, if the user believes that the gross area housing density differs from the neighbourhood density, the default value can be manually overridden.

When determining the input values for the North Leslie Development, the density of houses throughout the neighbourhood was assumed to be the homogeneous and as a result the default value was used. The gross area housing density was set by the model at 10.90; the same density level as the neighbourhood density. This value was also set for both the 2010 and 2030 VKT Estimate, as it was not expected to change over time.

\subsubsection{Number of Jobs within a one kilometer Radius}

Land use mixing is an important feature of a residential development. It reduces automobile use by providing opportunities for residents to walk, cycle, or take transit to 
local commercial and industrial sites. In order to evaluate the land use mix characteristics within the development, the model calculated a ratio by comparing the number of jobs within one kilometer of the development with the number of workers living in the development. When combined with other variables, the model's developers found the indicator to be a robust and statistically significant sign of automobile VKT (IBI Group, 2000). As a result, it was retained in the auto VKT sub-model.

While there is no business district within one kilometer of the North Leslie Development, there is currently one retail park, RIOCAN Elgin Hills Crossing at the south end of the development, at the corner of Leslie Street and Elgin Mills Road. It contains forty stores with approximately 450,000 square feet of retail space (Trinity, n.d). A map of the retail park is provided in the Figure 3-5.

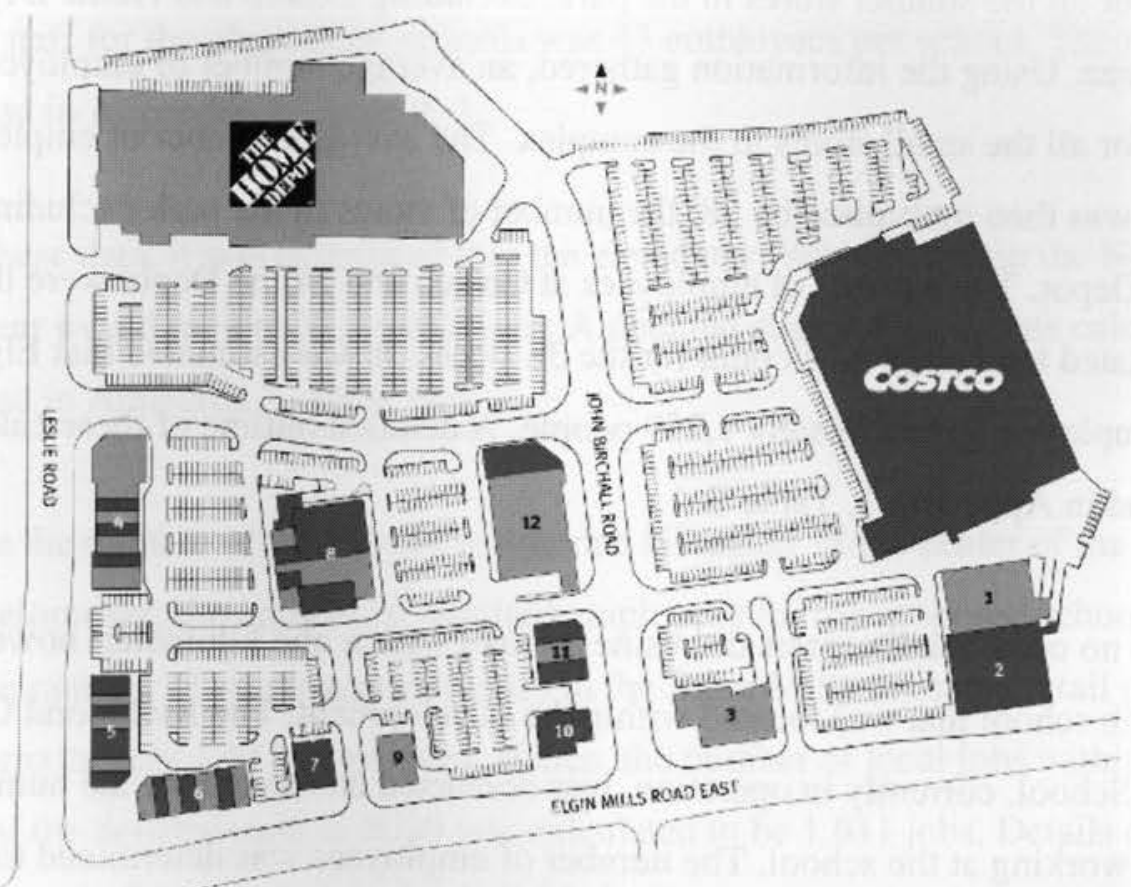

Figure 3-5: Map of Retail Stores in RIOCAN Elgin Hills Crossing Retail Park, Source: (Trinity, n.d.) Richmond Hill, Ontario

In order to approximate how many jobs are found within this area, telephone calls were made to hiring managers or customer service representatives in 10 of the stores in the retail centre. The staff members contacted were asked to estimate how many people the 
store had on staff, both part-time and full-time. The number of reported employees is listed in Table 3-3.

Table 3-3: RIOCAN Elgin Hills Crossing Retail Park Employment Numbers, 2009

\begin{tabular}{ll}
\hline Store & Employees \\
\hline Costco & 220 \\
Home Depot & 165 \\
Petsmart & 30 \\
Michaels & 25 \\
Staples & 30 \\
Mark's Work Warehouse & 25 \\
TD Canada Trust & 14 \\
Scotia Bank & 16 \\
Kelseys & 40 \\
Tuxedo Royale & 5 \\
\hline
\end{tabular}

In order to estimate the number of employees in the retail park, first an average was calculated for all the smaller stores in the park, excluding Costco and Home Depot due to their large size. Using the information gathered, an average number of employees were calculated for all the small stores in the complex. The average number of employees per small store was then multiplied by 38 , the number of stores in the park excluding Costco and Home Depot. The number of employees at Costco and Home Depot were then added to the estimated total employee count for the 38 stores. It was estimated that Elgin Hills Crossing employed approximately 1,259 people. A detailed outline of these calculations can be found in Appendix 1, Table B-1.

There were no other retail centers or business parks within one kilometer; however, there was one high school that was located within the development. The Richmond Green Secondary School, currently in operation, was contacted and asked for the number of employees working at the school. The number of employees was determined to be 95 and this number of employees was then added to the employment numbers from the retail park. Together the retail park and the high school had 1,354 employees and this number was assumed to reflect the number of jobs within one kilometer of the centre of the North Leslie Development in 2010. An explanation of the calculations is found in Table B-2 in Appendix 1. 
With no area within the North Leslie Development Secondary Plan slated for commercial or industrial development and no access to plans indicating any extension of the current retail park, it was assumed that the employment area within one kilometer of the centre of the North Leslie Development would remain unchanged. In addition, there was little chance that the retail park would add square footage on top of the current buildings. Therefore, it was assumed that with no extra square footage, there would be no additional employment in the commercial or industrial sectors.

The Town of Richmond Hill's Planning Department map of the future North Leslie Development did suggest the development of six elementary schools within the development (Town of Richmond Hill, 2006). In order to determine the staffing requirements of these schools, six elementary schools in Richmond Hill where telephoned and asked to give the number of employees at their school. The average number of staff for the elementary schools was 43 employees per school. The raw data can be found in Appendix 1, Table B-3.

Based on these data, it was calculated that the elementary schools within the North Leslie Development would require 257 employees. A detailed explanation of this calculation can be found in Appendix 1, Table B-4.

To estimate the number of jobs found within one kilometer of the center of the North Leslie Development, the number of required employees for the proposed schools was added to the number of employees currently in the Elgin Mills Crossing retail park. This totaled approximately 1,611 employees. Hence, the number of local jobs within one kilometer of the development in 2030 was calculated to be 1,611 jobs. Details of this calculation can be found in Appendix 1, Table B-4.

\subsubsection{Number of Grocery Stores}

Shopping opportunities within walking distance of a household is assumed to decrease VKT. Therefore, during the development of the tool, travel behavior was observed to see 
whether the number of grocery stores within one kilometer of the neighbourhood centroid would significantly influence vehicle ownership, VKT or transit PTK. In this case, the definition of "grocery store" included all stores that would be listed under Grocers-Retail in the Yellow Pages and they could be of any size. It was found that auto VKT and transit PKT were negatively correlated with grocery shopping opportunities within one kilometer of the development.

Due to the fact that most construction in the area is fairly recent, both the Yellow Pages and on-site observations were used to determine the number of grocery stores found in the area. It was concluded that the only grocery store currently within a one kilometer radius of the neighbourhood centroid is the previously mentioned Costco located in the Elgin Hills Crossing retail park. Therefore, the value used for the 2010 VKT Estimate was one grocery store.

As for the 2030 VKT Estimate for the North Leslie development, the forecast number of grocery stores was based on the average number of grocery stores within one kilometer of any development in the GTA. This number was based on the information gathered by the authors of the TENS model during its development and is provided by the tool as the suggested default value (IBI Group, 2000). The average number is four grocery stores per development. It was determined that the default would be a good estimate seeing as once the development is built, there will likely be more grocers than there are at present; however, not likely more than the GTA's average.

\subsubsection{Socio-demographic Data}

\subsubsection{Household Size}

The average number of people living in each housing unit is the household size. This variable is very influential as it directly influences the number of drivers in the household. When evaluated for the tool, it had a statistically significant impact on all three sub-models and therefore was a very important variable for the VKT estimation. 
In order to find an accurate estimate of household size, the 2006 TTS was used (Data Management Group, 2008). The TTS is a very extensive travel survey conducted every five years in the Greater Toronto and Hamilton Area. It surveys approximately 115,000 homes in the GTA, which for the purposes of this thesis conveniently included all of the wards in the Town of Richmond Hill.

Since the TTS is broken down by ward, there were no data specifically for the North Leslie Development. Instead, a ward had to be selected to accurately represent the development. Unfortunately, household size varies greatly within the Town of Richmond Hill and as a result there was no single ward that could be selected to reliably predict the household size. As a result, it was decided that two wards would be selected to create a more accurate range of what the VKT estimate could be like for the North Leslie Development. That is, a high and low range VKT estimate would be created based on the larger and smaller average household sizes, given by the two selected wards from the 2006 TTS.

The selected ward for the high range VKT estimate was Ward 3. A map of this ward can be found in Figure 3-6. It is bound by Stouffville Road, Highway $404,16^{\text {th }}$ Avenue and Bayview Avenue, in the Town of Richmond Hill. It contains many brand new developments adjacent to where the North Leslie Development will be built and is also the same ward that will eventually house the North Leslie Development. However, the housing typology within this ward is not reflective of what will be found in the North Leslie Development and therefore the average 3.7 persons per household may be too high for the North Leslie Development since there is a far higher percentage of detached and semi-detached homes in Ward 3 than in the development in question (Data Management Group, 2008). 

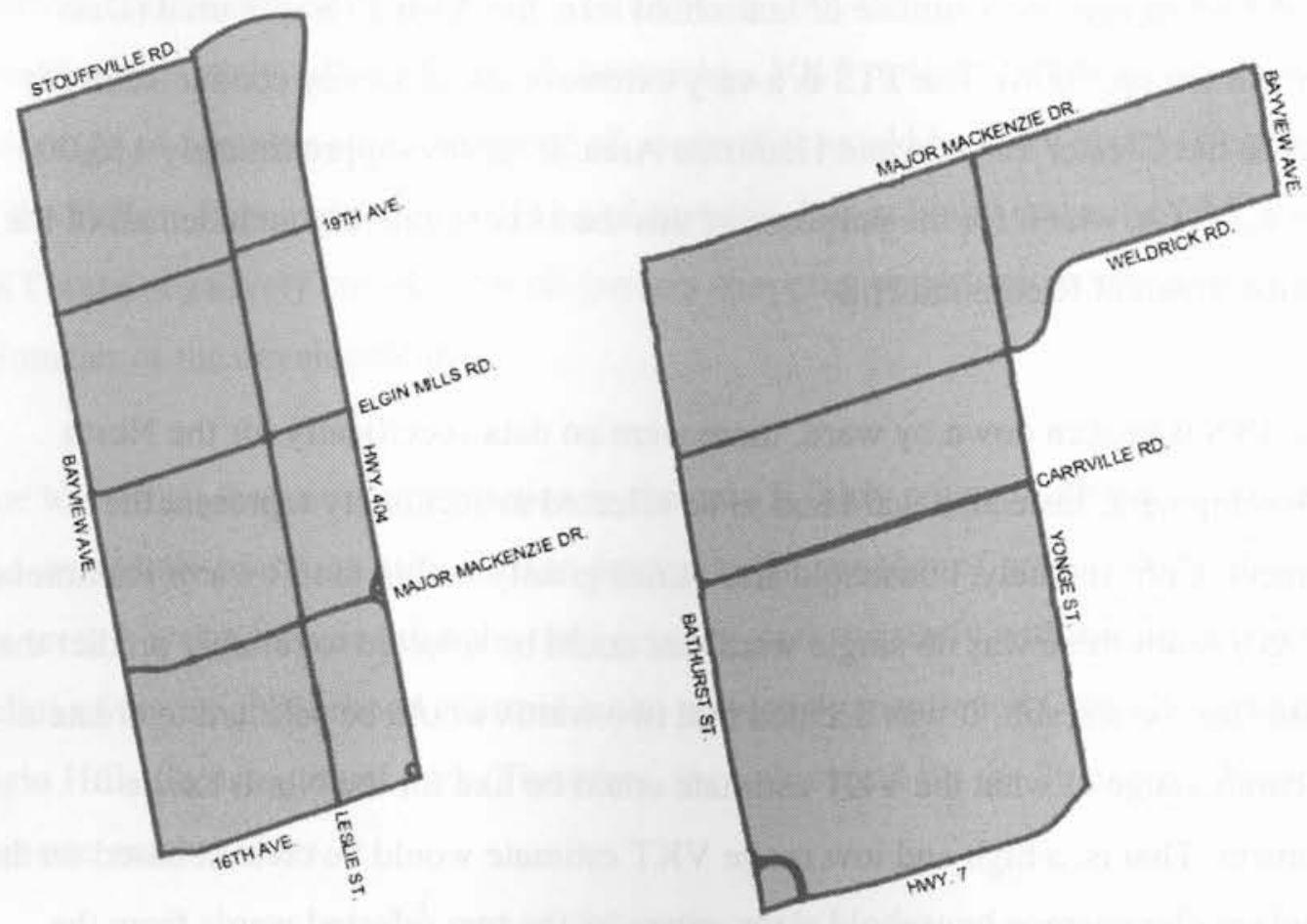

Figure 3-6: Map of Ward 3 (left) and Ward 5 (right) from the 2006 TTS Source: (Data Management Group, 2008, p. 31 and p. 33)

The ward selected for the low range VKT estimate was Ward 5, which is bound by Major Mackenzie Drive, Bayview Avenue, Weldrick Road, Yonge Street, Highway 7 and Bathurst Street. A map of this ward is provided in Figure 3-6. This ward is southwest of where the North Leslie development and its housing typology is very comparable to the proposed housing mix of the North Leslie development. However, it contains much older housing developments, which may influence household size. The average household size in Ward 5 is 2.8 persons (Data Management Group, 2008).

The household size estimate was kept constant for the 2010 and the 2030 VKT estimates. This was due to the fact that in Richmond Hill, the household size has not changed over the last three census studies. From 1991 to 2006, Richmond Hill has had an average of 3.2 persons per household (SHS Consulting \& Centre for Spatial Economics, 2008). Therefore, it was believe that keeping the high and low range of average household sizes constant over the next 20 years was a reasonable estimation. 


\subsubsection{Percentage of the Population Under 16 Years Old}

The model used data on age distribution along with household size information to determine the number of adults per household. The age variable was found to be important since the number of adults per household significantly influenced household vehicle ownership (IBI Group, 2000). Therefore, this was retained for the auto-ownership sub-model.

In order to forecast the 2010 population of residents less than 16 years old living in the North Leslie development, Statistics Canada data were used. Unfortunately, when retrieving information on age characteristics, Statistics Canada collects age distribution data in four-year clusters. For example, the number of 10 to 14 year olds is collected as one cluster and the next cluster is from 15 to 19 year olds, making it difficult to calculate the percentage of the population less than 16 years old. As a result, the percentage used to reflect the number of residents under 16 years old was an estimate based on the percentage of people less than 15 years provided by Statistics Canada census data.

As for the census tract that was chosen to represent the future North Leslie Development, it was necessary to choose a development in a similar location. Spatial distribution can influence age distribution, as younger families may tend to find housing in the outer suburbs where housing is cheaper. Therefore, it was decided that the two census tracts encompassing the adjacent development to the west $(0424.04 ; 0424.05)$ and the single census tract to the south (0422.03) would be used to estimate the North Leslie development's age distribution (Statistics Canada, 2006a; Statistics Canada 2006b, Statistics Canada 2006c). A map of each census tract is found in Appendix 1 as Figure C1 (0422.03), Figure C-2 (0424.04), and Figure C-3 (0424.05). 
Table 3-4: Percentage of the Population Under 15 Years Old Averaged Across Three Census Tracts

\begin{tabular}{llll}
\hline Census Tract & $\begin{array}{l}\text { Total Population } \\
\text { Under 15 Years Old }\end{array}$ & $\begin{array}{l}\text { Total } \\
\text { Population }\end{array}$ & $\begin{array}{l}\text { Percentage of } \\
\text { Population Under 15 } \\
\text { Years Old }\end{array}$ \\
\hline 0422.03 & 1,270 & 5,470 & $23.2 \%$ \\
\hline 0424.04 & 540 & 2,610 & $20.7 \%$ \\
\hline 0424.05 & 1,850 & 8,620 & $21.5 \%$ \\
\hline Average of All Three Census Tracts & & $21.8 \%$ \\
\hline
\end{tabular}

Source: (Statistics Canada, 2006a; Statistics Canada 2006b, Statistics Canada, 2006c)

Taken from the average of the three census tracts mentioned above, 21.8 per cent was used as the value for the number of residents under 16 years old in the 2010 VKT Estimate. Table 3-4 outlines this data.

As for the 2030 forecast, Statistics Canada 2006 census data for the entire Town of Richmond Hill were used (Statistics Canada, 2006d). In Town of Richmond Hill, approximately 19.4 per cent of the population was reported in the census to be less than 15 years old. This was assumed to be a reasonable estimate for the 2030 forecast for two reasons. Firstly, the average age of the residents is assumed to increase as the development gets older and therefore is expected to increase slightly over the next 20 years. Secondly, the assumption that approximately 19.4 per cent of the North Leslie Development will be under the age of 16 in 2030 is very similar to the 20 per cent average for the GTA average, given by the model (IBI Group, 2000). Therefore, the 2030 VKT Estimate presumed that 19.4 per cent of the North Leslie Development was under 16 years old.

\subsubsection{Average Household Income}

In the development of the model, two measures of income were considered when forecasting travel behavior: average employment income, and average household income. It was found by the model's designers that household employment income was a statistically significant predictor of vehicle ownership, while worker income was a more robust predictor of VKT than household income. As a result, both were incorporated into 
the model. Household employment income was used as a variable in the auto ownership sub-model, and worker income was used in the auto VKT sub-model (IBI Group, 2000).

To simplify the tool for users, it only required the input of average household income. From this number, the tool then divided the household employment income by 1.5 to produce a reasonable estimate of the individual employment income. The value of 1.5 represented the average number of workers per household in the Toronto CMA (IBI Group, 2000).

The average household income for the North Leslie Development was predicted by using census tract data provided by Statistics Canada 2006 census data. However, instead of the average household income, the census provides the median household income for each census tract. Therefore, the distribution of income was assumed to be normal and the median was used to forecast the future average employment income of the North Leslie Development.

Due to the range of varying incomes in the residential developments surrounding the North Leslie Development, it was decided that a high and low income range would be used to help predict the most accurate measures of VKT. For the 2010 VKT Estimate, the census tract income data from two adjacent developments were retrieved and used in the model. In the high range 2010 VKT Estimate, the median household income from census tract 0424.04 was input, which was the larger income at $\$ 94,687 /$ household/year (Statistics Canada, 2006a). Alternatively, for the low range 2010 VKT Estimate, the median household income from census tract 0424.05 was input, which was the smaller income at \$79,471/household/year (Statistics Canada, 2006b). Maps for these census tracts can be found in Appendix 1, Figure C-2 (0424.04) and Figure C-3 (0424.05).

In the case of the 2030 VKT Estimate, the range of household income levels needed to be adjusted to reflect future income levels. Due to a lack of available historical census data, a study of vehicle ownership and income growth (Dargay, 2007) was used to derive the average real income growth in Canada over the next 20 years. The study reported that 
real income growth in Canada from 2002 to 2030 was approximately 2.0 per cent per year. While the average rate of real income growth for the entire country may vary from that in the Town of Richmond Hill, this growth rate was assumed to be a reasonable estimate based on available information.

When the growth rate was applied to the 2010 income estimates, the high range 2030 income estimate became $\$ 140,701$ and the low range 2030 income estimate became $\$ 118,090$. The median household income values used in the TENS model for both 2010 VKT estimates and 2030 VKT estimates can be found in Table 3-5.

Table 3-5: Median Household Income Values Used for the 2010 and 2030 VKT Estimates

\begin{tabular}{lll}
\hline Census Tract & $\begin{array}{l}\text { 2010 VKT Estimate } \\
\text { (Scenario 1 and 2) }\end{array}$ & $\begin{array}{l}\text { 2030 VKT Estimate } \\
\text { (Scenario 3 and 4) }\end{array}$ \\
\hline $0424.04(\mathrm{HIGH})$ & $\$ 94,687$ & $\$ 140,701$ \\
\hline $0424.05(\mathrm{LOW})$ & $\$ 79,471$ & $\$ 118,090$ \\
\hline
\end{tabular}

Source: (Based on Statistics Canada, 2006a; Statistics Canada, 2006b).

\subsubsection{Locational Characteristics}

\subsubsection{Distance to the CBD}

Distance to the CBD is a very powerful variable in this tool as it influences all three submodels. During the development of the tool, it was found that within the Toronto CMA, VKT increased linearly as distance from the CBD increased. For every kilometer a household was located further from the CBD, the weekday VKT per household increased by approximately one kilometer.

The data used to develop the model were based on Toronto Census Metropolitan data, which locates the CBD at the intersection of King Street and Bay Street in downtown Toronto. Fortunately, the North Leslie Development is located within the Toronto CMA boundaries set by the model and therefore the same intersection was used to set the distance between the North Leslie Development and the CBD. 
The distance between the corner of King Street and Bay Street, Toronto, was measured using the 'Get Directions' Application in Google Maps and was found to be 36 kilometers (Google Maps, n.d.). This same number was used for the future emissions estimate, as the CBD is not expected to change significantly over the next 20 years.

\subsubsection{Number of Jobs within Five Kilometers Radius}

Proximity to work was assumed by the tool to reduce automobile dependence. In order to calculate the employment opportunities close to this development, the tool used the number of jobs within a five-kilometer radius of the neighbourhood's centroid. By plotting the number of jobs within five kilometers against household VKT, it was discovered by the designers of the model that as the number of jobs increased, the household VKT decreased. The number of jobs within five kilometers was found to have a statistically significant influence on auto VKT and as a result, the variable is used in the auto VKT sub-model.

In order to estimate the number of jobs within a five-kilometer radius of the North Leslie development, the total employment numbers of all four Richmond Hill business parks, provided by the Town of Richmond Hill Economic Policy Review Report, were incorporated into the employment numbers (Hemson Consulting Ltd., 2009). These would include the Beaver Creek Business Park, the Newkirk Business Park, the Headford Business Park and the Barker Business Park. A map of these locations is provided in Figure 3-7.

It is important to note that while the Beaver Creek Business Park is slightly outside of the five-kilometer radius, it was determined to be a very important employment hub, as it is the largest employment area in Richmond Hill. There was concern that eliminating it would result in a misrepresentation of the development's location relative to large employment hubs and therefore it was included in the estimation. 


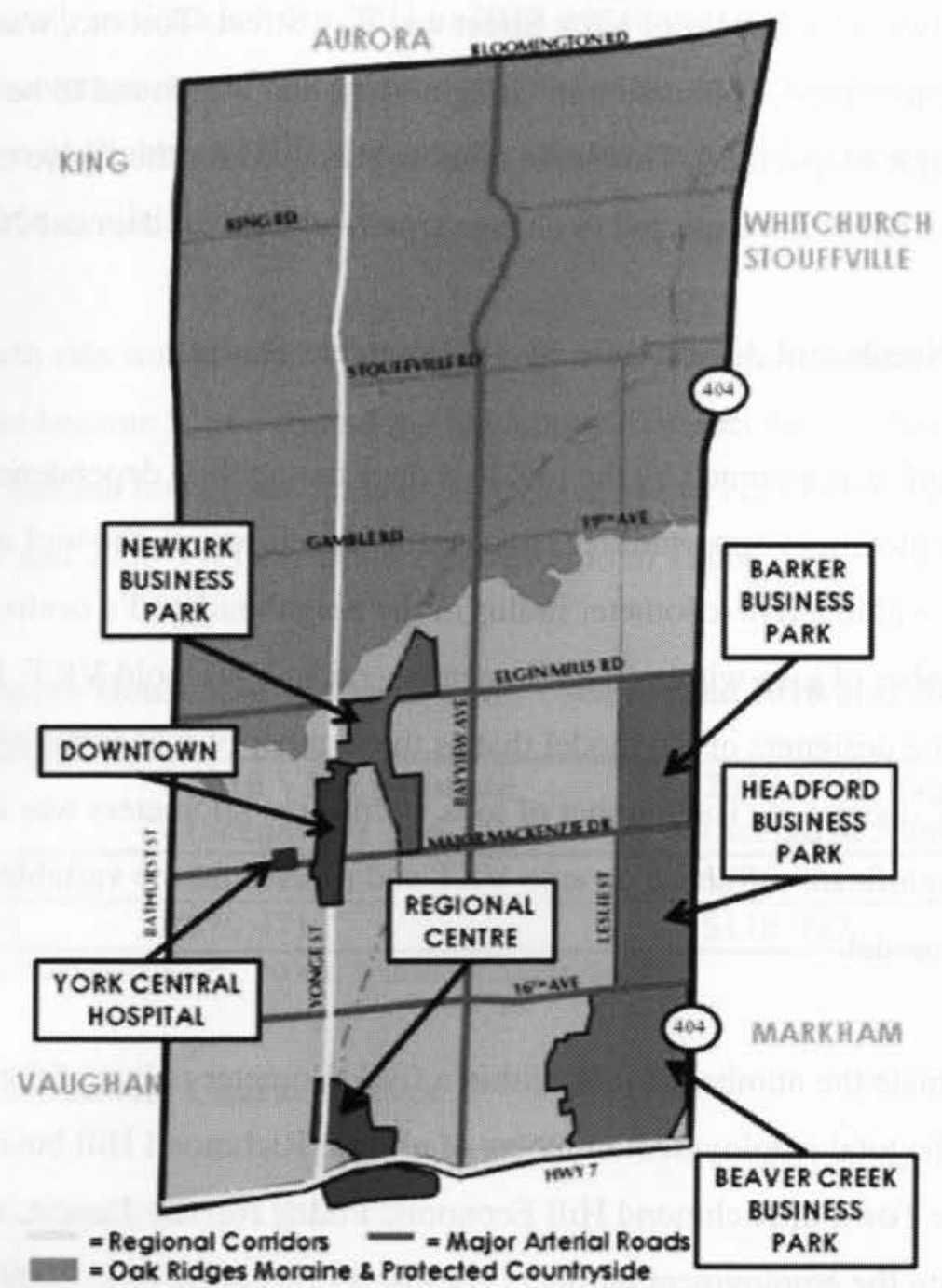

Figure 3-7: Employment Lands in the Town of Richmond Hill Source: (Hemson Consulting Ltd., 2009, p. 41)

Outside of business parks, the Town of Richmond Hill has a significant number of jobs dispersed around the municipality. The town's Economic Policy Report groups these employment centers by major roadway or large single employer, such as the local hospital or local government office (Hemson Consulting Ltd., 2009). The employment centers within approximately five kilometers of the North Leslie Development were included in the total job numbers. A list of these employment areas, along with their employment numbers, is provided in Table 3-6. 
Of all the employment centers established by the Economic Policy Report, all were included except for those categorized as employment along 'Highway 7' and 'Major Arterial Roads'. These were deemed inappropriate for the value of the variable as they were, on average, further than seven kilometers away from the North Leslie Development and therefore considered to be too far outside of the five kilometers radius. Two of the employment categories, 'Work at Home' and 'Other Community Based', were included even thought the distance from the North Leslie Development were dispersed throughout the town. As a result, the number of jobs available within five kilometers of the North Leslie Development was approximated at 56,330 jobs in 2010.

\section{Table 3-6: Richmond Hill Employment Distribution}

\begin{tabular}{lrr}
\hline Location & Number of Jobs & $\begin{array}{r}\text { Distance from North } \\
\text { Leslie Development }\end{array}$ \\
\hline Beaver Creek Business Park & 21,130 & $7 \mathrm{~km}$ \\
Newkirk Business Park & 5,240 & $1.8 \mathrm{~km}$ \\
Headford Business Park & 2,540 & $4.1 \mathrm{~km}$ \\
Barker Business Park & 150 & $2 \mathrm{~km}$ \\
\hline Business Park Sub-Total & & \\
\hline Yonge Street & 29,060 & $3 \mathrm{~km}-9 \mathrm{~km}$ \\
Highway 7 (not included) & 8,770 & $7 \mathrm{~km}-14 \mathrm{~km}$ \\
Major Arterial Roads (not included) & 1,570 & $1 \mathrm{~km}-17 \mathrm{~km}$ \\
Richmond Hill Regional Center & 5,160 & $5.9 \mathrm{~km}$ \\
Downtown & 2,120 & \\
York Central Hospital & & $3.9 \mathrm{~km}$ \\
Work at Home & 1,930 & $4 \mathrm{~km}$ \\
Other Community Based & 2,020 & Unknown \\
& 8,350 & Unknown \\
\hline
\end{tabular}

Total Employment in Richmond Hill

63,060

Total Employment within five kilometers of the North Leslie Development. 56,330

Source: (Based on Hemson Consulting Ltd., 2009)

In order to forecast the number of jobs that will exist within five kilometers of the development by 2030 , the forecasting data provided by the Town of Richmond Hill Economic Policy Review Report produced by Hemson Consulting Ltd. (2009) were used. Based on Statistics Canada 2006 census data and York Region's growth information, Hemson Consulting Ltd. estimated that employment in Richmond Hill would grow from 61,100 in 2006 to 100,700 in 2031. 
Despite the fact that the forecast was conducted for the entire Town of Richmond Hill, the 2006 employment number, used to project the 2031 employment number, was close enough to the 2010 estimate, noted above, that it was believed to be a reasonable assumption to use the entire 2031 employment estimate provide by the Economic Policy Review Report to determine the 2030 projected five-kilometer radius employment number. Therefore, it was assumed that there would be 100,700 jobs within five kilometers of the North Leslie Development by 2030.

\subsubsection{Distance to Nearest Rapid Transit Station}

The influence of transit accessibility was evaluated during the development of the tool and it was found that access to a rapid transit station within one kilometer of the development significantly decreases automobile ownership and significantly influenced household VKT when the station was at varying distances from the development. As a result, this variable was included by the model's designers in both the auto ownership sub-model and the auto VKT sub-model. It was also found to be a robust and statistically significant indicator of increased PKT when the station was within one kilometer of the development. Therefore, the variable was also included in the transit PKT model.

The distance to the nearest rapid transit station was found by measuring the distance from the center of the proposed development to the nearest subway or light rail station. The model does not consider diesel locomotive with unpowered passenger cars, like the GO Transit trains in the Greater Toronto Area, to be rapid transit. Therefore, through the use of the 'Get Directions' application provided by Google Maps and the Toronto Transit Commission Subway (TTC) Map, the distance between the centre of the development and the closest TTC subway station, Finch Station, located at Finch Street and Yonge Street in Toronto was found to be 20 kilometers for the 2010 VKT Estimate (Google Maps, n.d.; TTC, n.d.). 
In order to estimate the location of subway or rapid transit stations in 2030 , the MoveOntario 2020 transit plan was used. This transit plan, proposed by the Government of Ontario in 2007, is anticipated to boost public transit ridership in the GTA and Hamilton Area with the addition or improvement of 902 kilometers of rapid transit at a cost of $\$ 17.5$ billion (ECO, 2008). Part of the MoveOntario 2020 plan is to extend the Yonge Street subway line north from Finch Station to Highway 7 and Langstaff Road by 2020 (Government of Ontario, 2007).

With the additional transit infrastructure, the new distance between the centre of the North Leslie Development and the nearest subway station, at Highway 7 and Langstaff, would be 13 kilometers. The distance was calculated using the 'Get Directions' application provided by Google Maps (Google Maps, n.d).

\subsubsection{Distance to the Nearest Commuter Rail Station}

Within the TENS model, the variable accounting for distance to the nearest commuter rail station is defined by how many kilometers there are between the development and rail stations, such as GO Transit in Toronto, BC Transit Commuter Rail in Vancouver and AMT Commuter Rail in Montreal. Unlike the variable accounting for the distance to nearest rapid transit station, the distance to the nearest commuter rail station was found not to have a statistically significant influence on automobile ownership or auto VKT during the development of the tool. However, the variable was found to influence transit PKT when the rail station was located within two kilometers of the development. Therefore, it was included as a variable within the transit PKT sub-model.

With respect to the 2010 VKT Estimate, the closest commuter rail station to the North Leslie Development is a GO transit station located five kilometers from the development, at Major MacKenzie Drive East and Newkirk Road. The location of the nearest commuter rail station was retrieved from the GO Transit service map (GO Transit, 2009). The distance was calculated using the Google Maps ‘Get Directions’ Application (Google Maps, n.d.). 
The location of commuter rail stations around the North Leslie Development in 2030 was based on the MoveOntario 2020 transit plan, as were the forecast rapid transit plans. However, unlike the proposal for the rapid transit extensions, MoveOntario 2020 does not plan to add additional stations in Richmond Hill. While the proposal does intend to expand rail line capacity from Richmond Hill to Union Station in Toronto, there were no plans for the establishment of new stations closer to the North Leslie Development than the current station at Major MacKenzie Drive East and Newkirk Road (Government of Ontario, 2007). Therefore, the distance to the nearest commuter rail station remained at five kilometers from the development for the 2030 VKT Estimate.

\subsubsection{Transit Vehicle Service Hours}

When residents are provided with good public transit alternatives, it is assumed that household VKT will be reduced. Therefore, during the development of the tool, local bus service was studied by the model's designers to observe the impact that it would have on local VKT. As expected, it was found that local VKT decreased as public transit service hours increased. The decrease in VKT was determined to be the result of reduced vehicle ownership and increase in household transit use. It was therefore included in the auto ownership and transit PKT sub-models.

In order to quantify the level of bus service in an area, the tool used weekday bus vehicle service hours. This was a function of the frequency of bus service and the extent of route coverage in the community within one kilometer of the neighbourhood's centroid. The one-kilometer radius was set at the approximate distance a person would choose to walk to get to the nearest bus stop. 
Within the tool, the weekday bus vehicle service hours were calculated using four variables:

1. Length of segment of route within a one-kilometer radius $(\mathrm{km})$

2. Average time between buses during weekdays (minutes)

3. Total hours of route operations during weekdays (hours); and

4. Average bus speed ( $\mathrm{km} / \mathrm{hour})$.

The vehicle service hours were calculated using the equation:

Public transit service hours $=\frac{d}{v \cdot t \cdot f}$

$d=$ The total length of transit route segments passing through a circle of one kilometer radius, centered on the neighbourhood centroid.

$v=$ Average bus speed

$t=$ Total weekday service hours; and

$f=$ Average time between buses.

For the 2010 VKT Estimate, the four inputs were calculated for the only four bus routes currently serving this area. All of the information regarding bus service was collected from York Region Transit and VIVA Transit, the only two public transit bus companies currently serving the North Leslie Development Area (York Region Transit / VIVA, 2009). The segments of route length varied from 0.93 to 2.43 kilometers, the average time between buses fluctuated from 29 minutes to 52 minutes, and the total hours of operation varied between 13 and 18 hours. The complete data for these bus routes can be found in the Table 3-7. Maps of these bus routes can be found in Appendix 1, Figures D1 to D-4. All bus speeds were set at $60 \mathrm{~km} / \mathrm{h}$, as this was the local speed limit for the largest segments of the bus routes. Once this information was entered into the model, the transit service hours were calculated by the model to be 2.6 . 
Table 3-7: Current Public Transit Bus Routes Serving the North Leslie Development Used for the 2010 VKT Estimate

\begin{tabular}{lcccr}
\hline & \multicolumn{3}{c}{ Routes in North Leslie Development Currently } \\
\cline { 2 - 5 } & 82 & $83 \mathrm{~A}$ & 90 & $91 \mathrm{~A} / \mathrm{E}$ \\
\hline $\begin{array}{l}\text { Length of } \\
\text { Route Segment }\end{array}$ & $1.93 \mathrm{~km}$ & $0.93 \mathrm{~km}$ & $2.43 \mathrm{~km}$ & $1.17 \mathrm{~km}$ \\
\hline $\begin{array}{l}\text { Average Time } \\
\text { Between Buses }\end{array}$ & $41.2 \mathrm{~min}$ & $52.5 \mathrm{~min}$ & $29 \mathrm{~min}$ & $38 \mathrm{~min}$ \\
\hline $\begin{array}{l}\text { Total Hours of } \\
\begin{array}{l}\text { Route } \\
\text { Operation }\end{array}\end{array}$ & 14.3 hours & 13 hours & 14 hours & 18 hours \\
\hline $\begin{array}{l}\text { Average Bus } \\
\text { Speed }\end{array}$ & $60 \mathrm{~km} / \mathrm{h}$ & $60 \mathrm{~km} / \mathrm{h}$ & $60 \mathrm{~km} / \mathrm{h}$ & $60 \mathrm{~km} / \mathrm{h}$ \\
\hline
\end{tabular}

In order to establish a 2030 bus service estimate, a more mature development of similar size, design, and location was chosen to represent the future bus network of the North Leslie Development. It was assumed that an older development, containing more bus routes and more frequent pick-ups was an adequate comparator for the purposes of the transit service estimation. The area that was chosen is located south of the North Leslie Development and is bordered by Elgin Mills Road East, Bayview Avenue, Major Mackenzie and Yonge Street. A map of the area is presented in Figure 3-8. 


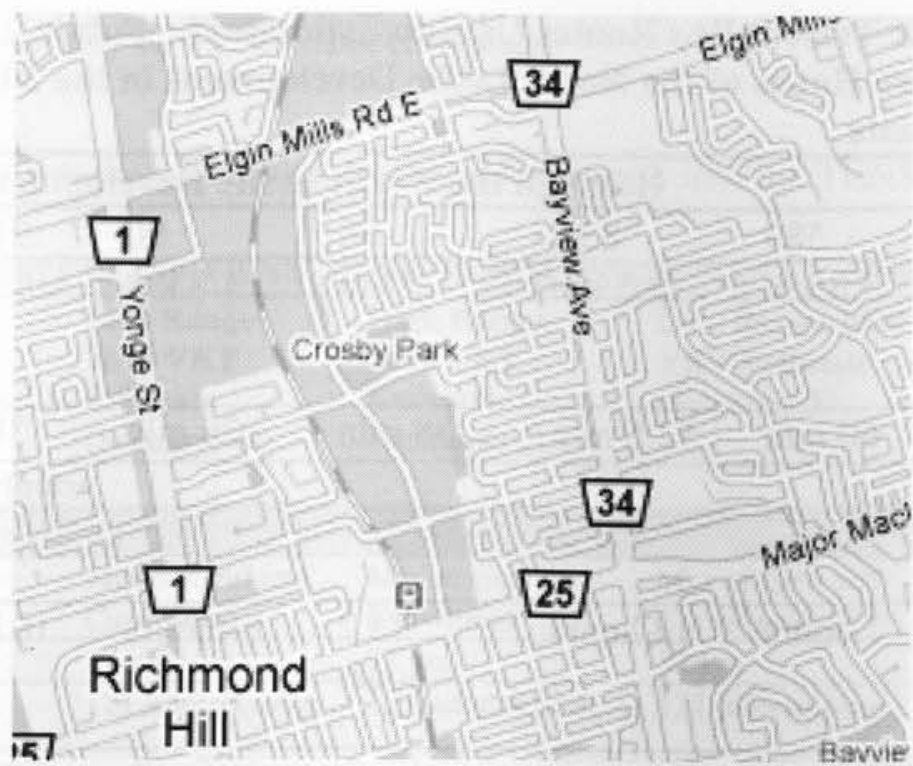

Figure 3-8: Map of the Area Used to Determine the Future Bus Service Network and Transit Service Hours for the North Leslie Development in 2030 Source: (Google Maps, n.d.)

The area shares three of the four bus routes currently serving the North Leslie Development area. It is also bordered by four major roadways, two of which also border the North Leslie Development. Because it is an older community, it is assumed that there has been time for public transit service expansion in and around the neighbourhood.

Therefore, with the input of the bus route characteristics for the representative development, the tool measured the transit service hours to be 7.5. The characteristics of the bus routes found in this area and used to calculate transit service hours are summarized in Table 3-8. Maps of the bus routes are found in Appendix 1, Figure D-1 to Figure D-7. 
Table 3-8: Public Transit Bus Routes Used to Estimate the Public Transit Vehicle Service Hours of the North Leslie Development in the 2030 VKT

Estimate

\begin{tabular}{lrrrrrr}
\hline & \multicolumn{5}{c}{ Route in the North Leslie Development } \\
\cline { 2 - 6 } & 589 & $83 \mathrm{~A}$ & 86 & 90 & $91 \mathrm{~A} / \mathrm{E}$ & 99 \\
\hline $\begin{array}{l}\text { Length of } \\
\text { Route } \\
\text { Segment }\end{array}$ & $3.8 \mathrm{~km}$ & $3.5 \mathrm{~km}$ & $3 \mathrm{~km}$ & $1.8 \mathrm{~km}$ & $4 \mathrm{~km}$ & $2.1 \mathrm{~km}$ \\
\hline $\begin{array}{l}\text { Average } \\
\begin{array}{l}\text { Time } \\
\text { Between } \\
\text { Buses }\end{array}\end{array}$ & $60 \mathrm{~min}$ & $52.5 \mathrm{~min}$ & $38 \mathrm{~min}$ & $29 \mathrm{~min}$ & $38 \mathrm{~min}$ & $18 \mathrm{~min}$ \\
\hline $\begin{array}{l}\text { Total Hours } \\
\text { of Route } \\
\text { Operation }\end{array}$ & 7 hours & 13 hours & $\begin{array}{r}15.2 \\
\text { hours }\end{array}$ & 14 hours & 18 hours & 19 hours \\
\hline $\begin{array}{l}\text { Average Bus } \\
\text { Speed }\end{array}$ & $60 \mathrm{~km} / \mathrm{h}$ & $60 \mathrm{~km} / \mathrm{h}$ & $60 \mathrm{~km} / \mathrm{h}$ & $60 \mathrm{~km} / \mathrm{h}$ & $60 \mathrm{~km} / \mathrm{h}$ & $60 \mathrm{~km} / \mathrm{h}$ \\
\hline
\end{tabular}




\subsubsection{Summary of TENS Model Inputs}

Listed in Table 3-9 are the values that were used as inputs into the TENS model.

Table 3-9: Summary of the TENS Model Inputs for the North Leslie Development

\begin{tabular}{|c|c|c|c|}
\hline $\begin{array}{l}\text { Low Range } \\
\text { 2010 VKT } \\
\text { Estimate } \\
\text { (Scenario 1) }\end{array}$ & $\begin{array}{l}\text { High Range } \\
\text { 2010 VKT } \\
\text { Estimate } \\
\text { (Scenario 2) }\end{array}$ & $\begin{array}{l}\text { Low Range 2030 } \\
\text { VKT Estimate } \\
\text { (Scenario 3) }\end{array}$ & $\begin{array}{l}\text { High Range } \\
2030 \text { VKT } \\
\text { Estimate } \\
\text { (Scenario 4) }\end{array}$ \\
\hline
\end{tabular}

Neighbourhood Attributes

\begin{tabular}{|c|c|c|c|c|}
\hline Road Layout Type & & & Transportation System & \\
\hline & Curvilinear & Curvilinear & $\begin{array}{l}\text { Mix of Urid and } \\
\text { Curvilinear }\end{array}$ & Curvilinear \\
\hline Total Road Length & $37 \mathrm{~km}$ & $37 \mathrm{~km}$ & $37 \mathrm{~km}$ & $37 \mathrm{~km}$ \\
\hline $\begin{array}{l}\text { Total Number of } \\
\text { Intersections }\end{array}$ & 121 intersections & 121 intersections & 121 intersections & 121 intersections \\
\hline $\begin{array}{l}\text { Total Length of Wide } \\
\text { Arterial Roads }\end{array}$ & $0 \mathrm{~km}$ & $0 \mathrm{~km}$ & $1.9 \mathrm{~km}$ & $1.9 \mathrm{~km}$ \\
\hline $\begin{array}{l}\text { Total Length of Bike } \\
\text { Routes }\end{array}$ & $0 \mathrm{~km}$ & $0 \mathrm{~km}$ & $9.59 \mathrm{~km}$ & $9.59 \mathrm{~km}$ \\
\hline \multicolumn{5}{|c|}{ Neighbourhood Development Information } \\
\hline Total Gross Land Area & $620 \mathrm{ha}$ & $620 \mathrm{ha}$ & $620 \mathrm{ha}$ & $620 \mathrm{ha}$ \\
\hline $\begin{array}{l}\text { Total Number of } \\
\text { Housing Units } \\
\end{array}$ & 6,755 units & 6,755 units & 6,755 units & 6,755 units \\
\hline $\begin{array}{l}\text { Housing Typologies } \\
\text { 1) Average Housing } \\
\text { Size }\end{array}$ & 7 rooms/unit & 7 rooms/unit & 7 rooms/unit & 7 rooms/unit \\
\hline 2) Housing Mix & 0.80 & 0.80 & 0.80 & 0.80 \\
\hline \multicolumn{5}{|c|}{ Local Area (1-km radius) Development and Services } \\
\hline $\begin{array}{l}\text { Gross Area Housing } \\
\text { Density }\end{array}$ & 10.90 & 10.90 & 10.90 & 10.90 \\
\hline Number of Jobs & 1,354 & 1,354 & 1,611 & 1,611 \\
\hline $\begin{array}{l}\text { Number of Grocery/ } \\
\text { Food Stores }\end{array}$ & 1 stores & 1 stores & 4 stores & 4 stores \\
\hline \multicolumn{5}{|l|}{ Socio-Demographic Data } \\
\hline Household Size & 2.8 & 3.7 & 2.8 & 3.7 \\
\hline $\begin{array}{l}\text { Expected Population } \\
\text { Under } 16 \text { years old }\end{array}$ & $21.8 \%$ & $21.8 \%$ & $19.4 \%$ & $19.4 \%$ \\
\hline $\begin{array}{l}\text { Expected Household } \\
\text { Employment Income }\end{array}$ & $\$ 79,471$ & $\$ 94,687$ & $\$ 118,090$ & $\$ 140,701$ \\
\hline \multicolumn{5}{|l|}{ Locational Characteristics } \\
\hline $\begin{array}{l}\text { Distance to Central } \\
\text { Business District }\end{array}$ & $36 \mathrm{~km}$ & $36 \mathrm{~km}$ & $36 \mathrm{~km}$ & $36 \mathrm{~km}$ \\
\hline $\begin{array}{l}\text { Number of Jobs within a } \\
\text { 5-Km Radius }\end{array}$ & 56,330 & 56,330 & 100,700 & 100,700 \\
\hline $\begin{array}{l}\text { Distance to Nearest } \\
\text { Rapid Transit Station }\end{array}$ & $20 \mathrm{~km}$ & $20 \mathrm{~km}$ & $13 \mathrm{~km}$ & $13 \mathrm{~km}$ \\
\hline $\begin{array}{l}\text { Distance to Nearest } \\
\text { Commuter Rail Station }\end{array}$ & $5 \mathrm{~km}$ & $5 \mathrm{~km}$ & $5 \mathrm{~km}$ & $5 \mathrm{~km}$ \\
\hline $\begin{array}{l}\text { Transit Vehicle Service } \\
\text { Hours }\end{array}$ & 2.6 & 2.6 & 7.5 & 7.5 \\
\hline
\end{tabular}




\subsubsection{Results from VKT Estimations for the North Leslie Development}

Once the values were put into the TENS model, the VKT estimates for both the 2010 scenario and the 2030 scenario were calculated. A summary of the VKT estimates can be found in Table 3-10. Also, A summary page provided by the model for each scenario is provided in Figure 3-9 to Figure 3-12. The four summary pages, one for each scenario, provides a summary of the neighbourhood descriptive variables along with the model parameters, annual VKT output, annual PKT output, and annual GHG emissions from personal travel per household.

Table 3-10: Weekday VKT per Household Estimates by the TENS Model for the North Leslie Development

\begin{tabular}{ll}
\hline Scenario & Weekday VKT Estimate per Household \\
\hline $\begin{array}{l}\text { Low Range 2010 VKT Estimate } \\
\text { (Scenario 1) }\end{array}$ & 99.7 VKT per household \\
\hline $\begin{array}{l}\text { High Range 2010 VKT Estimate } \\
\text { (Scenario 2) }\end{array}$ & 118.2 VKT per household \\
\hline $\begin{array}{l}\text { Low Range 2030 VKT Estimate } \\
\text { (Scenario 3) }\end{array}$ & 106.7 VKT per household \\
\hline $\begin{array}{l}\text { High Range 2030 VKT Estimate } \\
\text { (Scenario 4) }\end{array}$ & 127.0 VKT per household \\
\hline
\end{tabular}




\begin{tabular}{ll}
\hline Date: & 02-Nov-09 \\
User/Author: & $?$ \\
Scenario Description: & Low 2010
\end{tabular}

\begin{tabular}{|c|c|c|c|}
\hline \multicolumn{4}{|c|}{$\begin{array}{l}\text { MUM A ARY OF NEICHBOUAHOOD DESCAIPTWE VAFIABLES } \\
\text { Neighbourhood Attributes }\end{array}$} \\
\hline Rosd layout type: & fid ane Cumlineat & Number af heusing unis:s: & \multirow{2}{*}{$\begin{array}{r}6,755 \\
7\end{array}$} \\
\hline Total ipngth of non-expressway roads ( $\mathrm{km}$ ): & 37 & Average housing unit size: & \\
\hline Total number of intersections: & 1210 & Housing Mix: & 0.80 \\
\hline Total length of wide arterial roacs (km): & 0.0 & Area housing dersity (1-km rastus) (unitsina). & 10.90 \\
\hline Total length of bike rauses $(\mathrm{kn})$ : & 0.0 & Number of Jobs ( 1 -km ratius): & 1.354 \\
\hline Daily bus VSH $(1-\mathrm{km}$..): & 2.6 & Number al grocerylood storas (1-km radius): & 1 \\
\hline \multirow[t]{3}{*}{ Land area (ha): } & 8200 & & \\
\hline & & Locational Characteristics & \\
\hline & & Distance to CED (km): & 36.0 \\
\hline Socio-Demographic Data & & No. of jobs ( $5 \cdot \mathrm{km}$ radius). & 56.330 \\
\hline Expected avg. persans/th: & 2.80 & Distance to nearest rapid transi station (kv7): & 20.0 \\
\hline Expected $\%$ population < 16 yrs oid $(\%)$ : & 21.8 & Uiban area is served by commuter rail: & TRUE \\
\hline Expocted avg househoid income: & 579,471 & Distances to nearest commuter ral station $(\mathrm{k} \pi)$ : & 50 \\
\hline
\end{tabular}

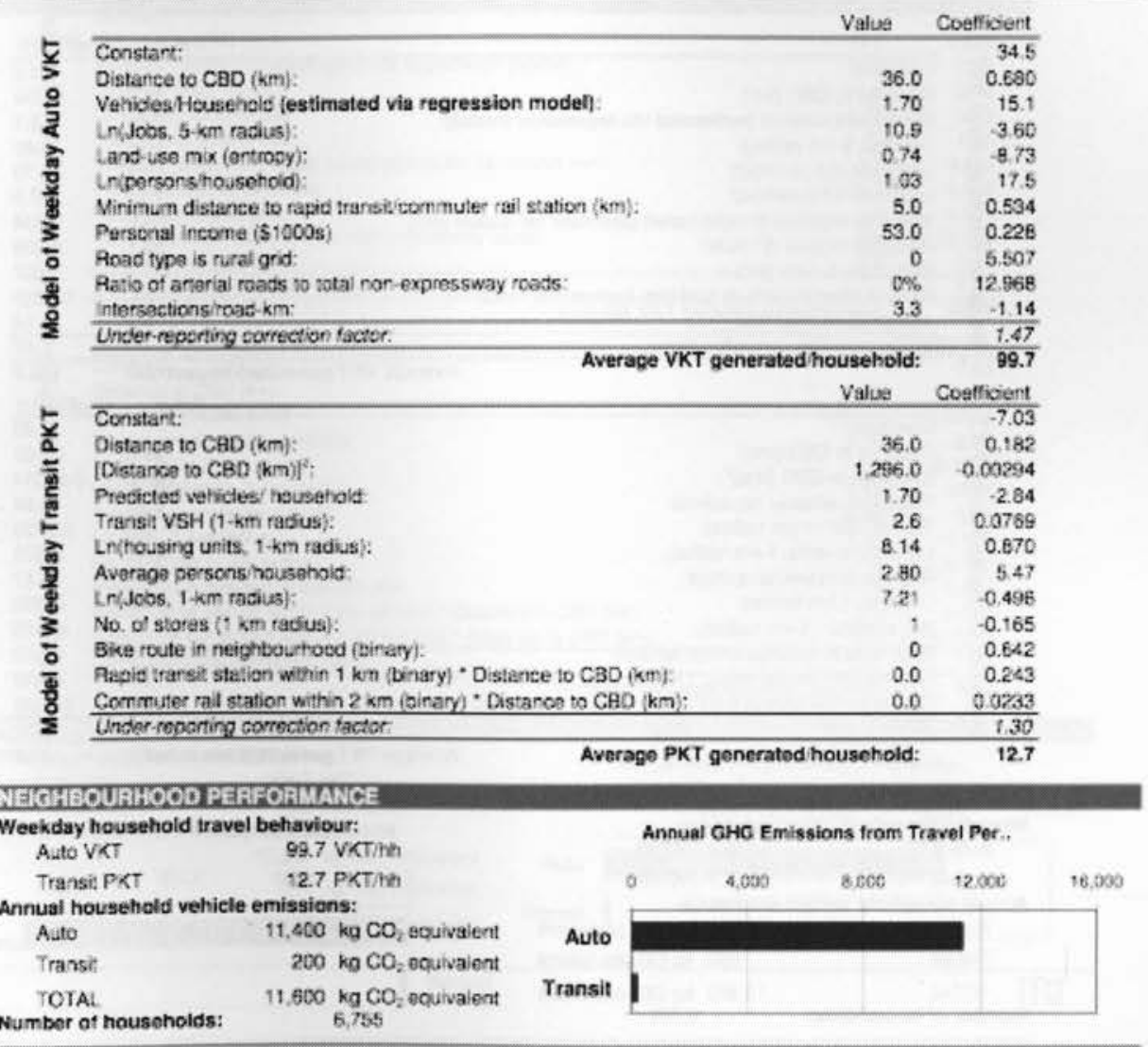

Figure 3-9: Tool for Evaluating Neighbourhood Sustainability: Summary of Model Input and Results for the Low 2010 VKT Estimate 


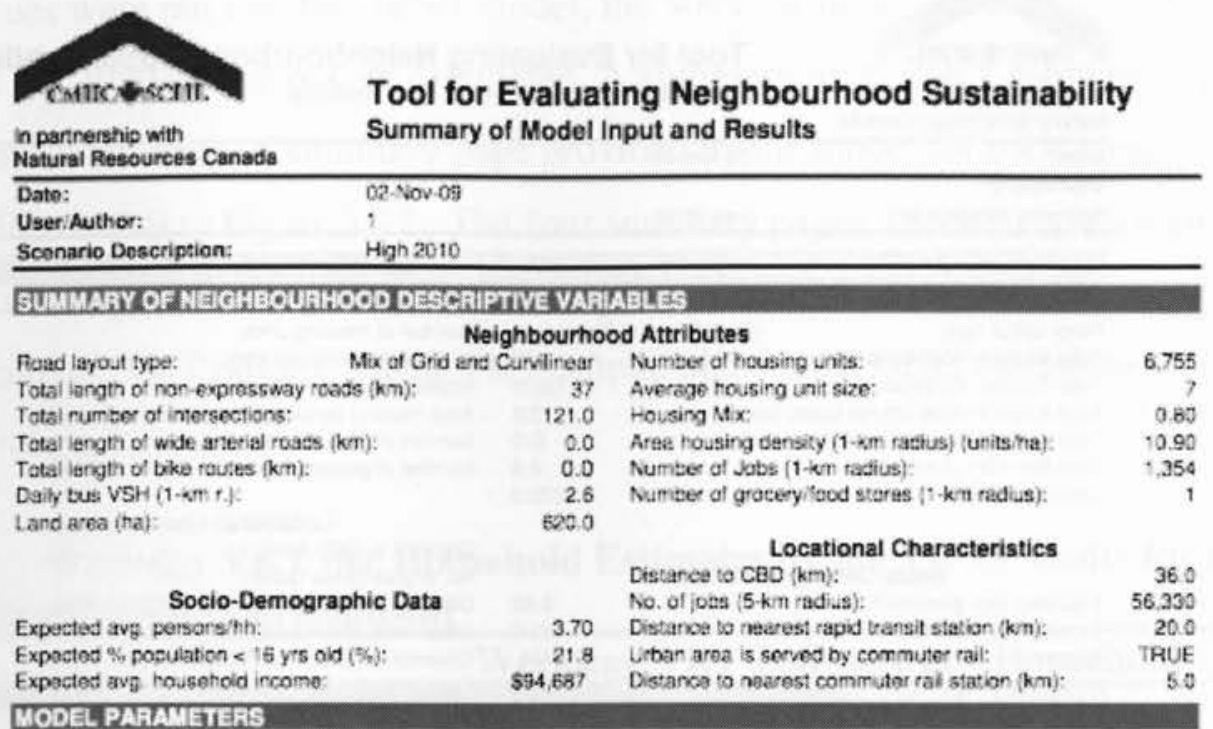

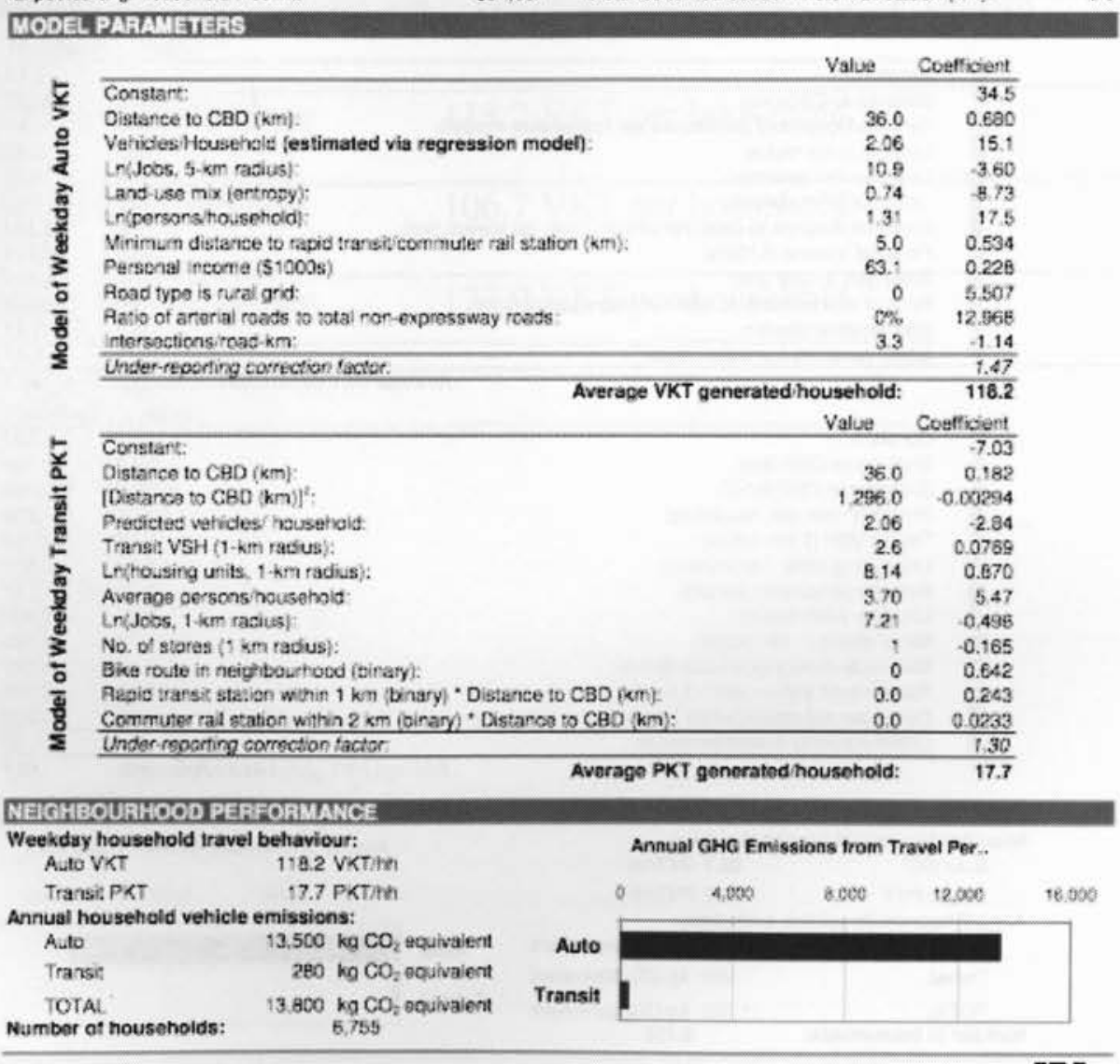

Figure 3-10: Tool for Evaluating Neighbourhood Sustainability: Summary of Model Input and Results for the High 2010 VKT Estimate 


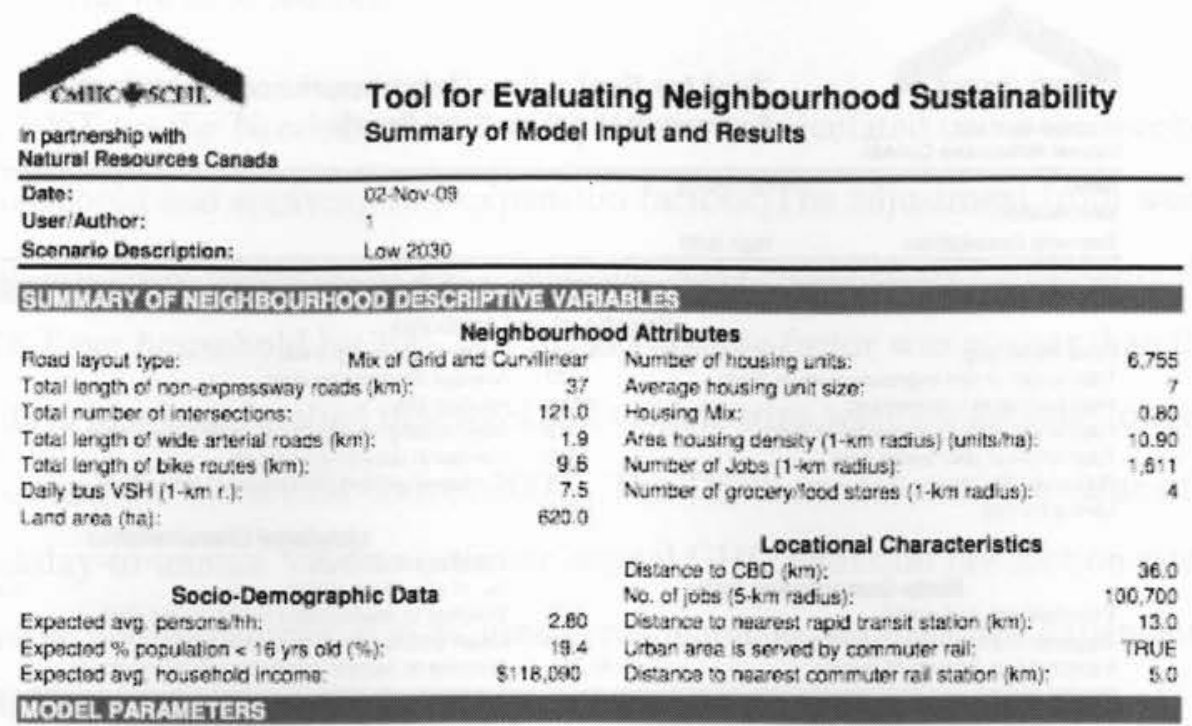

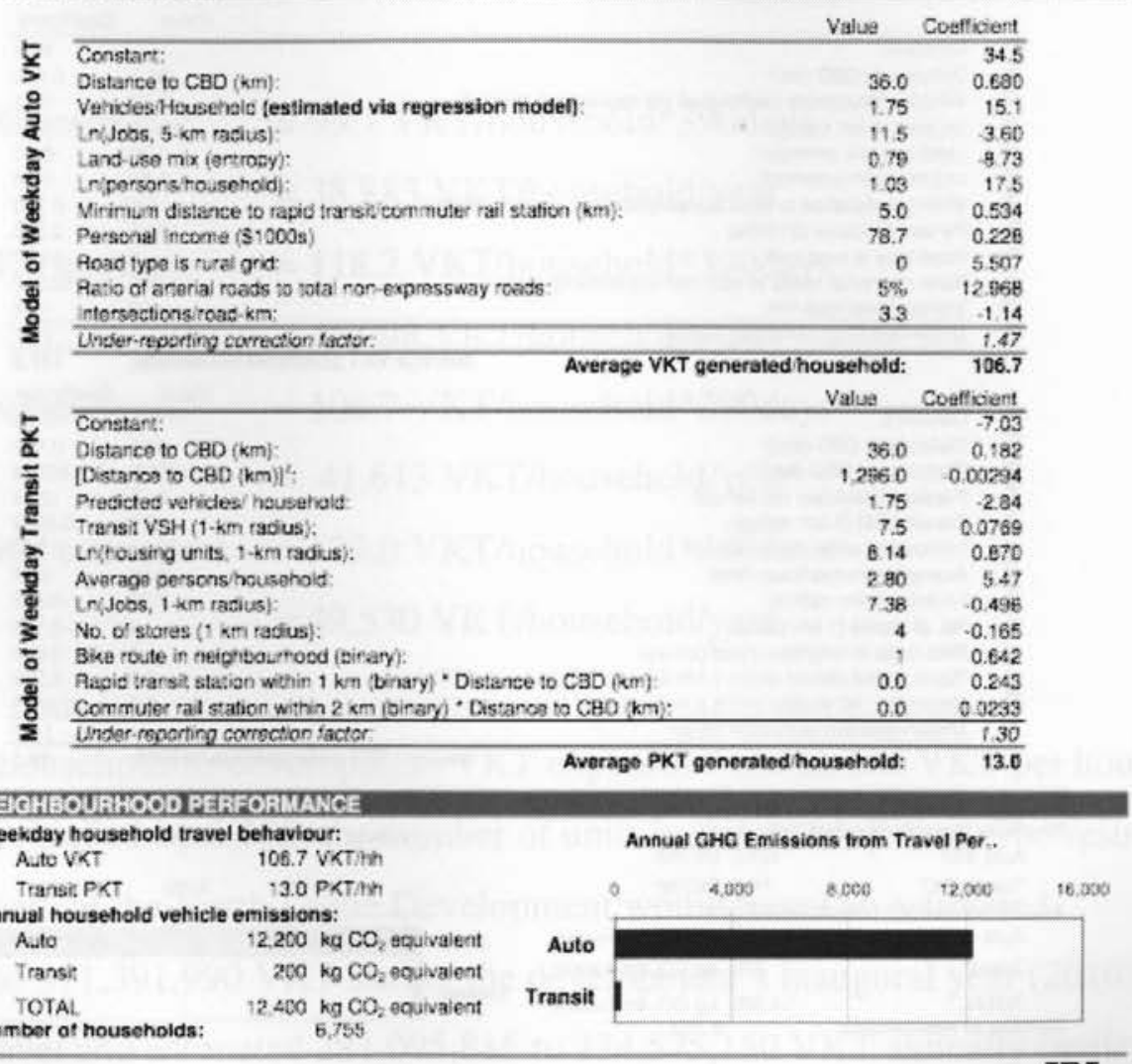

Figure 3-11: Tool for Evaluating Neighbourhood Sustainability: Summary of Model Input and Results for the Low 2030 VKT Estimate 


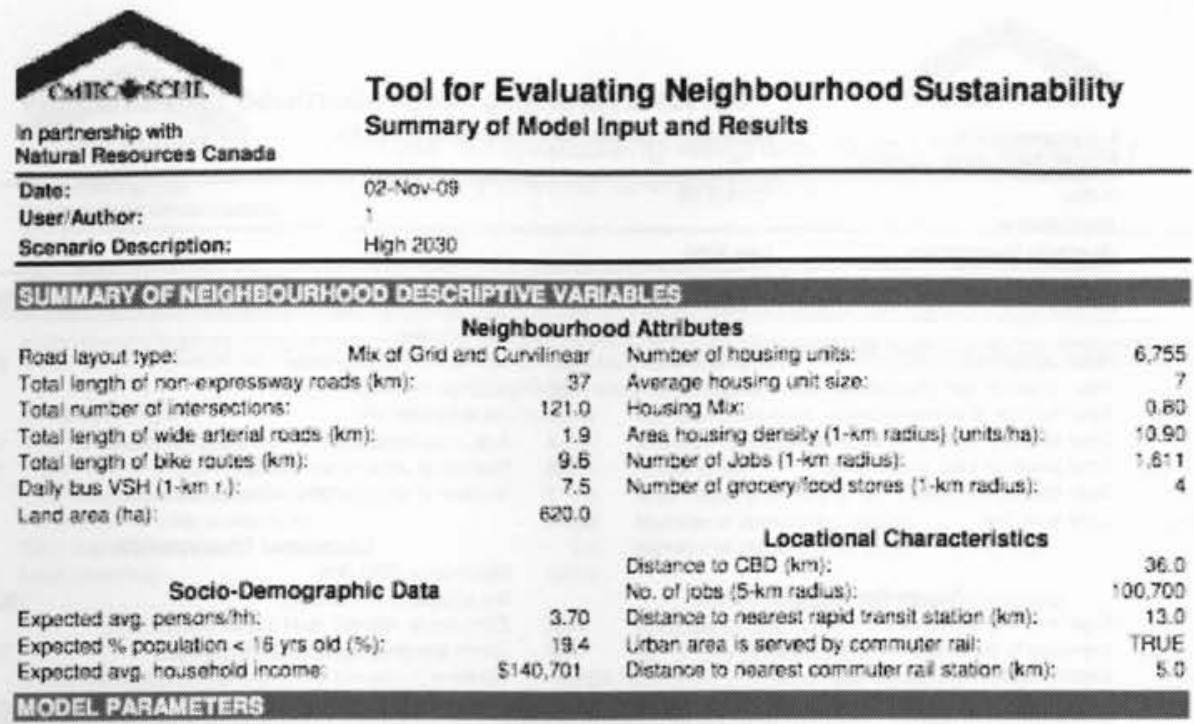

\begin{tabular}{|c|c|c|c|}
\hline \multirow{13}{*}{ 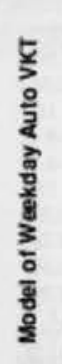 } & & Value & Coefficient \\
\hline & Gonstant: & & 345 \\
\hline & Distance to CBD $(\mathrm{km})$ : & 36.0 & 0.680 \\
\hline & Vehicies/Houseneld (estimated via regression model): & 2.12 & 15.1 \\
\hline & In (Joos, $5 \mathrm{~km}$ radius): : & 11.5 & 3.60 \\
\hline & Land uso $m \times$ (ortropy): & 0.79 & 8.73 \\
\hline & Ln(porsonshouseheid): & 1.31 & 17.5 \\
\hline & Virimum distance to fapid transticommuter cail station ( $\mathrm{km}$ ): & 5.0 & 0.534 \\
\hline & Personal incume (\$1000s) & $\$ 9.8$ & 0.226 \\
\hline & Road type is rural grid & o & 5.507 \\
\hline & Aatio of anarial roads to sotal non-exprossway roads: & $5 \%$ & 12.968 \\
\hline & intersections ione $\mathrm{km}$ : & 3.3 & -1.14 \\
\hline & Under-regorting carrection fanter. & & 7.47 \\
\hline \multirow{15}{*}{ 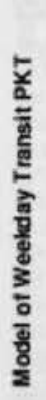 } & Average VK & ousehold: & 127.0 \\
\hline & & Value & Conefficent \\
\hline & Constars: & & -7.02 \\
\hline & Distance to CAD (km): & 36.0 & 0.182 \\
\hline & [Dietance to C8D $(\mathrm{km})]^{2}$ : & 1256.0 & 0.00894 \\
\hline & Predicted vehides housetrald: & 2.12 & 2.84 \\
\hline & Transil VSH (1-km rabus). & 7.5 & 0.0769 \\
\hline & Lnprousing units, $1-\mathrm{km}$ radus): & Q.14 & 0.870 \\
\hline & Average persons/househoid: & 370 & 5.47 \\
\hline & Ln(Joos, 1 -km radius): & 738 & -0.496 \\
\hline & No of stores (1 $\mathrm{km}$ radius): & 4 & -0.165 \\
\hline & Bika route in neighthourtood (tirary): & 1 & 0.642 \\
\hline & Aapid trarsit staten whenin $1 \mathrm{~km}$ (benary) ${ }^{\cdot}$ Distance to CSD $(\mathrm{km})$. & 0.0 & 0.243 \\
\hline & Comeruter ral station within $2 \mathrm{~km}$ (airam) - Distanoa to $\mathrm{CBO} / \mathrm{km})$ : & 00 & 0,0333 \\
\hline & Under-roporting corroction tactor & & 1.30 \\
\hline
\end{tabular}

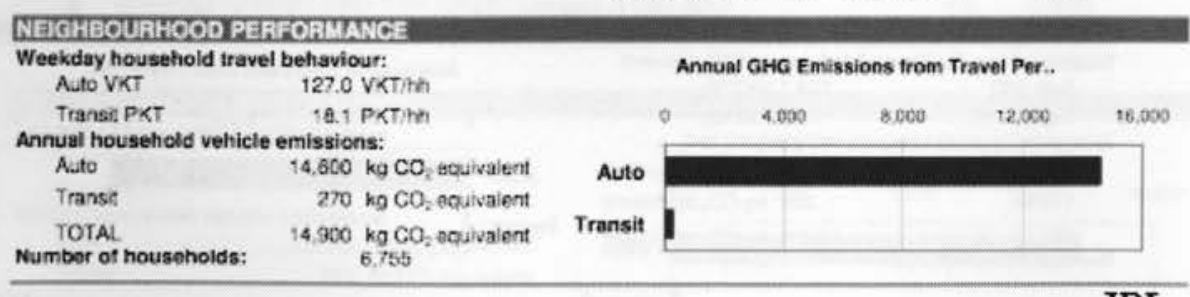

Figure 3-12: Tool for Evaluating Neighbourhood Sustainability: Summary of Model Input and Results for the High 2030 VKT Estimate 


\section{MEASURING ANNUAL VKT FOR THE NORTH LESLIE DEVELOPMENT}

The annual VKT for the North Leslie Development was calculated using the weekday VKT per household and applying two expansion factors. The adjustment from weekday VKT per household to annual VKT per household was calculated by multiplying the weekday VKT per household by 390 . The reason that the factor was greater than the number of days in a year implied that weekend vehicle trips were on average longer than trips taken during the week (IBI Group, 2000). The TENS model used the value of 390 to expand weekday-to-annual VKT to estimate annual GHG emission production rates by neighbourhood, and therefore it was assumed reasonable to use the same expansion factor within the thesis to estimate annual VKT per household.

$$
\begin{aligned}
\text { Low } 2010 \mathrm{VKT} \text { estimate } & =99.7 \mathrm{VKT} / \text { household*390days } \\
& =38,883 \mathrm{VKT} / \text { household/year } \\
\text { High } 2010 \mathrm{VKT} \text { estimate } & =118.2 \mathrm{VKT} / \text { household*390days } \\
& =46,098 \mathrm{VKT} / \text { household/year } \\
\text { Low } 2030 \mathrm{VKT} \text { estimate } & =106.7 \mathrm{VKT} / \text { household*390days } \\
\text { High } 2030 \mathrm{VKT} \text { estimate } & =41,613 \mathrm{VKT} / \text { household/year } \\
& =127.0 \mathrm{VKT} / \text { household*390days } \\
& =49,530 \mathrm{VKT} / \text { household/year }
\end{aligned}
$$

To achieve a household-to-development VKT expansion, the annual VKT per household was simply multiplied by 6,755 , the number of units in the development. The result was that the residents of the North Leslie Development would travel an estimated $262,654,665$ to $311,391,990$ VKT during the development's inaugural year (2010), and they would travel and estimated $281,095,815$ to $334,575,150$ VKT annually twenty years later. The data are summarized in Table 4-1.

$$
\begin{aligned}
\text { Low } 2010 \text { VKT estimate } \quad & =38,883 \mathrm{VKT} / \text { household/year } * 6,755 \text { homes } \\
& =262,654,665 \mathrm{VKT} / \text { year }
\end{aligned}
$$


High 2010 VKT estimate $\quad=46,098 \mathrm{VKT} /$ household/year $* 6,755$ homes

$=311,391,990 \mathrm{VKT} /$ year

Low 2030 VKT estimate $\quad=41,613 \mathrm{VKT} /$ household/year $* 6,755$ homes

$=281,095,815 \mathrm{VKT} /$ year

High 2030 VKT estimate $\quad=49,530$ VKT/household/year $* 6,755$ homes

$=334,575,150 \mathrm{VKT} /$ year

Table 4-1: Annual VKT for the Entire North Leslie Development

\begin{tabular}{ll}
\hline Scenario & Annual VKT Estimate \\
\hline $\begin{array}{l}\text { Low Range 2010 VKT Estimate } \\
\text { (Scenario 1) }\end{array}$ & $262,654,665$ VKT per year \\
\hline $\begin{array}{l}\text { High Range 2010 VKT Estimate } \\
\text { (Scenario 2) }\end{array}$ & $311,391,990$ VKT per year \\
\hline $\begin{array}{l}\text { Low Range 2030 VKT Estimate } \\
\text { (Scenario 3) }\end{array}$ & $281,095,815$ VKT per year \\
\hline $\begin{array}{l}\text { High Range 2030 VKT Estimate } \\
\text { (Scenario 4) }\end{array}$ & $334,575,150$ VKT per year \\
\hline
\end{tabular}


To convert the annual VKT estimation from the North Leslie Development into an estimation of CAC emissions, the UTEC model was used. The UTEC model, created by the IBI Group for Transport Canada, is designed to estimate annual emissions from personal, commercial and public transit vehicles. The UTEC estimates GHG emissions and CAC emissions from a VKT measurement and five other inputs describing fleet composition and travel behavior characteristics. CAC emission factors are used to determine the quantity of $\mathrm{CO}, \mathrm{NO}_{\mathrm{x}}, \mathrm{SO}_{2}$, VOCs, total particulate matter (TPM), $\mathrm{PM}_{10}$, and $\mathrm{PM}_{2.5}$ (IBI Group, 2008). The model has been used by municipal and transportation professionals as they are challenged to quantify and reduce emissions produced by transportation. It was designed to be used for long term planning or to assess the benefits of proposed and constructed developments (Engel-Yan \& Kassierer, January 2009 [Teleconference]).

The model was designed to be very versatile and user-friendly. It can be modified to suit different proportions of city to highway driving conditions, multiple vehicle types, and changes in fuel technology, such as ethanol, compressed natural gas, propane, diesel and gasoline. The default expansion factors reflect travel characteristics of large urban areas, such as the GTA (IBI Group, 2008). The model cannot forecast the emission implications of land uses unless the transportation activity data are available; however, with the VKT estimate of the North Leslie Development for the TENS model, the use of this model was appropriate to calculate the annual CAC emissions from personal travel. Details on how this was done are described in Section 5.1.

\subsection{Mechanics of the UTEC Model}

The basic equation used by the model is:

CAC emissions $=\Sigma($ emissions factors $\mathrm{x}$ distance traveled $)$

where emissions factors are in grams per kilometer and distance traveled is in kilometers. 
The CAC emission factors are in grams per kilometer units since the distance a vehicle travels is a better estimate of CAC emissions than the quantity of fuel a vehicle consumes (Engel-Yan \& Kassierer, January 2009 [Teleconference]). Therefore, each vehicle type with varying emission factors is allocated a certain percentage of the total VKT along with an emission factor. The product of these two values is calculated for each vehicle type to quantify the CAC emissions for the particular vehicle type. Each quantity of CAC emissions from these calculations is then summed together. This results in CAC emissions estimation in tonnes for the entire length of the VKT (IBI Group, 2008).

While simple, the model includes many variable inputs to individualize each modeling scenario. The primary input is VKT. The remaining inputs allow the user to modify default values to tailor the results to local conditions. The inputs, in order of appearance, are (IBI Group, 2008):

1) Evaluation year;

2) Province;

3) VKT;

4) Time period over which the VKT was measured;

5) Expansion factors (optional);

6) Driving conditions (optional);

7) Fleet breakdown (optional); and

8) Fuel technology fleet breakdown (optional).

Of the eight inputs, the user must input an evaluation year, a province, a VKT measurement and the time period over which the VKT measurement was taken. Default values are provided for all other inputs based on provincial and national data. Data sources for the default values are discussed in Section 5.2. These default values can also be overwritten to suit the scenario being modeled.

Using the CAC emission factors, provided by the MOBILE6.2C model developed by Environment Canada and the VKT measurement, the CAC emissions can then be 
calculated by the model. The CAC emission results are broken down into seven pollutants and are reported in tonnes. The pollutants are:

- Carbon Monoxide (CO)

- Nitrous Oxides $\left(\mathrm{NO}_{\mathrm{x}}\right)$

- Sulfur Dioxide $\left(\mathrm{SO}_{2}\right)$

- Volatile Organic Compounds (VOC)

- Total Particulate Matter (TPM)

- Particulate Matter up to 10 micrometers $\left(\mathrm{PM}_{10}\right)$

- Fine Particulate Matter up to 2.5 micrometers $\left(\mathrm{PM}_{2.5}\right)$

The model can also report on GHG emissions from the VKT and upstream fuel emissions, however this feature was not utilized as it was beyond the scope of the thesis.

\subsubsection{Data Sources for the UTEC Model CAC Emission Factors}

The data used in the model were drawn from government sources. The CAC emission factors used to determine $\mathrm{CO}, \mathrm{NO}_{\mathrm{x}}, \mathrm{SO}_{2}$, VOCs, TPM, $\mathrm{PM}_{10}$, and $\mathrm{PM}_{2.5}$, for conventional vehicle operation were developed based on forecasts of CAC emissions from Environment Canada's MOBILE6.2C model outputs from the National Inventory of CAC Emissions (IBI Group, 2008). MOBILE6.2C is a computer program developed by Environment Canada that is used to calculate emission factors from an official inventory of emissions affecting air quality from on-road sources and national VKT, which is calculated for specific categories of vehicles. Parameters such as national emission control technology, vehicle fleet age and type, and fuel technology are considered in the MOBILE6.2C emission factor calculations (Environment Canada, 2008). Environment Canada prepared runs of MOBILE6.2C for the years 1980 to 2030 specifically to design the UTEC model, which took into account technological and fleet changes over time at the national level (IBI Group, 2008). These results provided the CAC emission factors and fuel efficiencies for the model. The 2006 and 2031 CAC emission factors used in the model can be found in Appendix 1, Table E-1. 
While the UTEC model can be used to estimate CAC emissions for personal, commercial and public transit vehicles in an urban context, it was only used to estimate CAC emissions from personal travel for this study.

There were four CAC emission estimations conducted for the North Leslie Development. There were two done to convert the CAC emissions from VKT in the year 2010, both in the high and low range, while the other two were done to calculate the high and low range of CAC emissions from the North Leslie Development in 2030. While the four CAC emission estimations had different VKT values and evaluation years, the rest of the inputs remained constant. Details of these inputs are described over Section 5.2 subsections.

\subsubsection{Evaluation Year}

The model permits the user to select an evaluation year between 2006 and 2031 at 5-year intervals, consistent with Statistic Canada Census years. In other words, the options were 2006, 2011, 2016, 2021, 2026 or 2031. The evaluation year determined the emission factors and took into account future improvements in fuel efficiencies over time. The baseline fuel efficiency was set using Environment Canada's MOBILE6.2C model, which took into account the age of the national vehicle fleet by vehicle class. A yearly improvement factor of 0.5 per cent was then incorporated into the model. The 0.5 per cent improvement factor was set higher than the MOBILE6.2C estimates; however, it was set at the conservative end of Natural Resources Canada's Emissions Outlook Report, which estimated efficiency improvements between 0.5 and 1 per cent (IBI Group, 2008).

The 2006 evaluation year was selected for the CAC emissions estimate of the 2010 North Leslie Development. The year 2006 was selected in order to do as little forecasting as possible in the 2010 estimation. To remain consistent with the objectives of the 2010 scenario, which was to evaluate the impact of the North Leslie Development if it were to 
be built in the present, it was believed that fuel technology should not be assumed to have improved from the baseline in 2006. Alternatively, for the CAC emissions estimate of the North Leslie Development in 2030, the 2031 evaluation year was selected. The year 2031 was assumed to be the closest forecast to 2030 and, while it was projecting slightly better fuel efficiencies, this was thought to be a reasonable assumption.

\subsubsection{Province}

The model, designed for use in Canada, required the user to input a province where the evaluation took place. This selection determined the default value of fleet composition for the light-duty personal vehicles (LDPV), a value that was estimated on a provincespecific scale (IBI Group, 2008). The proportions were based on 2005 data reported by the Office of Energy Efficiency Comprehensive Energy Use Database, Transportation Sector (IBI Group, 2008).

Because the North Leslie Development is located in Ontario, the LDPV fleet composition was set at 70 per cent cars and 30 per cent light trucks and sports utility vehicles. The fleet composition is discussed further in Section 5.2.6.

\subsubsection{Kilometers Traveled}

The kilometers traveled input was simply the number of VKT estimated for the North Leslie Development using the TENS model. The VKT values used for each scenario are summarized in Table 4-1.

\subsubsection{Time Over Which VKT was measured}

As previously mentioned, the model required the user to input a VKT value collected on an annual, daily or peak hour basis. In order for the model to adjust the VKT to an annual rate, the time over which the VKT was measured had to be selected. The model would then adjust the measurement to an annual rate using expansion factors. 
In the case of the North Leslie Development, the VKT estimate was adjusted to an annual measurement using the expansion factors provided by the TENS model. Therefore, when input into the UTEC model, the collection time period was set as annual. As a result the expansion factors were, by default, set at 1 . This reflected the fact that the data were already set for an annual measurement and did not need to be further expanded in the UTEC model.

\subsubsection{Driving Conditions}

The driving conditions were measured as a proportion of city to highway driving. They were used in the model to estimate fuel efficiency. It was assumed that city driving consumed 30 per cent more fuel than highway driving for conventionally fuelled vehicles. This value was based on the 2008 Fuel Consumption Guide, produced by Natural Resources Canada and the fuel efficiencies reported in Natural Resources' GHGenius (IBI Group, 2008). ${ }^{3}$ The 2006 and 2031 fuel efficiency values by vehicle class, used in the UTEC model, can be found in Appendix 1, Table F-1 and Table F-2.

After consulting with a transportation analyst at Transport Canada, it was decided that the $75 / 25$ city to highway split, chosen by UTEC developers as the model's default values, would be a conservative estimate favouring higher city driving, yet an appropriate selection for driving conditions of those residing in the North Leslie Development (D. Coldrey, Sustainable Transportation Analyst for Transport Canada, personal communication through e-mail, October $\left.13^{\text {th }}, 2009\right)$. The national average proportion of city to highway driving is typically set at 55 per cent city and 45 per cent highway driving, however the UTEC default was set to reflect the travel behavior of urban dwellers and therefore it was assumed that there would be a larger proportion of city driving compared to the national average (IBI Group, 2008). While Richmond Hill and the North Leslie Development would not be located in a 'city', the VKT traveled by North Leslie Development residents on highways cannot be considered to be free-flowing

\footnotetext{
${ }^{3}$ The Fuel Consumption Guide 2008, released by the Office of Energy Efficiency, Natural Resources Canada (2007), reported that city driving can consume from 20 per cent to 65 per cent more fuel per kilometer than highway driving. This is assuming that the highway driving is free flow, while the city driving is stop and go (NRCan, 2007).
} 
at all times either. The high congestion levels in Richmond Hill suggest that even highway driving during the peak driving periods is likely more stop-and-go than free flowing. Therefore, the default was selected as an appropriate assumption of driving conditions.

\subsubsection{LDPV Fleet Breakdown}

The UTEC model has the capability of estimating GHG and CAC emissions from many vehicles types, including:

- Light-duty passenger vehicles (LDPV)

- Light-duty commercial vehicles (LDCV)

- Medium-duty commercial vehicles (MDCV)

- Heavy-duty commercial vehicles (HDCV)

- Public transit buses (BUS)

- Public trolley buses (TB)

- Light rail (LR)

- Subway/Metro (SM)

- Heavy rail (HR) (diesel)

In the case of the North Leslie Development, the model was only used to determine the CAC emissions from personal vehicles and therefore the fleet composition only consisted of LDPV.

The LDPV category was broken down in the model into two groups, automobiles and light-trucks or sports utility vehicles. A distinction was made in the model between these two types of vehicles due to the difference in their fuel consumption. As a result, the LDPV fleet breakdown had to be specified to accurately estimate CAC emissions. The default values for fleet breakdown of LDPV into automobiles and light-trucks or sports utility vehicles were measured using province-specific data. By selecting the province of Ontario earlier in the model, the fleet breakdown was set at 70 per cent cars and 30 per cent light trucks and sports utility vehicles automatically by the tool. This default was 
used, as the default was assumed to be a reasonable estimation of fleet breakdown for the North Leslie Development.

\subsubsection{Fleet Breakdown by Fuel Technology}

The fuel technology breakdown variable allowed the user to specify the proportion of the fleet by fuel technology. The input was entered as a percentage of the total fleet. Within the model, the default values were based on MOBILE6.2C data, which were derived from national VKT data by vehicle type. The values for the LDPV fuel technology were 98.5 per cent gasoline powered vehicles and 1.5 per cent diesel powered vehicles.

In the case of the North Leslie Development, the fuel technology default values were used. These values did not change with evaluation years. While it is possible that over time the vehicle fleet might include more hybrid or alternatively-powered vehicles, a conservative approach was taken, assuming that the vehicle fleet would not change significantly to new fuel technologies over the next twenty years. Therefore the default values, representing national fleet characteristics, were set at 98.5 per cent gasoline and 1.5 per cent diesel. 
Listed in Table 5-1 are the values that were used as inputs into the UTEC model.

Table 5-1: Summary of the UTEC Model Inputs for the North Leslie Development

\begin{tabular}{|c|c|c|c|c|}
\hline & $\begin{array}{l}\text { Low Range } \\
2010 \text { VKT } \\
\text { Estimate } \\
\text { (Scenario 1) }\end{array}$ & $\begin{array}{l}\text { High Range } \\
\text { 2010 VKT } \\
\text { Estimate } \\
\text { (Scenario 2) }\end{array}$ & $\begin{array}{l}\text { Low Range } \\
\text { 2030 VKT } \\
\text { Estimate } \\
\text { (Scenario 3) }\end{array}$ & $\begin{array}{l}\text { High Range } \\
\text { 2030 VKT } \\
\text { Estimate } \\
\text { (Scenario 4) }\end{array}$ \\
\hline Evaluation Year & 2006 & 2006 & 2031 & 2031 \\
\hline Province & Ontario & Ontario & Ontario & Ontario \\
\hline VKT by LDPV & $\begin{array}{l}262,654,665 \\
\text { VKT per year }\end{array}$ & $\begin{array}{l}311,391,990 \\
\text { VKT per year }\end{array}$ & $\begin{array}{l}281,095,815 \\
\text { VKT per year }\end{array}$ & $\begin{array}{l}334,575,150 \\
\text { VKT per year }\end{array}$ \\
\hline Time Period of Data & Annual & Annual & Annual & Annual \\
\hline $\begin{array}{l}\text { Personal Expansion } \\
\text { Factors }\end{array}$ & & & & \\
\hline $\begin{array}{l}\text { 1) Peak Hour to } \\
\text { Daily }\end{array}$ & 1 & 1 & 1 & 1 \\
\hline 2) Daily to Annual & 1 & 1 & 1 & 1 \\
\hline $\begin{array}{l}\text { Driving Conditions } \\
\% \text { City / \% } \\
\text { Highway }\end{array}$ & $75 \% / 25 \%$ & $75 \% / 25 \%$ & $75 \% / 25 \%$ & $75 \% / 25 \%$ \\
\hline $\begin{array}{l}\text { Breakdown of } \\
\text { LDPV Fleet } \\
\text { \% Cars / \% Trucks }\end{array}$ & $70 \% / 30 \%$ & $70 \% / 30 \%$ & $70 \% / 30 \%$ & $70 \% / 30 \%$ \\
\hline $\begin{array}{l}\text { Fleet Breakdown by } \\
\text { Fuel Technology } \\
\% \text { Gas / \% Diesel }\end{array}$ & $98.5 \% / 1.5 \%$ & $98.5 \% / 1.5 \%$ & $98.5 \% / 1.5 \%$ & $98.5 \% / 1.5 \%$ \\
\hline
\end{tabular}


Once the values were input into the UTEC model, the CAC emissions estimates for both the 2010 scenarios and the 2030 scenarios were calculated. A summary of the UTEC CAC emissions estimates can be found in Table 5-2.

Table 5-2: Summary of the Annual CAC Emission Outputs from the North Leslie Development Data (Tonnes)

\begin{tabular}{|c|c|c|c|c|}
\hline $\begin{array}{l}\text { Criteria Air } \\
\text { Pollutants }\end{array}$ & $\begin{array}{l}\text { Low Range } \\
\text { 2010 CAC } \\
\text { Emissions } \\
\text { Estimate } \\
\text { (Scenario 1) }\end{array}$ & $\begin{array}{l}\text { High Range } \\
\text { 2010 CAC } \\
\text { Emissions } \\
\text { Estimate } \\
\text { (Scenario 2) }\end{array}$ & $\begin{array}{l}\text { Low Range } \\
2030 \text { CAC } \\
\text { Emissions } \\
\text { Estimate } \\
\text { (Scenario 3) }\end{array}$ & $\begin{array}{l}\text { High Range } \\
\text { 2030 CAC } \\
\text { Emissions } \\
\text { Estimate } \\
\text { (Scenario 4) }\end{array}$ \\
\hline $\mathrm{CO}$ & 2970 & 3521 & 1523 & 1813 \\
\hline $\mathrm{NO}_{\mathrm{x}}$ & 157.7 & 187 & 32.68 & 38.9 \\
\hline $\mathrm{SO}_{2}$ & 1.089 & 1.291 & 0.946 & 1.127 \\
\hline VOCs & 175.7 & 208.3 & 50.96 & 60.65 \\
\hline TPM & 4.403 & 5.22 & 4.284 & 5.1 \\
\hline $\mathrm{PM}_{10}$ & 4.333 & 5.136 & 4.228 & 5.033 \\
\hline $\mathrm{PM}_{2.5}$ & 2.1 & 2.489 & 1.866 & 2.221 \\
\hline
\end{tabular}


The results of this thesis provide the findings for the first step of a two-part study to estimate the health impacts of a single large-scale suburban development. In this first part, the goal was to quantify the $\mathrm{CAC}$ resulting from an increase in vehicular emissions from the approval of the North Leslie Development. This section describes the VKT estimates and CAC emission estimates found through the use of the TENS model and the UTEC model. It also goes on to present the CAC emissions estimates in context by demonstrating how they compared to the NPRI's annual mss threshold values.

Based on an extensive literature review, no one had yet published a study that examined the air pollution contribution of a large-scale suburban development. The results of this thesis can now be used in a future study to estimate the health impacts of the North Leslie Development.

\subsection{Estimating the VKT of a Large-scale Urban Development from Personal Vehicle Use}

As part of the first step in this thesis, annual VKT estimations were calculated for the North Leslie Development. A scenario describing the development in 2010 and one describing the development 20 years later, in 2030 were evaluated. From the estimates provided by the TENS model, the number of VKT was calculated annually for the North Leslie Development. The annual VKT calculated using the TENS for each scenario can be found in Table 4-1.

The high and low VKT ranges were established due to significant inconsistencies in household size and household income across the Town of Richmond Hill. The ranges prove to be significantly different. The 2010 VKT estimate varied by approximately 48.7 million annual VKT between the high and low estimate, and the 2030 VKT estimate varied by approximately 53.5 million annual VKT. In order to establish more accurate estimates for the North Leslie Development it would be necessary to better approximate the number of residents per household and the household income levels for the 
development. However, this may prove to be impractical in practice, as this process is meant to be predictive and therefore, it is likely that information gaps will occur as they did in this study.

As indicated in Section 5, after establishing the UTEC input data according to the auto VKT, travel behavior and fleet characteristics of the North Leslie Development, the CAC emission estimates were calculated in tonnes per year. The weights of the CAC emissions are summarized in Table 5-2. From the four scenarios, a range of CAC emissions quantities were determined for the 2010 , which was meant to represent the characteristics of the development when it is first built, and for the year 2030, which represents the development over a common planning time period.

Both the significance of the CAC emission estimations and the decrease in CAC emissions over time will be discussed further in the next two sub-sections.

\subsection{1 \\ CAC Emission Estimates in Context Using the National Pollutant Release Inventory}

In Canada, facilities that produce significant levels of pollutants are required to report pollutant releases into air, water and land. The legislated monitoring system, called the National Pollutant Release Inventory (NPRI) tracks over 300 substances produced in over 8,500 facilities (Environment Canada, 2009a). In order to be required to report, the quantity of the pollutant being released must be over the threshold level set by the NPRI. The objective of this program is to identify pollution prevention priorities, help to develop targeted regulations to reduce the release of pollutants and encourage the reduction of pollutant releases (Environment Canada, 2009b).

In 2002, CACs were added to the list of over 300 substances tracked by the NPRI due to their contribution to smog, acid rain and poor air quality. As a result, any facility with stationary combustion equipment producing CAC emissions above the threshold 
reporting level was required to report the quantities of their pollutant releases

(Environment Canada, 2009c). The NPRI's threshold levels of CAC emissions are summarized in Table 6-1.

Despite the fact that these threshold levels are meant to reflect point sources, the levels at which the North Leslie Development is estimated to produce CAC emissions from VKT in 2010 and 2030 will far exceed most of the annual threshold levels set by the NPRI.

Table 6-1: NPRI Threshold Reporting Levels for CAC Emissions Compared to the North Leslie Development CAC Emissions Estimates (Tonnes)

\begin{tabular}{llllll}
\hline Substance & $\begin{array}{l}\text { NPRI Annual } \\
\text { Mass } \\
\text { Threshold }\end{array}$ & $\begin{array}{l}\text { Low Range } \\
\text { 2010 CAC } \\
\text { Emissions } \\
\text { Estimate } \\
\text { (Scenario 1) }\end{array}$ & $\begin{array}{l}\text { High Range } \\
\text { 2010 CAC } \\
\text { Emissions } \\
\text { Estimate } \\
\text { (Scenario 2) }\end{array}$ & $\begin{array}{l}\text { Low Range } \\
\text { 2030 CAC } \\
\text { Emissions } \\
\text { Estimate } \\
\text { (Scenario 3) }\end{array}$ & $\begin{array}{l}\text { High Range } \\
\text { 2030 CAC } \\
\text { Emissions } \\
\text { Estimate } \\
\text { (Scenario 4) }\end{array}$ \\
\hline $\mathrm{CO}$ & 20 & 2970 & 3521 & 1523 & 1813 \\
\hline $\mathrm{NO}_{\mathrm{x}}$ & 20 & 157.7 & 187 & 32.68 & 38.9 \\
\hline $\mathrm{SO}$ & 20 & 1.089 & 1.291 & 0.946 & 1.127 \\
\hline $\mathrm{VOC}$ & 10 & 175.7 & 208.3 & 50.96 & 60.65 \\
\hline $\mathrm{TPM}_{2}$ & 20 & 4.403 & 5.22 & 4.284 & 5.1 \\
\hline $\mathrm{PM}_{10}$ & 0.5 & 4.333 & 5.136 & 4.228 & 5.033 \\
\hline $\mathrm{PM}_{2.5}$ & 0.3 & 2.1 & 2.489 & 1.866 & 2.221 \\
\hline
\end{tabular}

Source for NPRI data: (Environment Canada, 2009c)

Due to the fact that the NPRI thresholds are based on stationary sources, the quantities of CAC emissions calculated from the VKT of the North Leslie Development cannot be directly compared. The quantity of pollutants from a point source will have much higher local concentrations than those coming from mobile sources, such as cars. That being said, the quantities of CAC emissions from the VKT of the North Leslie Development are clearly non-trivial and should be taken into account in the approval granted in the planning process.

\subsubsection{Significant Ranges of High and Low CAC Emissions Estimates}

As was previously mentioned, the high and low ranges for both the 2010 estimates and the 2030 estimates varied significantly. Nevertheless, even the low range estimates for both the 2010 and the 2030 VKT estimates demonstrated some CAC emission levels 
above the NPRI annual mass threshold values. $\mathrm{CO}, \mathrm{NO}_{\mathrm{x}}, \mathrm{VOCs}, \mathrm{PM}_{10}$ and $\mathrm{PM}_{2.5}$, although lower, remained above the NPRI's annual mass threshold values.

\subsubsection{Improvements in Fuel Technology Over Time}

While it was hypothesized that there would be an increase in the quantity of CAC emissions between the 2010 and 2030 estimates, this did not occur. The TENS model did estimate an increase in VKT over time, however the fuel technology improvements assumed by the UTEC model resulted in an overall decrease in the quantity of CAC emissions over time. The extent of the fuel technology improvements assumed by the UTEC was not anticipated.

Nevertheless, the CAC emissions estimates both for the 2010 and the 2030 scenarios were found to be non-trivial when evaluated next to the NPRI annual mass threshold values. The both the high and low 2030 CAC emission estimates for the North Leslie Development exceed the NPRI's annual mass threshold for $\mathrm{CO}, \mathrm{NO}_{\mathrm{x}}, \mathrm{VOCs}, \mathrm{PM}_{10}$, and $\mathrm{PM}_{2.5}$. This helps to demonstrate that even though emission rates are decreasing through improvements in fuel technology, CAC emissions from personal vehicle travel will continue to be a problem for many years to come. 


\subsection{Benefits of Research}

Increasingly, the negative impacts of low-density, suburban sprawl are being recognized by public health and planning officials. The vehicle dependence created by urban sprawl has been well studied along with the impacts of air contaminants on human health.

Despite improvements in vehicle technology and increasing regulatory controls, vehicles continue to create the largest proportion of air pollution as the built environment forces people away from transit and walking or cycling, and into personal vehicles.

While the impact that air pollution and vehicle emissions have on health has been quantified by the Ontario Medical Association, Toronto Public Health and others, little work had been done to investigate how specific land-use decisions affect the airshed through automobile use. This is particularly relevant to large-scale urban land uses, such as subdivisions, since most planning decisions are made on an individual development scale.

Although there were many assumptions made due to resource limitations, information gaps and forecasting uncertainties, the objectives set out in this thesis were achieved. The resulting $\mathrm{CAC}$ emissions estimations demonstrated the non-trivial impact that the North Leslie Development, a large-scale, low-density, urban development will have on the airshed through the generation of CAC emissions from vehicle use. The result of this thesis not only demonstrates the significant impact that a common residential development can have on the surrounding airshed but also indicates the need for future research in order to quantify the health impacts of individual suburban developments, once the emission quantities are known.

\section{2}

\section{Conclusions}

There were many limitations in this study due to the very nature of the thesis' objective. In order to forecast the characteristics of a neighbourhood that does not yet exist, it is 
necessary to make assumptions using the most appropriate information available.

Therefore, although the process required many assumptions to be made, it is believed that this is how this process would have to be conducted by any municipal planner or public health official conducting similar research. Therefore the conclusions drawn from this thesis, though based on assumptions, are thought to be reasonable estimations of CAC emissions and relevant to both public health and environmental professional, along with urban and municipal planners.

The key conclusions of this work are summarized below:

1) Based on the results of the TENS model, VKT per household for the North Leslie Development is expected to increase over time.

2) Based on the results of the UTEC model, CAC emissions from personal travel from the North Leslie Development will decrease over time.

3) CAC emissions from personal vehicle travel from the North Leslie Development are non-trivial. Both in the 2010 and 2030 estimates, the CO, NO , VOCs, $\mathrm{PM}_{10}$ and $\mathrm{PM}_{2.5}$ emissions produced by the North Leslie Development through personal travel exceed NPRI Threshold Reporting Levels.

4) The results of this thesis demonstrate that additional research needs to be conducted to quantify the health impacts of the additional CAC emissions from the North Leslie Development in order for this information to be taken into account in the approval process of large-scale urban developments.

\subsection{Recommendations for Improvements}

\subsubsection{Model Improvements}

The data used to develop the TENS model were based on 1996 TTS data. Therefore, information such as vehicle ownership rates and VKT distances in the GTA were based on data from 1996. Considering the enormous population growth and urban sprawl that 
has occurred over the past 10 years in Southern Ontario, it would be not only interesting, but also very important to update the TENS model with the new 2006 TTS. This could have an impact on the VKT estimates determined by the TENS model.

As discussed in Section 2 of this thesis, ground-level ozone is a CAC that can cause many human health problems. Therefore, when considering the health consequences of vehicle pollutant on human health, this pollutant is an important contaminant to consider. Unfortunately, the UTEC model does not estimate the quantity of ground-level ozone produced by the VKT and therefore it must be estimated in some other fashion.

The UTEC model should incorporate an $\mathrm{O}_{3}$ output. Like the other pollutants included in the model, it is a significant air pollutant and should be considered in planning and transportation decision making.

\subsubsection{Data Collection Improvements}

Due to the fact that appeals were still being heard at the OMB in regards to the North Leslie Development when this study took place, some information was not accessible through the Richmond Hill Planning Department. Once this planning information becomes available, it would be important to fill the information gaps within this study to achieve the most accurate CAC emission estimates possible for the development.

Most of the default values within the UTEC model were used to describe the vehicle characteristics and driving behaviors of the North Leslie Development. This was thought to be acceptable seeing as the default values were based on national or provincial data. However, in order to achieve more accurate estimates, the use of more local data would have been ideal. Unfortunately, this information was not available at the time of study. If and when more specific information of travel behavior and vehicle characteristics becomes available for the North Leslie Development, or the Town of Richmond Hill, it would be important to modify the UTEC input to reflect these specifics. 
This investigation into the quantity of CAC emissions produced by a large-scale urban development was conducted as the first step in demonstrating the health impacts that large-scale urban developments have on human health. As mentioned previously, decisions regarding urban planning are most often conducted on a local, individual development scale. Therefore, if the decisions to approve developments are to ever consider the impact they have on human health, the evaluation of how much they with impact health must be available on a large-scale, individual development basis. While the first steps of this process have been demonstrated in this thesis, significant work remains to be done not only to recognize the impact that low-density, suburban developments have on human health, but also in developing an appropriate process to do it.

\subsubsection{Quantifying the Human Health Impact of Large-scale Urban Development from Vehicle Use}

Everyday, hundreds of thousands of people spend an increasing amount of time in their cars, polluting the air they breathe, in order to travel in the built environment that surrounds them. Low-density urban design is one major contributor to VKT increases and from the work conducted in this thesis, it has been demonstrated that large-scale land use decisions that permit low-density sprawl do impact the airshed in a non-trivial way.

As a result, the next logical step in this field of research would be to quantify the health impacts and health care costs related to the VKT associated with the vehicle emissions from the North Leslie Development. From the information gathered in this thesis, the process of determining the health impacts of a large-scale development would begin by determining the dispersion of the pollutants from annual VKT from the North Leslie Development. This could be conducted using an air dispersion model, which would be used to predict ambient concentrations of the CACs in part of the airshed that would impact human health. Once the ambient concentration of the pollutants from the development were estimated, a model such as Health Canada's Air Quality Benefit Assessment Tool (AQBAT) would be used to quantify the health impacts and health 
related costs from the North Leslie Development's vehicle emissions. With the ambient pollution concentrations as inputs, the AQBAT model would be able to estimate the human health damages associated with the additional air pollution contributed by the North Leslie Development. This model would estimate the number of morbidity and mortality cases, along with a monetary valuation of the human health impacts.

With future study into the quantification of health impacts associated with large-scale, individual developments, it is hoped that more attention will be drawn to the impact that low-density, urban sprawl has on human health. This information will help to inform the political decision making process and perhaps encourage change at the community level. Within a planning context, the ability to quantify the health impacts of urban developments will hopefully lead to the prevention of vehicle reliant developments through appropriate legislation. For example, requiring new developments to meet design requirements that limit vehicle dependence and in turn produce healthier communities. 
Adams, H., Nieuwenhuijsen, M., Colvile, R., McMullen, M. \& Khandelwal, P. (2001). Fine particle (PM2.5) personal exposure levels in transport microenvironments. Science of the Total Environment, 279, 29-44.

Anderson, A. and Schroeer, W. (1999). The impact of infill vs. greenfield development: A comparative case study analysis. Prepared for the U.S. Environmental Protection Agency, Office of Policy, EPA publication \#231-R-99-005.

Anderson, M.R., De Leon, A.P., Bland, J.M., Bower J.S. \& Strachan, D.P. (1996). Air Pollution and daily mortality in London: 1987-1992. British Medical Journal, 312, 665-669.

Bailey, H. (1999). Transportation and environmental analysis of the Atlantic steel development project. Prepared for the U.S. Environmental Protection Agency, Our Built and Natural Environments.

Bell, M.L., Ebisu, K., Belanger, K. (2007) Ambient air pollution and low birth weight in Connecticut and Massachusetts. Environmental Health Perspectives, 115(7), 1118-1125.

Borgia, P., Forastiere, F., Rapiti, E., Rizzelli, R., Magliola, M.E., Perucci, C.A. (1994) Mortality among taxi drivers in Rome: a cohort study. American Journal Industrial Medicine, 25, 507-517.

Bray, R., Vakil, C., \& Elliot, D. (2005). Report on public health and urban sprawl in Ontario: A review of the pertinent literature. Environmental Health Committee, Ontario College of Family Physicians: Toronto, Ontario.

Brook, R. D., Franklin, B., Cascio, W., Hong, Y., Howard, G., Lipsett, M. Luepker, R., Mittleman, M., Samet, J., Smith, S., \& Tager, I. (2004). Air pollution and cardiovascular disease: A statement for healthcare professionals from the expert panel on population and prevention science of the American Heart Association. Circulation, 109, 2655-2671.

Burchell, R.W., Shad, N.A., Listokin, D., Phillips, H., Downs, A., Seskin, S., Davis, J.S., Moore, T., Helton, D., \& Gall, M. (1998). The costs of sprawl revisited: Report 39, Transit Cooperative Research Program. Washington, D.C.: National Academy Press.

Burda, C. (2008). Getting tough on urban sprawl: Solutions to meet Ontario climate change targets.

The Pembina Institute Provincial Progress Report 2007: Drayton Valley, Alberta.

Burnett, R.T., Brook, J., Dann, T., Delocia, C., Philips, O., Cakmak, S. (2000). Association between particulate- and gas-phase components of urban air pollution and daily mortality in eight Canadian cities. Inhalation Toxicology, 12 Supplement (4), 15-39.

Burnett, R.T., Cakmak, S. \& Brook, J.R. (1998). The effects of the urban ambient air pollution mix on daily mortality rates in 11 Canadian cities. Canadian Journal of Public Health, 89.3, 152-156.

Campbell, M.E., Li, Q., Gingrich, S.E., Macfarlane, R.G., \& Cheng, S. (2005). Should people be physically active outdoors on smog alert days? Canadian Journal of Public Health, 96, 24-28.

Canadian Medical Association. (2008). No breathing room: National illness cost of air pollution. Office of Public Health, Canadian Medical Association: Ottawa, Ontario.

Canadian Mortgage and Housing Corporation. (CMHC, 2007). Canadian housing observer. 
Canzi, M. (2008). The state of active transportation: Greater Toronto, Hamilton and Beyond. Prepared for Metrolinx by the Clean Air Partnership. (Web link:

http://www.metrolinx.com/docs/1/News/CAP_for_Metrolinx-Final.pdf as accessed in November 2009)

Cervero, R. (2003). Road expansion, urban growth, and induced travel: A path analysis. Journal of the American Planning Association, 69(2), 145-163

Cervero, R. (1996). Mixed Land Uses and Commuting. Evidence from the American Housing Survey. Transportation Research A, 30(5), 361-377.

Cervero, R. \& Kockelman, K. (1997). Travel demand and the 3Ds: Density, diversity and design. Transportation Research D. 2, 199-219

Chan, B. \& Young, W. (1999). Burden of cardiac disease. Cardiovascular Health \& Services in Ontario. (Web link: http://www.ices.on.ca/file/TechMeth_Appendix1.pdf, as assessed in September 2009)

Chardon, B., Lefranc, A., Granados, D., \& Gremy, I. (2007). Air pollution and doctors' house calls for respiratory diseases in Greater Paris area (2000-2003). Occupational and Environmental Medicine, 64(5), 320-324.

Clean Air Partnership (CAP; 2003). Smog news, Vol. 1, 1.

Collins Perdue, W., Stone, L. \& Gostin, L. (2003). The built environment and it relationship to the public's health: the legal framework. American Journal of Public Health, 93(9), 1390-1384.

Corburn, J. (2007). Urban land use, air toxics and public health: Assessing hazardous exposures at the neighbourhood scale. Environmental Impact Assessment Review, 27, 145-160.

Dargay, J., Gately, D. \& Sommer, M. (2007). Vehicle ownership and income growth, worldwide: 19602030. The Energy Journal, 28(4), 143-170.

Data Management Group. (2008). 2006 transportation tomorrow survey summaries by ward: Town of Richmond Hill. (Web link: http://www.dmg.utoronto.ca/pdf/tts/2006/richmond_wards06.pdf as accessed in November 2009).

Data Management Group. (n.d.). 2006, 2001 and 1996 travel survey summary for the Transportation Tomorrow Survey Area [image]. Retrieved November $3^{\text {rd }}, 2009$, from http://www.dmg.utoronto.ca/transportationtomorrowsurvey/2006/regional_travel_summaries.html\#o verall

David Suzuki Foundation. (1998). Taking our breath away: The health effects of air pollution and climate change. Author. (Web link: http://www.davidsuzuki.org, as assessed in September 2009).

De Ridder, K., Lefebre, F., Adriaensen, S., Arnold, U., Beckroege, W., Bronner, C., Damsgaard, O., Dostal,I., Dufek, J. (2008). Simulating the impact of urban sprawl on air quality and population exposure in the German Ruhr area. Atmospheric Environment, 42(30), 7070-7077.

De Rosa, M., Zarrilli, S., Paesano, L., Carbone, U., Boggia, B., Petretta, M. (2003). Traffic pollutants affect fertility in men. Human Reproduction, 18, 1055-1061.

Donnan, J. (2008). Economic implications and consequences of population growth, land use trends, and urban sprawl in southern Ontario. Prepared for the Environmental Commissioner of Ontario. Environmental Economics Services: West Hill.

Downs, A. (1997). The challenge of our declining big cities. Housing Policy Debate, 8(2), 359-408. 
Dunphy, R. T., \& Fisher, K. M. (1994). Transportation, congestion, and density: New insights. Paper presented at the 73rd Annual Meeting of the Transportation Research Board, Washington, DC. January 1994.

Engel-Yan, J. (IBI Group) \& Kassierer, J. (Transport Canada). (January 2009). Estimating emissions from urban transportation using UTEC [Teleconference]. Toronto, Canada: Transport Canada. (Web link: https://admin.na5.acrobat.com/_a782512023/p90829037/ as accessed November 2009).

Environment Canada. (2009a). About the national pollutant release inventory (NPRI). (Web link: http://www.ec.gc.ca/inrp-npri/default.asp?lang=En\&n=CA8D2224-1 as accessed in November 2009).

Environment Canada. (2009b). National pollutant release inventory: Tracking pollution in Canada. (Web link: http://www.ec.gc.ca/inrp-npri/default.asp?lang=En\&n=4A577BB9-1 as accessed in November 2009).

Environment Canada. (2009c). National pollutants release inventory 2008 - Are you required to report?: Part 4 - Criteria air contaminants (CACs). (Web link: http://www.ec.gc.ca/inrpnpri/default.asp?lang=En\&n=208A760B-1\&offset $=5 \&$ toc $=$ show as accessed in November 2009)

Environment Canada. (2008). How do we know a vehicle of model year 1995 or earlier emits 19 times more smog-forming air pollutants than one of model year 2004 or later? Clean Air Online, Participation Initiatives and Resources, Transportation outreach. (Web link: http://www.ec.gc.ca/cleanair-airpur/default.asp?lang=en\&n=54522D8C-1 as accessed in November 2009).

Environment Canada. (October1997). Canadian 1996 NO $/$ VOC scientific assessment.

Environmental Commissioner of Ontario. (ECO; 2008). Getting to k(no)w: Annual report 2007-2008. (Web link: http://www.eco.on.ca/eng/uploads/eng_pdfs/2008/ar2007.pdf as accessed in November 2009).

Environmental Commissioner of Ontario. (ECO; 2007). Reconciling our priorities: Annual report 2006 2007. (Web link: http://www.eco.on.ca/eng/uploads/eng_pdfs/2007/Annual_report-0607-FINALEN.pdf as accessed in November 2009).

Ewing, R. (1997). Is Los-Angeles-style sprawl desirable? American Planning Association, 63(1), 107-126.

Ewing. R. (1994). Characteristics, causes and effects of sprawl: A literature Review. Environmental and Urban Issues, 21(2), 1-15.

Ewing, R. \& Kreutzer, R. (2006). Understanding the relationship between public health and the built environment. Report Prepared for the LEED-ND Core Committee. (Web link: http://www.cnu.org/sites/www.cnu.org/files/leed_public_health.pdf , as assessed in November 2009).

Ewing, R. \& Cervero, R. (2001). Travel and the built environment: a synthesis. Transportation Research Record, 1780, 87-122.

Finkelstein, M.M., Jerrett, M., \& Sears, M.R. (2004). Traffic air pollution and mortality rate advancement periods. American Journal of Epidemiology, 160, 173-177.

Frank, L., \& Pivo, G. (1994). The relationship between land use and travel behavior in the Puget Sound Region. WA-RD 351.1. Olympia, WA: Washington State Department of Transportation. 
Frank, L., Stone, B., \& Bachman, W. (2000). Linking land use with household vehicle emissions in the Central Puget Sound: Methological Framework and Findings. Transportation Research Part D, 5 , 173-196.

Friedman, M., Powell, K., Hutwagner, L., Graham, L. \& Teague, W.. (1998). Impact of changes in transportation and commuting behaviors during the 1996 Summer Olympic Games in Atlanta on air quality and childhood asthma. Journal of the American Medical Association, 285(7), 897-905.

Gee, I.L., \& Raper, D.W. (1999). Commuter exposure to respirable particles inside buses and by bicycle. Science of the Total Environment, 235, 403-405.

GO Transit. (2009). System map for schedule finder. (Web link: http://www.gotransit.com/publicroot/en/schedule/sysmap.aspx as accessed in October 2009).

Golob, T. F., \& Brownstone, D. (2005). The impact of residential density on vehicle usage and energy consumption. Energy Policy and Economics, Working Paper UCI-ITS-WP-05-1, 1-26.

Goodwin, P. (1996). Empirical evidence on induced traffic: A review and synthesis. Transportation, 23, 35-54.

Google Maps. (n.d.) Google maps. (Web link: http://maps.google.com/ as accessed in November 2009)

Government of Ontario. (2007). MoveOntario 2020 projects. Newsroom - For Residents, June 15, 2007.

(Web link: http://www.news.ontario.ca/opo/en/2007/06/moveontario-2020-projects.html as accessed in November 2009).

Guberan, E., Usel, M., Raymond, L., Bolay, J., Fioretta, G. \& Puissant, J. (1992). Increased risk for lung cancer and for cancer of the gastrointestinal tract among Geneva professional drivers. British Journal of Industrial Medicine, 49, 337-344.

Hansen, J., Raaschou-Nielson, O. \& Olsen, J.H. (1998). Increased risk of lung cancer among different types of professional drivers in Denmark. Occupational and Environmental Medicine, 55, 115-118.

Hansen, M. \& Huang, Y. (1997). Road supply and traffic in California urban areas. Transportation Research Part A: Policy and Practice, 31(3), 205-218.

Hemson Consulting Ltd. (2009). Economic policy review: Stage 1 background research \& policy report. Prepared for the Town of Richmond Hill. (Web link:

http://www.richmondhill.ca/documents/op_economic_report.pdf as accessed in November 2009).

Hoek, G., Meliefste, K., Cyrys, J., Lewne, M., Bellander, T., Brauer, M. (2002). Spatial variability of fine particle concentrations in three European areas. Atmospheric Environment, 36, 4077-4088.

Hoffman, B. (2007). Residential exposure to traffic is associated with coronary atherosclerosis. Circulation, $116,489-496$.

Holtzclaw, J. (1994). Using residential patterns and transit to decrease auto dependence and costs. Natural Resources Defense Council. Web link: http://www.smartgrowth.org/library/cheers.html as accessed in November 2009).

Hong, Y., Leem, J., Lee, K., Park, D., Jang, J. \& Kim, S. (2005). Exposure to air pollution and pulmonary function in university students. International Archives of Occupational and Environmental Health, $78,132-138$. 
IBI Group. (2008). User guide for Urban Transportation Emissions Calculator (UTEC). Prepared for Transport Canada. (Web link: http://wwwapps.tc.gc.ca/Prog/2/UTEC-CETU/PDF/UTEC-CETUE.pdf as accessed in November 2009).

IBI Group \& Dillon Consulting Ltd. (2002). Toronto-related region futures study - Interim report: Implications of business-as-usual development. Toronto: Neptis Foundation.

IBI Group. (2000). Greenhouse gas emissions from urban travel: Tool for evaluating neighbourhood sustainability. Canadian Housing and Mortgage Corporation (CMHC) Research Report. Prepared for the CHMC and the Department of Natural Resources, Government of Canada.

iTRANS Consulting Inc. (2006). Transportation master plan: Summary report. Prepared for the Town of Richmond Hill. Project \# 3413.

Jakobsson, R., Gustavsson, P. \& Lundberg, I. (1997). Increased risk of lung cancer among male professional drivers in urban but not rural areas of Sweden. Occupational and Environmental Medicine, 54, 189-193.

Johnson, RL. 2004. Relative effects of air pollution on lungs and heart. Circulation, 109, 5-7.

Jones, A., Lam, P. \& Dean A. (2006). Respiratory health of bus drivers in Hong Kong. International Archives of Occupational and Environmental Health, 79, 414-418.

Kaur, S., Nieuwenhuijsen, M. \& Colvile, R. (2005). Personal exposure of street canyon intersection users to PM2.5, ultrafine particle counts and carbon monoxide in Central London, UK. Atmospheric Environment, 39, 3629-3641.

Kitamura, R., Mokhtarian, P.L. \& Laidet, L. (1994). A micro-analysis of land use and travel in five neighborhoods in the San Francisco Bay Area. Institute of Transportation Studies, University of California: Davis.

Kockelman, K. (January 1997). Travel behavior as a function of accessibility, land use mixing and land use balance: Evidence from the San Francisco Bay Area. Submission to the $76^{\text {th }}$ Annual Meeting on the Transportation Research Board.

Kunzli, N., Jerrett, M, Mack, W.J., Beckerman, B., LaBree, L., Gilliland, F., Thomas, D., Peters, J. \& Hodis, H. (2005). Ambient air pollution and atherosclerosis in Los Angeles. Environmental Health Perspectives, 113(2), 201-206.

Metrolinx. (2007). Towards sustainable transportation: Discussion paper \#1. December 2007. (Web link: http://www.metrolinx.com/docs/general/RTPGreenPaper1.pdf as accessed in November 2009).

Mieszkowski, P. \& Mills, E. (1993). The causes of metropolitan suburbanization. Journal of Economic Perspectives, 7(3), 135-147.

Ministry of Public Infrastructure Renewal. (2008). Built boundary for the Growth Plan for the Greater Golden Horseshoe, 2006. Province of Ontario. (Web link:

https://www.placestogrow.ca/images/pdfs/Built_Boundary.pdf as accessed in November 2009).

Ministry of the Environment. (2009a). Carbon monoxide. Author. (Web link:

http://www.airqualityontario.com/science/pollutants/carbon.cfm as accessed in December 2009).

Ministry of the Environment. (2009b). Sulphur Dioxide. Author. (Web link:

http://www.airqualityontario.com/science/pollutants/sulphur.cfm as accessed in December 2009). 
MMM Group Limited, Go for Green, \& Decima Research Inc. (2008). Pedestrian \& cycling master plan study: Towards a more sustainable region - final report. Prepared for York Region. (Web link: http://www.york.ca/departments/planning+and+development/pedestrian+and+cycling+master+plan. htm as accessed in November 2009).

Nafstad, P., Haheim, L.L., Oftedal, B., Gram, F., Holme, I. \& Hjermann. (2003). Lung cancer and air pollution: a 27 year follow up of 16209 Norwegian men. Thorax, 58, 1071-1076.

National Snow and Ice Data Centre. (NSIDC, n.d.) Arctic climatology and meteorology glossary: smog. Author. (Web link: http://nsidc.org/arcticmet/glossary/smog.html as accessed in December 2009).

Natural Resources Canada. (NRCan; 2007). Fuel consumption guide 2008. (Web link: http://oee.nrcan.gc.ca/transportation/tools/fuelratings/fuel-consumption-guide-2008.pdf as accessed in November 2009).

Nie, J., Beyea, J., Bonner, M.R., Han, D., Vena, J.E. \& Rogerson, P. (2007). Exposure to traffic emissions throughout life and risk of breast cancer : the Western New York Exposures and Breast Cancer (WEB) study. Cancer Causes and Control, 18, 947-955.

North Leslie Developers Group Secondary Plan. (November 15, 2005). Proposed unit breakdown. Project No. $9516-3$

Nyberg, F., Gustavsson, P., Jarup, L., Bellander, T., Berglind, N. \& Jakobsson, R. (2000). Urban air pollution and lung cancer in Stockholm. Epidemiology, 11, 487-495.

O’Donoghue, R.T., Gill, L.W., McKevitt, R.J. \& Broderick, B. (2007). Exposure to hydrocarbon concentrations while commuting or exercising in Dublin. Environment International, 33, 1-8.

Ontario Medical Association. (OMA; 2005). Illness cost of air pollution: 2005-2026 health and economic damage estimates. ISBN 0-919047-54-8. (Web link: http://www.oma.org/Health/smog/report/ICAP2005_Report.pdf as accessed in November 2009).

Ontario Ministry of Finance. (March 22, 2007). 2007 Ontario budget backgrounder: Expanding prosperity through Ontario's infrastructure. (Web link: http://www.fin.gov.on.ca/en/budget/ontariobudgets/2007/bk8.html as accessed in November 2009).

Ontario Municipal Board. (OMB; June 18 $\left.{ }^{\text {th }}, 2008\right)$. Decision/Order No. 20080018. Memorandum of oral decision delivered by Susan de Avellar Schiller on June $4^{\text {th }}$, 2008. Case Number PL020446. Case Description: Bayview East / North Leslie OPA

Ontario Municipal Board. (OMB; November 23, 2006). Decision/Order No. 3289. Decision delivered by M.F.V Eger and D.L. Gates. Case Number PL020446. Case Description: Bayview East / North Leslie OPA.

Parent, M.E., Rousseau, M.C., Boffetta, P., Cohen, A. \& Siemiatycki, J. (2007). Exposure to diesel and gasoline engine emissions and the risk of lung cancer. American Journal of Epidemiology, 165, 5362.

Pearson, R.L., Wachtel, H. \& Ebi, K.L. (2000). Distance-weighted traffic density in proximity to a home is a risk factor for leukemia and other childhood cancers. Journal of Air and Waste Management Association, 50, 175-180. 
Pim, L. \& Ornoy, J. (2005). Urban sprawl costs us all. In Ontario Nature, Federation of Ontario Naturalists (Eds.) A smart future for Ontario: How to create greenways and curb urban sprawl in your community (Chapter 1). (Web link: http://www.ontarionature.org/enviroandcons/smart_growth/ as accessed in November 2009).

Pollution Probe. (2002). The smog primer. Author. (Web link: http://www.pollutionprobe.org, as assessed in September 2009).

Pope, C.A. III, Burnett, R.T., Thurston, G.D., Thun, M.J., Calle, E.E. \& Krewski, D. (2004). Cardiovascular mortality and long-term exposure to particulate air pollution: epidemiological evidence of general pathophysiological pathways of disease. Circulation, 109(1), 71-77.

Pope, C.A. III, Burnet, R.T., Thun, M.J., Calle, E.E., Krewski, D. \& Ito, K. (2002). Lung cancer, cardiopulmonary mortality, and long-term exposure to fine particulate air pollution. Journal of the American Medical Association, 287(9), 1132-1141.

Rutherford, G.S., McCormack, E. \& Wilkinson. (1996). Travel impacts of urban form: implications from an analysis of two Seattle area travel diaries. TMIP Conference on Urban Design, Telecommuting and Travel Behavior. October 27-30.

Salam, M.T., Millstein, J., Li, Y., Lurmann, F.W. \& Margolis, H.G. (2005). Birth outcomes and prenatal exposure to ozone, carbon monoxide, and particulate matter: results from the Children's Health Study. Environmental Health Perspectives, 113, 1638-1644.

Sawyer, D., Stiebert, S. (Marbek Resource Consultants Ltd.) \& Welburn, C. (RWDI Inc.). (2007). Evaluation of total cost of air pollution due to transportation in Canada. Produced for Transport Canada. RFP\# T8080-06-0292. (Web link:

http://www.tc.gc.ca/pol/en/Report/FullCostInvestigation/Transmodal/t006/t006.pdf as accessed in November 2009).

Schikowski, T., Sugiri, D., Ranfit, U., Gehring, U., Heinrich, J. \& Wichmann, H. (2005). Long- term air pollution exposure and living close to busy roads are associated with COPD in women. Respiratory Research, 6, 152.

Sharman, J.E., Cockcroft, J.R. \& Coombes, J.S. (2004). Cardiovascular implications of exposure to traffic air pollution during exercise. QJ Medicine, 97, 637-643.

SHS Consulting \& Centre for Spatial Economics. (2008). Socio-economic study for the town of Richmond Hill - FINAL. (Web link http://www.richmondhill.ca/documents/rh_socio_economic_study.pdf, as accessed in November 2009).

Soltic, P., \& Weilenmann, M. (2002). Partitioning of $\mathrm{NO}_{x}$ emissions for gasoline passenger cars and light duty trucks. The $11^{\text {th }}$ International Symposium, Transport and air pollution. June 19-21, Graz, Austria.

Sram, R.J., Binkova, B., Dejmek, J. \& Bobak, M. (2005). Ambient air pollution and pregnancy outcomes: a review of the literature. Environmental Health Perspectives, 113, 375-382.

Statistics Canada. (2006a). Census tract profile for 0424.04, Toronto, Ontario. (Web link: http://www.recensement2006.ca/census-recensement/2006/dp-pd/prof/92597/P3.cfm?CTuid=5350424.04\&Lang=E as accessed in November 2009).

Statistics Canada. (2006b). Census tract profile for 0424.05, Toronto, Ontario. (Web link: http://www.recensement2006.ca/census-recensement/2006/dp-pd/prof/92-

597/P3.cfm?CTuid=5350424.05\&Lang=E as accessed in November 2009). 
Statistics Canada. (2006c). Census tract profile for 0422.03, Toronto, Ontario. (Web link:

http://www.recensement2006.ca/census-recensement/2006/dp-pd/prof/92-

597/P3.cfm?CTuid=5350422.03\&Lang=E as accessed in November 2009.

Statistics Canada. (2006d). Richmond Hill community profile. (Web link:

http://www12.statcan.gc.ca/census-recensement/2006/dp-pd/prof/92-

591/details/Page.cfm?Lang=E\&Geo1=CSD\&Code1 $=3519038 \&$ Geo $2=$ PR \&Code $2=35 \&$ Data=Count

$\&$ SearchText=richmond $\% 20$ hill $\&$ SearchType $=$ Begins $\&$ SearchPR $=01 \& B 1=$ All \&Custom $=$ as

accessed in November 2009).

Steenland, K., Silverman, D.T. \& Hornung, R.W. (1990). Case-control study of lung cancer and truck driving in the Teamsters Union. American Journal of Public Health, 80, 670-674.

Stieb, D.M., Judek, S. \& Burnett, R.T. (2002). Meta-analysis of time-series studies of air pollution and mortality: effects of gases and particles and the influence of cause of death, age, and season. Journal of Air and Waste Management Association, 52, 470-484.

Stieb, D.M., Pengelly, L.D., Arron, N. (1995). Health effects of air pollution in Canada: Expert panel findings for The Canadian Smog Advisory Program. Canadian Respirology Journal, 2(3).

Sunyer, J., Jarvis, D., Gotschi, T., Garcio-Esteban, R., Jacquemin, B. \& Aguilera, I. (2006). Chronic bronchitis and urban air pollution in an international study. Occupational and Environmental Medicine, 63, 836-843.

Toronto Public Health. (November 2007). Air pollution burden of illness from traffic in Toronto - problems and solutions. City of Toronto: Toronto, Ontario.

Toronto Public Health. (2004). Air pollution burden of illness in Toronto: 2004 summary. City of Toronto: Toronto, Ontario.

Toronto Transit Commission. (n.d.) System map: Toronto and Greater Toronto Area system map. (Web link: http://www3.ttc.ca/Routes/General_Information/Maps/System.jsp as accessed in November 2009).

Transport Canada. (2008a). 2006 CAC emission factors $(\mathrm{g} / \mathrm{km})$. (Web link: http://wwwapps.tc.gc.ca/Prog/2/UTEC-CETU/CacEmissionFactors.aspx?lang=eng as accessed in November 2009.

Transport Canada. (2008b). 2030 CAC emission factors ( $\mathrm{g} / \mathrm{km})$. (Web link: http://wwwapps.tc.gc.ca/Prog/2/UTEC-CETU/CacEmissionFactors.aspx?lang=eng as accessed in November 2009).

Transport Canada. (2008c). 2006 Fuel efficiency by vehicle class. (Web link: http://wwwapps.tc.gc.ca/Prog/2/UTEC-CETU/FuelEfficiency.aspx?lang=eng as accessed in November 2009).

Transport Canada. (2008d). 2030 Fuel efficiency by vehicle type. (Web link: http://wwwapps.tc.gc.ca/Prog/2/UTEC-CETU/FuelEfficiency.aspx?lang=eng as accessed in November 2009).

Trinity Development Group. (n.d.) New properties under development - Elgin Hills Crossing, Richmond Hill, ON. (Web link: http://www.trinity-group.com/index.php?q=node/155 as accessed in November 2009).

Turcotte, M. (n.d.). Life in metropolitan areas: The city/suburb contrast: How can we measure it? Canadian Social Trends. Statistics Canada, Catalogue No. 11-008. 
U.S. Environmental Protection Agency. (U.S. EPA, n.d.). Automobile and carbon monoxide. Author. (Web link: http://www.epa.gov/otaq/consumer/03-co.pdf, as accessed in September 2009).

U.S. Environmental Protection Agency. (U.S. EPA, 2009a). Carbon monoxide. Author. (Web link: http://www.epa.gov/air/urbanair/co/index.html, as accessed in September 2009).

U.S. Environmental Protection Agency. (U.S. EPA, 2009b). Carbon monoxide: National trends in CO emissions. Author. (Web link: http://www.epa.gov/airtrends/carbon.html, as accessed in September 2009).

U.S. Environmental Protection Agency. (U.S. EPA, 2009c). Ground-level ozone. Author. (Web link: http://www.epa.gov/groundlevelozone/ as accessed in December 2009).

U.S. Environmental Protection Agency. (U.S. EPA, 2009d). Particulate Matter. Author. (Web link: http://www.epa.gov/oar/particlepollution/ as accessed in December 2009).

U.S. Environmental Protection Agency. (U.S. EPA, 2009e). Volatile Organic Compounds: An Introduction to Indoor Air Quality. Author. (Web link; http://www.epa.gov/iaq/voc.html as accessed in December 2009).

Van Wijnen, J.P., Verhoeff, A.P., Jans, H. \& van Bruggen, M. (1995). The exposure of cyclists, car drivers and pedestrians to traffic-related air pollutants. International Archives of Occupational and Environmental Health, 67, 187-193.

Villeneuve, P.J., Chen, L., Stieb, D. \& Rowe, B.H. (2006). Associations between outdoor air pollution and emergency department visits for stroke in Edmonton, Canada. European Journal of Epidemiology, 21, 689-700.

Vineis, P., Hoek, G., Krzyzanowski, M., Vigna-Taglianti, F., Veglia, F. \& Airoldi, L. (2006). Air pollution and risk of lung cancer in a prospective study in Europe. International Journal of Cancer, 119, 169174.

Wilhelm, M. \& Ritz, B. (2005). Local variations in CO and particulate air pollution and adverse birth outcomes in Los Angeles County, California, USA. Environmental Health Perspectives, 113, 1212 1221 .

Willis, M.R. \& Keller, A.A. (2007). A framework for assessing the impact of land use policy on community exposure to air toxics. Journal of Environmental Management, 83, 213-227.

World Health Organization Regional Office for Europe. (WHO Regional Office for Europe, 2000). Air quality guidelines for Europe. WHO Regional Publications, European Series, NO. 91. Second Edition. Copenhagen: WHO Library. (Web Link: http://www.euro.who.int/document/e71922.pdf).

York Region Transit / VIVA. (2009). YRT / Viva system map. (Web link: http://www.yrt.ca/maps/maps/YRT-Viva_system_map_current.pdf as accessed in November 2009).

York Region Transit / VIVA. (n.d.). Richmond Hill route navigators and maps. (Web link: http://www.yorkregiontransit.com/maps/richmondhill.asp as accessed in November 2009).

Zhou, W., Yuan, D., Ye, S., Qi, P., Fu, C. \& Christiani, D.C. (2001). Health effects of occupational exposures to vehicle emissions in Shanghai. International Journal of Occupational and Environmental Health, 7, 23-30.

Ziskind, R.A., Fite, K. \& Mage, D.T. (1997). Pilot field study: carbon monoxide exposure monitoring in the general population. Environment International, 8, 283-293. 


\section{APPENDIX 1}


Table A-1: Road Layout/Configuration Descriptions from the TENS Model

\begin{tabular}{|l|l|}
\hline Strict Rectangular Grid & $\begin{array}{l}\text { Describes a zone that contains exclusively urban grid } \\
\text { networks, typical of pre-1950s development. }\end{array}$ \\
\hline Industrial Grid & $\begin{array}{l}\text { Describes a zone with fairly widely spaced roads passing } \\
\text { through primarily industrial areas. }\end{array}$ \\
\hline Primarily Rectangular Grid & Consists of grid networks with some breaks. \\
\hline $\begin{array}{l}\text { *Mix of Rectangular and } \\
\text { Curvilinear }\end{array}$ & $\begin{array}{l}\text { Describes a zone where there is a predominance of } \\
\text { curvilinear streets intermixed with a grid network. } \\
\text { *Road layout selected for the North Leslie } \\
\text { Development* }\end{array}$ \\
\hline Regular Curvilinear & $\begin{array}{l}\text { Describes a zone consisting primarily of curved streets } \\
\text { with at least some continuity. }\end{array}$ \\
\hline Random Curvilinear & $\begin{array}{l}\text { Describes a zone with road layout patterns typical of post } \\
1970 \text { s development consisting of a high proportion of } \\
\text { streets ending with cul-de-sacs and butting onto large } \\
\text { arterial roadways. }\end{array}$ \\
\hline Rural Grid & $\begin{array}{l}\text { Describes zones in the outer areas of the Greater Toronto } \\
\text { Area that are largely undeveloped and consists of widely } \\
\text { spread regional arterials, townships roads and rural } \\
\text { highways. }\end{array}$ \\
\hline
\end{tabular}

Source: (IBI Group, 2000, p.16)

* Road layout chosen to represent the future North Leslie Development. 


\section{Hills Crossing Retail Park}

From the 8 small stores that were contacted and the total number of employees was

estimated:

30 (Petsmart) +

25 (Michaels) +

30 (Staples) +

25 (Mark's Work Warehouse) +

14 (TD Canada Trust) +

16 (Scotia Bank) +

40 (Kelseys) +

5 (Tuxedo Royale)

$=185$ employees

The total number of employees from the 8 small stores contacted in the retail park was then divided by the number of small stores contacted (8) to determine the average number of employees per store:

Employees / Number of small stores contacted = Average \# of employees per store

185 employees $/ 8$ small stores contacted $=23.1=\mathbf{2 3}$ employees per store

The average number of employees per small store was then multiplied by the number of small stores in the retail park (38):

Average number of employees per small store X Number of small stores

$=$ Estimation of the total number of employees in all small stores in retail park

23 employees per small store X 38 small stores in retail park

$=874$ employees in all small stores in retail park

The number of employees from the 2 large stores were then added to the employee estimate from all the small stores to estimate the number of employees in the entire retail park:

Estimate of the total number of employees from all small stores + Costco + Home Depot $=$ Total number of employees in retail park

874 (employees from small stores) +220 (Costco) +165 (Home Depot)

$=1,259$ estimate of the number of employees in the entire retail park 
Table B-2: Calculation of the Total Number of Employees within one kilometer of the North Leslie Development in 2010

The number of employees at the Richmond Green Secondary School, within the North Leslie Development area, were added to the number of employees in the RIOCAN Elgin Hills Crossing retail park:

95 (number of employees at Richmond Green High School) + 1,259 (number of employees in the retail park)

$=1,354$ employees within one kilometer of the center of the North Leslie Development area 
Table B-3: Sample of School Employment Numbers, 2009

\begin{tabular}{|l|l|}
\hline Elementary Schools & Employees \\
\hline Michaelle Jean Public School & 35 \\
Beverley Acres Public School & 30 \\
H.G. Bernard Public School & 50 \\
Redstone Public School & 52 \\
Richmond Rose Public School & 50 \\
Silver Stream Public School & 40 \\
\hline
\end{tabular}


Table B-4: Calculation of the Total Number of Employees within one kilometer of the North Leslie Development in 2030

The estimated number of all employees for the proposed elementary school in the area was determined by first determining an average number of employees per elementary school:

35 (Michaelle Jean Public School) +

30 (Beverley Acres Public School) +

50 (H.G. Bernard Public School) +

52 (Redstone Public School) +

50 (Richmond Rose Public School) +

40 (Silver Stream Public School)

$=257$ employees

Total \# employees $/$ \# of schools contacted = Average \# of employees per school

257 employees $/ 6$ schools $=42.8$

= Average of $\mathbf{4 2 . 8}$ employees per elementary school

The total number of employees working in the 6 proposed schools in the North Leslie Development area was calculated by taking the average number of current employees per elementary school and multiplying that number by the number of proposed schools:

Average \# of employees per school X \# of proposed schools

$=\#$ of employees in all proposed schools

43 (average \# of employees per school) X 6 (number of proposed schools)

$=257$ employees for the proposed schools in the North Leslie Development Area

The total number of employees within one kilometer of the North Leslie Development was calculated by adding the additional employment numbers from the proposed elementary schools to the number of employees calculated in the 2010 estimate:

Number of employees from the proposed schools +

Number of employees from the 2010 employment number estimate

$=$ Estimated number of employees within one kilometer of the North Leslie Development in 2030

257 (employees from the proposed schools) + 1,354 (number of employees from the 2010 estimate) $=$ 1,611 estimated number of employees within one kilometer of the North Leslie Development in 2030 


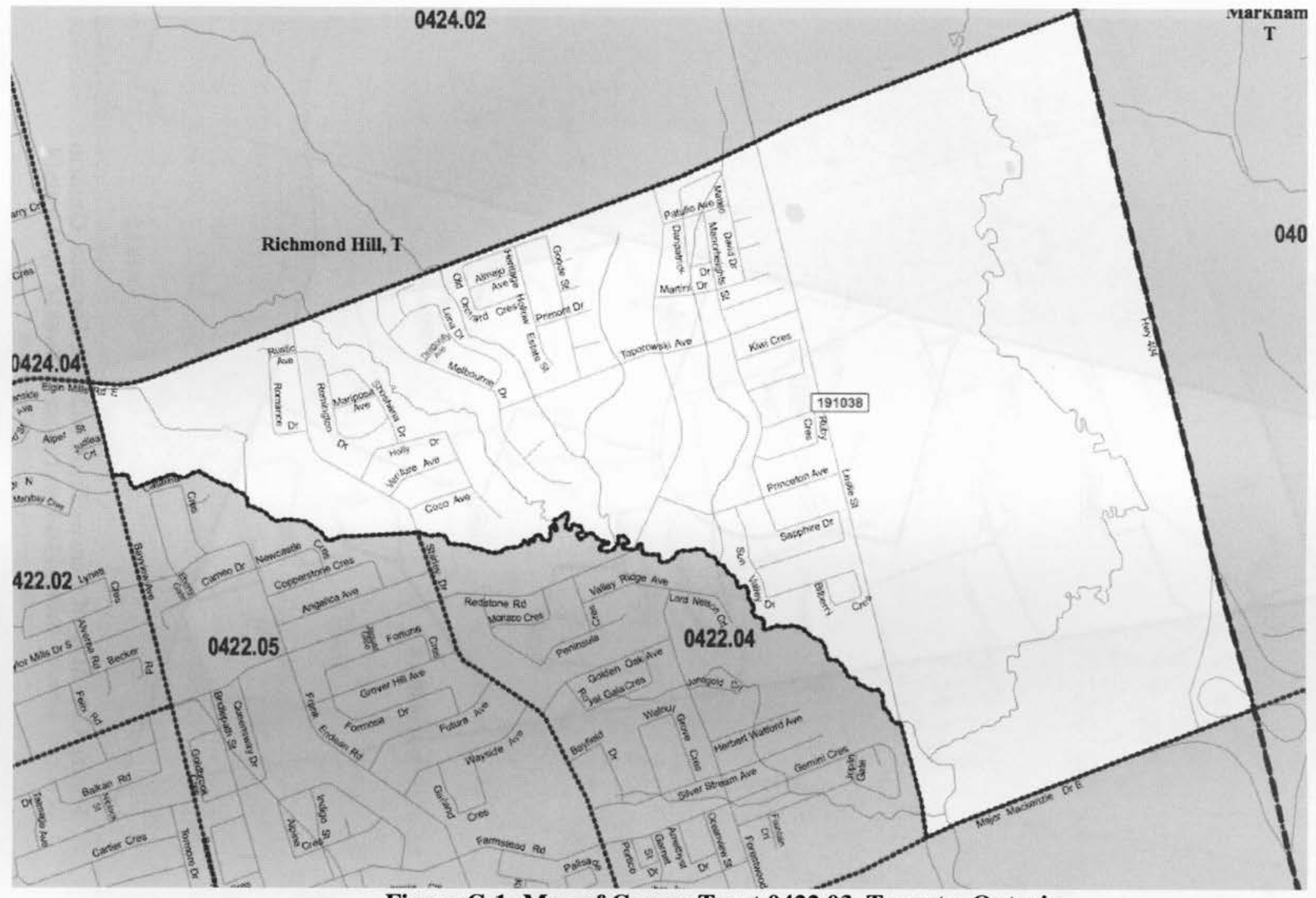

Figure C-1: Map of Census Tract 0422.03, Toronto, Ontario Source: (Statistics Canada, 2006c) 


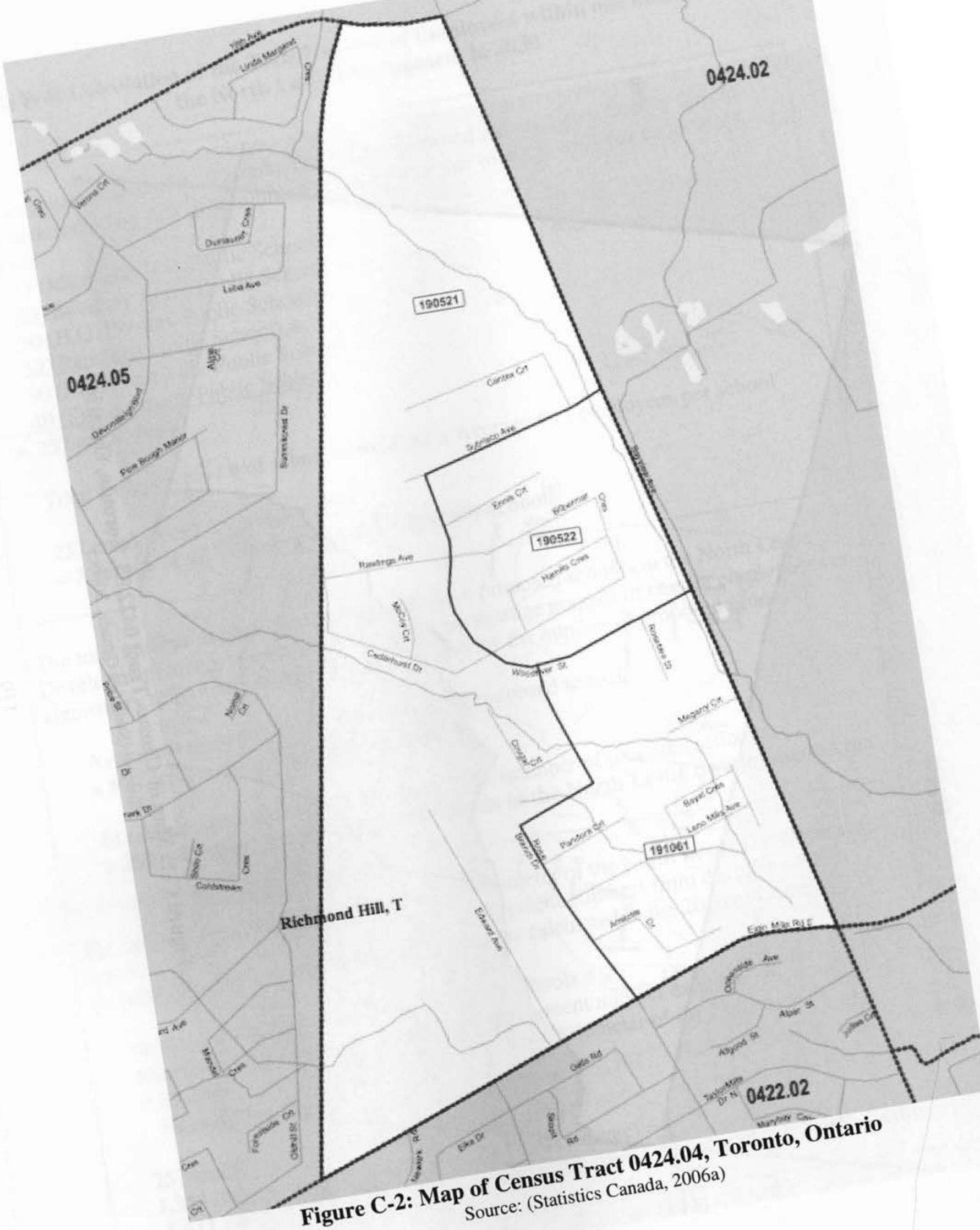




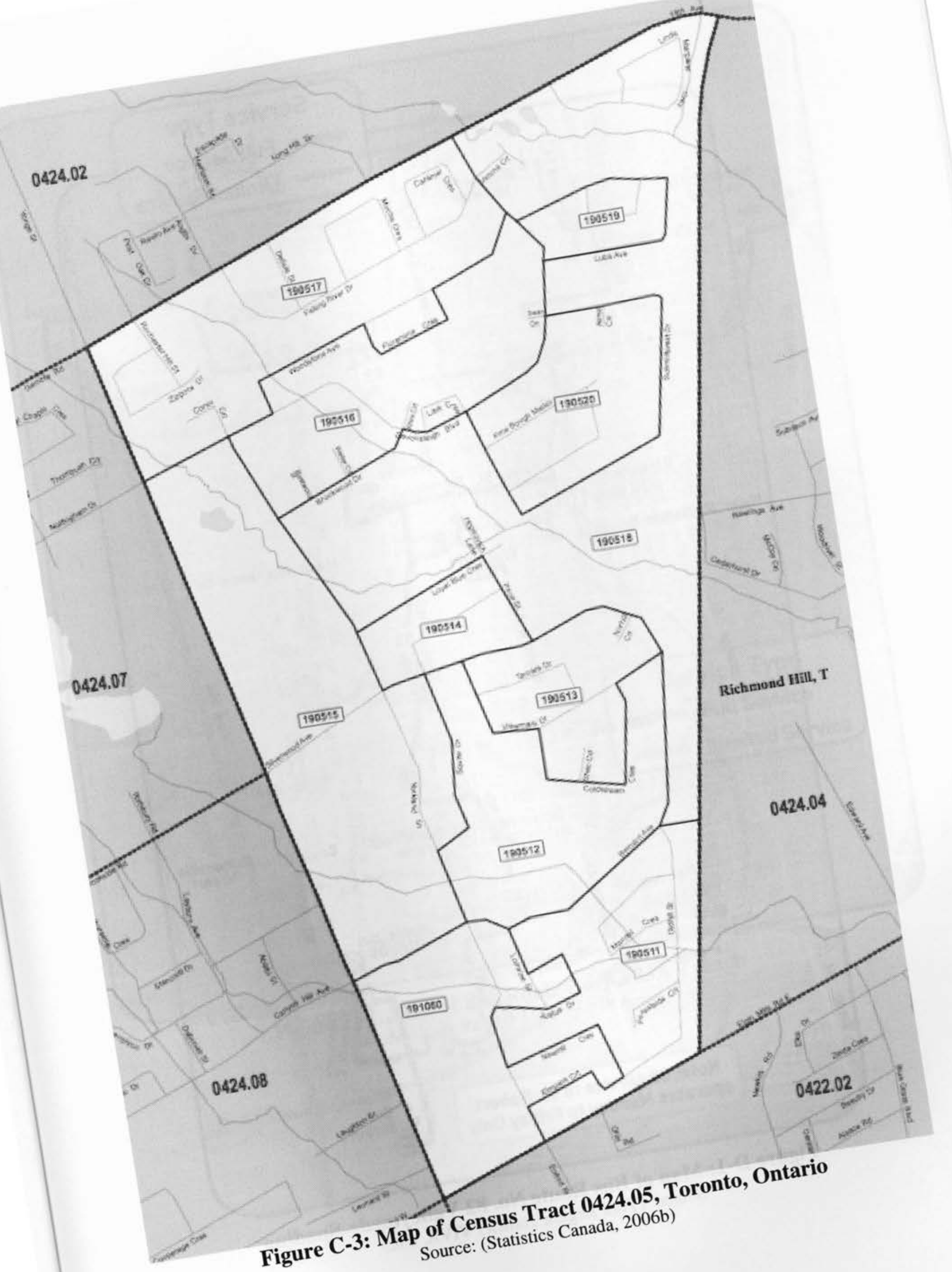




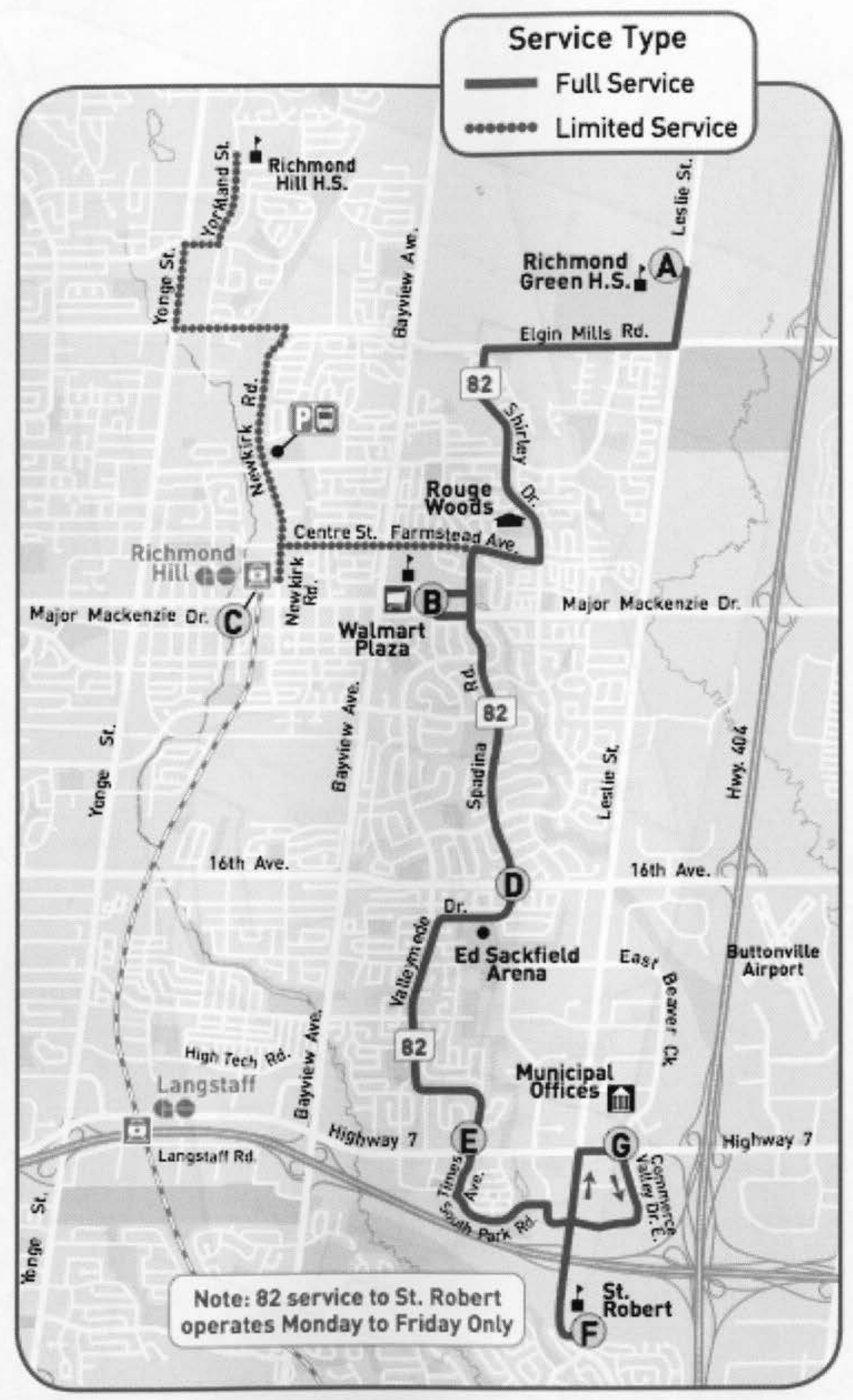

Figure D-1: Map of Bus Route No. 82 Valleymede-Spadina Source: (York Region Transit/ VIVA, n.d.) 


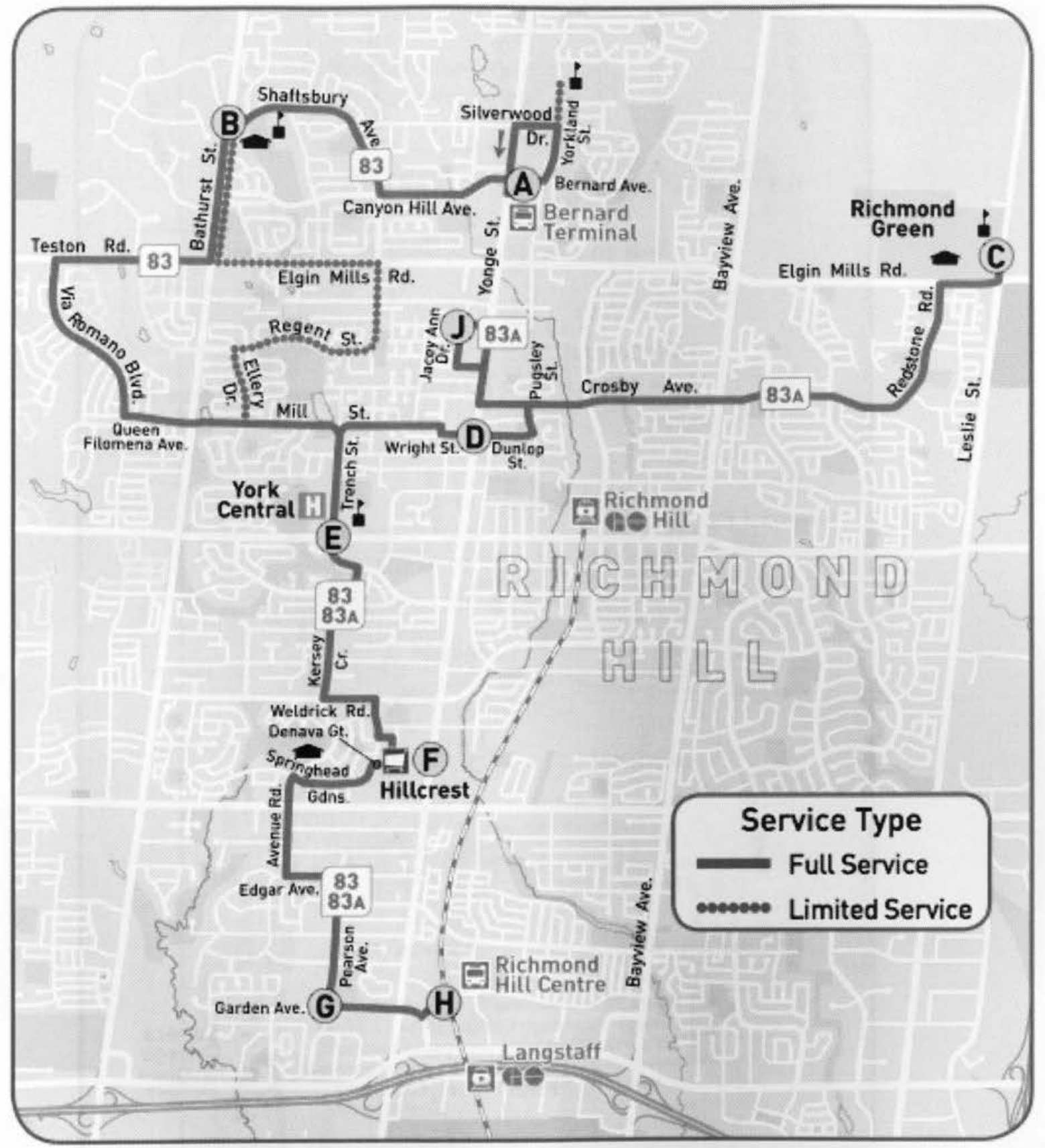

Figure D-2: Map of Bus Route No. 83/83A Trench

Source: (York Region Transit / VIVA, n.d.) 


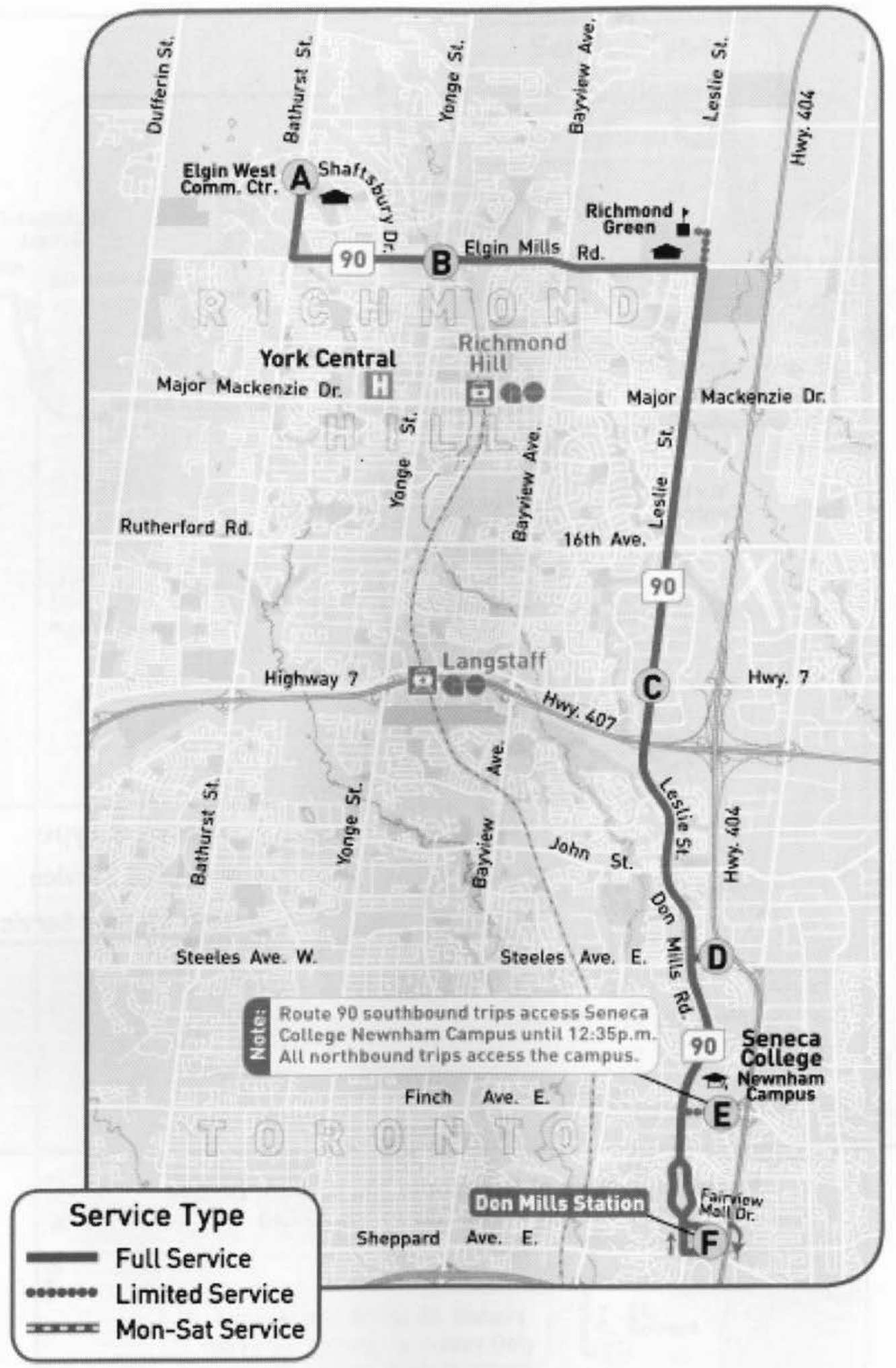

Figure D-3: Map of Bus Route No. 90 Leslie South

Source: (York Region Transit, n.d.) 


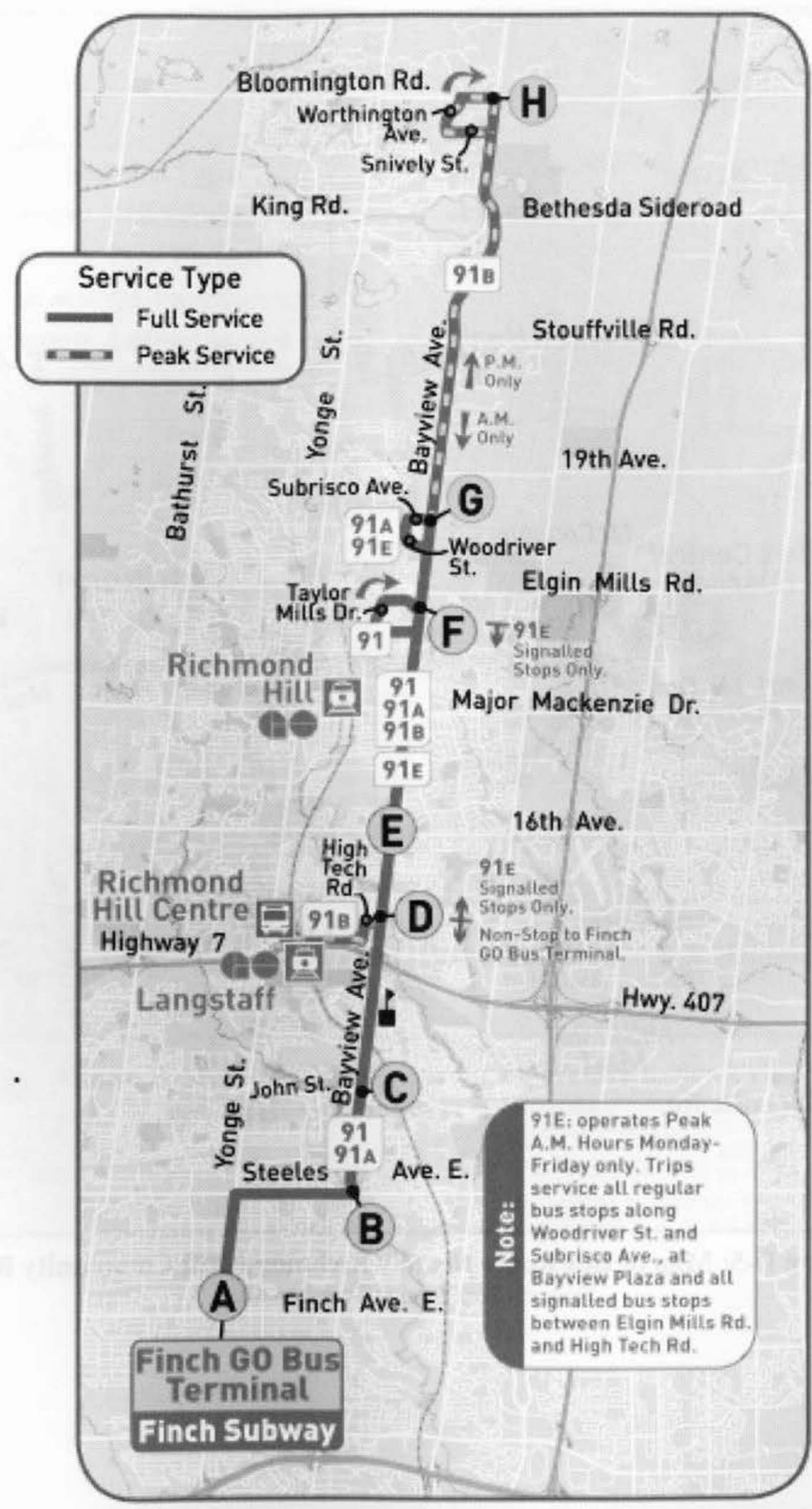

Figure D-4: Map of Bus Route No. 91/91A/91E Bayview South Source: (York Region Transit, n.d.) 


\section{ஸे

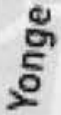

Elgin Mills Rd.

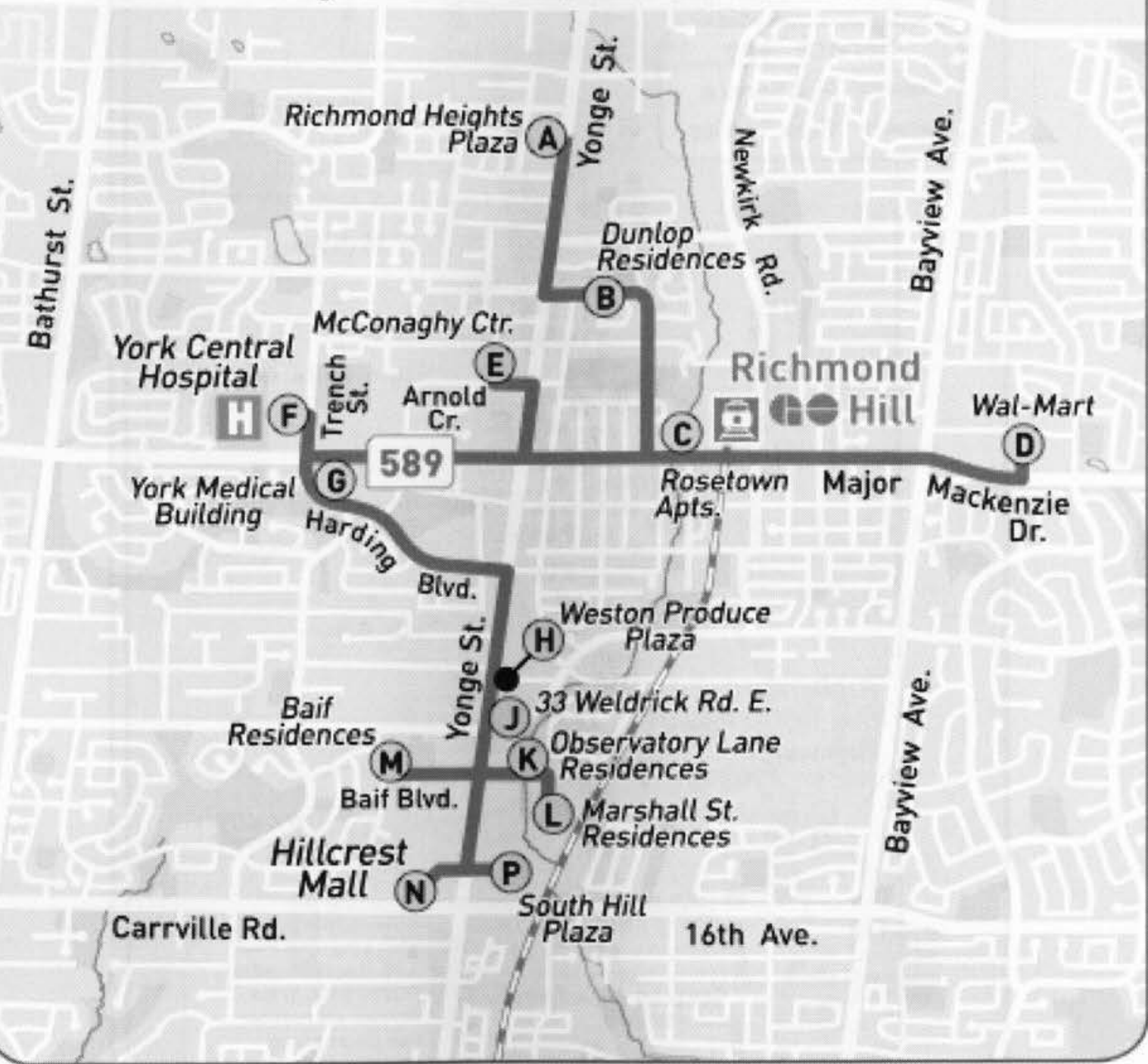

Figure D-5: Map of Bus Route No. 589 Richmond Hill Community Bus

Source: (York Region Transit, n.d.) 


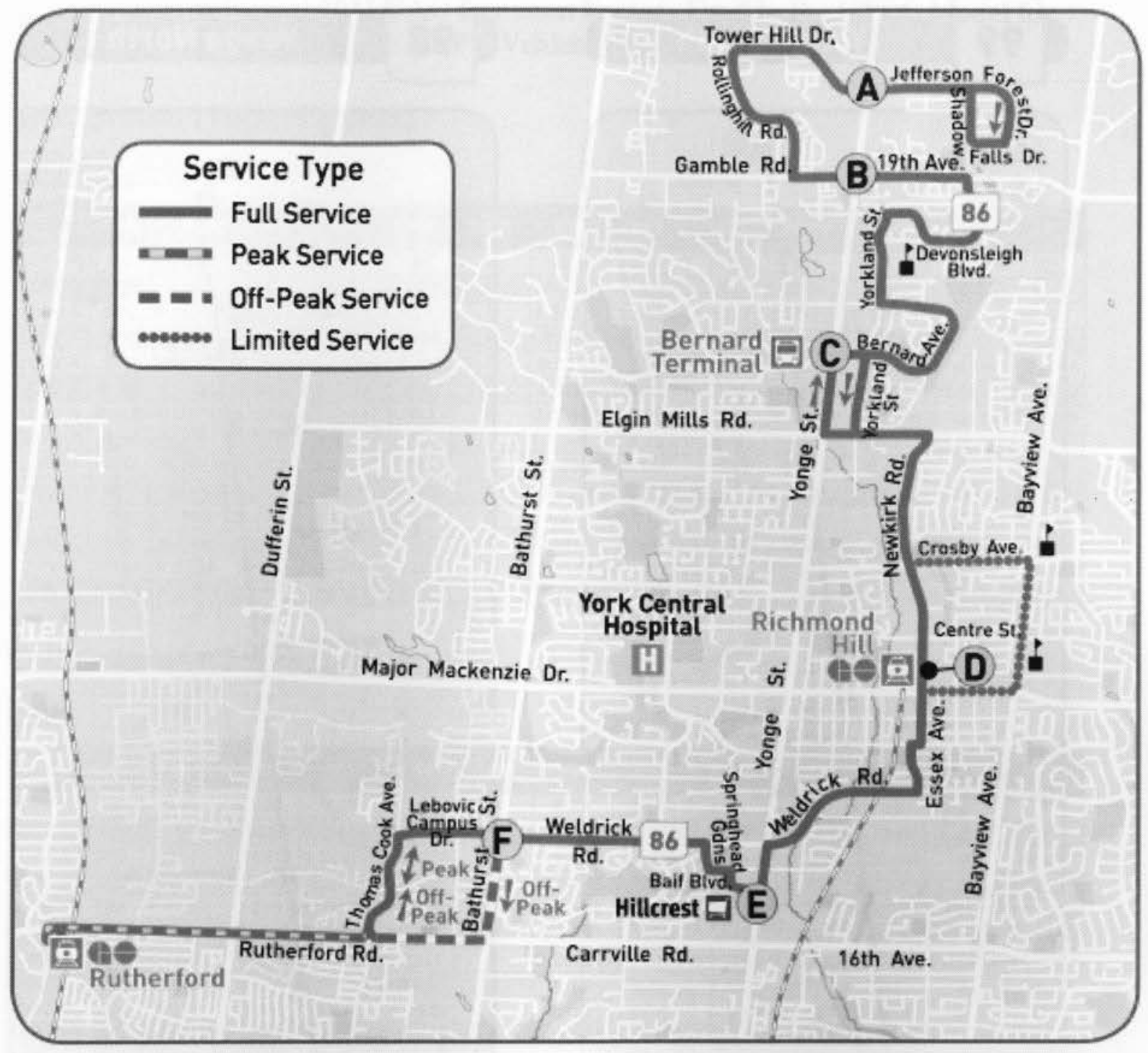

Figure D-6: Map of Bus Route No. 86 Weldrick-Newkirk

Source: (York Region Transit, n.d.) 


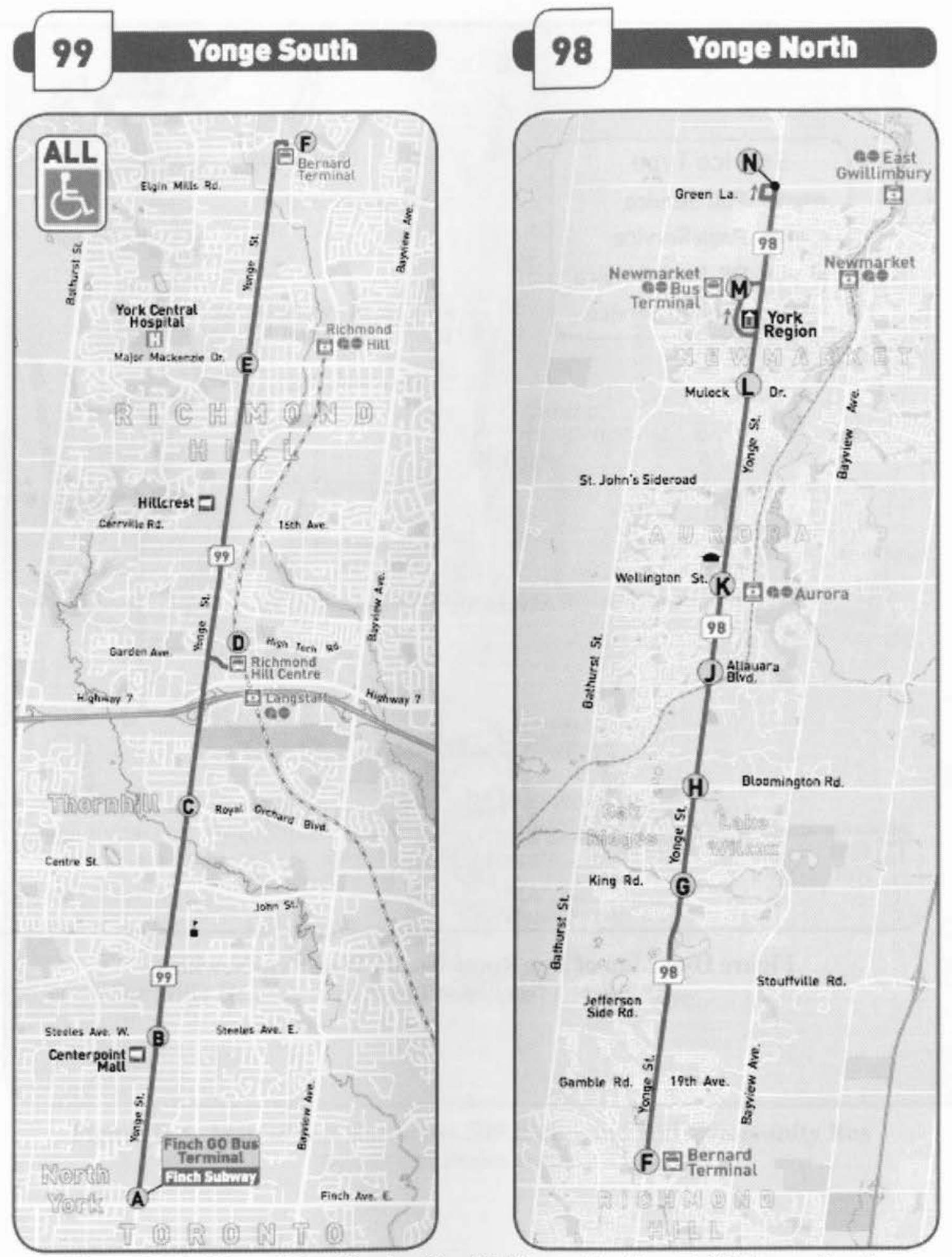

Figure D-7: Map of Bus Routes No. 98 Yonge North and 99 Yonge South

Source: (York Region Transit, n.d.) 


\section{Table E-1: 2006 and 2031 CAC Emission Factors Used in the UTEC Model for LDPV Vehicle Classes}

\section{CAC Emission Factors $(\mathrm{g} / \mathrm{km})$}

\begin{tabular}{|c|c|c|c|c|c|c|c|c|c|c|c|c|c|}
\hline $\begin{array}{l}\text { Yehicle } \\
\text { Class }\end{array}$ & CAC & 0 & D & $\mathbf{P}$ & CNG & LNG & E10 & E85 & M85 & PHEV & HYB & $\mathbf{E V}$ & FC \\
\hline LDPV-A & $\mathrm{CO}$ & 10.9 & 0.662 & 6.54 & 2.87 & 0 & 10.6 & 7.44 & 7.65 & 3.5 & 7 & 0 & 0 \\
\hline LDPV -A & NOx & 0.559 & 0.507 & 0.504 & 0.607 & 0 & 0.556 & 0.515 & 0.518 & 0.18 & 0.359 & 0 & 0 \\
\hline LDPV-A & $\mathrm{SO} 2$ & 0.00354 & 0.0216 & 0.00094 & 0.00043 & 0 & 0.00344 & 0.0024 & 0.00171 & 0.00114 & 0.00227 & 0 & $8 E-05$ \\
\hline LDPV-A & VOC & 0.662 & 0.166 & 0.128 & 0.0885 & 0 & 0.199 & 0.0176 & 0.184 & 0.0577 & 0.115 & 0 & 0.0118 \\
\hline LDPV-A & TPM & 0.0158 & 0.0683 & 0.00394 & 0.0266 & 0 & 0.0151 & 0.00826 & 0.00871 & 0.00506 & 0.0101 & 0.00946 & 0.00946 \\
\hline LDPV-A & PM10 & 0.0155 & 0.0582 & 0.00388 & 0.0262 & 0 & 0.0149 & 0.00813 & 0.00858 & 0.00498 & 0.00997 & 0.00932 & 0.00932 \\
\hline LDPV-A & PM2.5 & 0.0071 & 0.0556 & 0.00178 & 0.012 & 0 & 0.00681 & 0.00372 & 0.00392 & 0.00228 & 0.00456 & 0.00298 & 0.00298 \\
\hline LDPV-T & Co & 12.8 & 0.558 & 7.67 & 3.37 & 0 & 12.4 & 8.73 & 8.97 & 4.1 & 8.21 & 0 & 0 \\
\hline LDPV-T & NOx & 0.701 & 0.572 & 0.631 & 0.761 & 0 & 0.696 & 0.645 & 0.648 & 0.225 & 0.45 & 0 & 0 \\
\hline LDPV-T & $\mathrm{SO} 2$ & 0.00453 & 0.0313 & 0.0012 & 0.00055 & 0 & 0.0044 & 0.00307 & 0.00218 & 0.00145 & 0.0029 & 0 & 0.0001 \\
\hline LDPV-T & VOC & 0.709 & 0.268 & 0.137 & 0.0948 & 0 & 0.213 & 0.0188 & 0.197 & 0.0617 & 0.123 & 0 & 0.0127 \\
\hline LDPV-T & TPM & 0.016 & 0.0942 & 0.00401 & 0.027 & 0 & 0.0154 & 0.0084 & 0.00886 & 0.00515 & 0.0103 & 0.00962 & 0.00962 \\
\hline LDPV-T & PM10 & 0.0158 & 0.094 & 0.00395 & 0.0266 & 0 & 0.0151 & 0.00827 & 0.00872 & 0.00507 & 0.0101 & 0.00947 & 0.00947 \\
\hline LDPV-T & PM2.5 & 0.0073 & 0.0794 & 0.00183 & 0.0123 & 0 & 0.007 & 0.00382 & 0.00403 & 0.00234 & 0.00469 & 0.00307 & 0.00307 \\
\hline
\end{tabular}

\section{CAC Emission Factors $(\mathrm{g} / \mathrm{km})$}

2031

\begin{tabular}{|c|c|c|c|c|c|c|c|c|c|c|c|c|c|}
\hline $\begin{array}{l}\text { Vehicle } \\
\text { Class }\end{array}$ & CAC & G & D & P & CNG & LN & E10 & E85 & M85 & HEV & HYB & EV & FC \\
\hline LDPV-A & $\mathrm{CO}$ & .49 & 322 & 3.29 & 45 & 0 & .33 & 3.75 & 3.85 & 1.76 & 3.52 & 0 & 0 \\
\hline LDPV-A & NOX & 0.103 & 0.0163 & 0.0924 & 1 & 0 & 0.102 & 0.0945 & 0.095 & 0.0329 & 0.0659 & 0 & 0 \\
\hline LDPV-A & 502 & 0.0031 & 0.00251 & 0.00082 & 0.00038 & 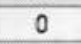 & 0.00301 & 0.0021 & 0.00149 & 0.00099 & 0.00199 & 0 & $7 E-05$ \\
\hline LDPV-A & VOC & 0.177 & 0.0248 & 0.0343 & 0.0237 & 0 & 0.0533 & 0.00471 & 0.0492 & 0.0155 & 0.0309 & 0 & 0.00317 \\
\hline LDPV-A & TPM & 52 & 0.018 & 0.0 & & 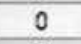 & & 795 & 0.00839 & 0.0 & 975 & 0911 & 0.00911 \\
\hline LOPV-A & PM10 & 0.015 & 0.0178 & 0.00374 & 0.0 & 0 & 0.0143 & 0.00784 & 0.00827 & 0.0048 & 0.00961 & 0.00898 & 0.00898 \\
\hline LDPV-A & PM 2.5 & 0.0066 & 0.00923 & 0.00165 & 0.0111 & 0 & 0.00632 & 0.00346 & 0.00365 & 0.00212 & 0.00424 & 0.00277 & 0.00277 \\
\hline LDPV-T & $\mathrm{CO}$ & 5.51 & 0.16 & 3.31 & 1.45 & 0 & 5.36 & 3.76 & 3.87 & 1.77 & 3.54 & 0 & 0 \\
\hline LOPV-T & NOX & 0.152 & 0.0367 & 0.137 & 0.165 & 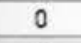 & 51 & 0.14 & 0.14 & 0.0487 & 0.0974 & 0 & 0 \\
\hline LDPV-T & 502 & 0.00402 & 0.00339 & 0.00107 & 0.00049 & 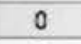 & 0.00391 & 0.00273 & 0.00194 & 0.00129 & 0.00258 & 0 & $9 E-05$ \\
\hline LDPV-T & VOC & 0.199 & 0.0376 & 0.0385 & 0.0266 & 0 & 0.0598 & 0.00529 & 0.0553 & 0.0174 & 0.0347 & 0 & 0.00356 \\
\hline LDPV-T & TPM & 0.0152 & 0.018 & 0.0038 & 0.0256 & 0 & 0.0145 & 0.00795 & 0.00839 & 0.00487 & 0.00975 & 0.00911 & 0.00911 \\
\hline LDPV-T & PM10 & 0.015 & 0.0178 & 0.00374 & 0.0252 & 0 & & 0.00784 & 0.00827 & 0.0048 & 0.00961 & 0.00898 & 0.00898 \\
\hline LDPV-T & PM2.5 & 0.0066 & 0.00925 & 0.00165 & 0.0111 & 0 & 0.00632 & 0.00346 & 0.00365 & 0.00212 & 0.00424 & 0.00277 & 0.00277 \\
\hline
\end{tabular}

Source: Adapted from Transport Canada's CAC Emission Factor Tables for the UTEC Model (Transport

Canada, 2008a; Transport Canada, 2008b)

*Note: $\mathrm{G}=$ Gasoline; $\mathrm{D}=$ Diesel.

LDPV-A = Light Duty Passenger Vehicle - Automobile

LDPV-T = Light Duty Passenger Vehicle - Truck / Sports Utility Vehicle 
Table F-1: 2006 Fuel Efficiency by Vehicle Class Used in the UTEC Model

\section{Fuel Efficiency by Vehicle Class}

$2006 \quad \vdots$

City Driving Conditions

\begin{tabular}{|c|c|c|c|c|c|c|c|c|c|c|c|c|c|c|}
\hline $\begin{array}{l}\text { Yehicle } \\
\text { Class }\end{array}$ & $\begin{array}{c}6 \\
(\mathrm{~L} / 100 \\
\mathrm{km})\end{array}$ & $\begin{array}{c}\text { D } \\
(\text { L/100 } \\
\mathrm{km})\end{array}$ & $\begin{array}{c}P \\
(L / 100 \\
\mathrm{km})\end{array}$ & $\begin{array}{c}\text { CNG } \\
(\mathrm{m} 3 / 100 \\
\mathrm{km})\end{array}$ & $\begin{array}{l}\text { LNG } \\
(\text { L/100 } \\
\mathrm{km})\end{array}$ & $\begin{array}{c}E 10 \\
(L / 100 \\
\mathrm{km})\end{array}$ & $\begin{array}{c}\begin{array}{c}E 85 \\
(L / 100 \\
\mathrm{km})\end{array} \\
\end{array}$ & $\begin{array}{c}M 85 \\
(L / 100 \\
\mathrm{km})\end{array}$ & $\begin{array}{c}E D 10 \\
(L / 100 \\
\mathrm{km})\end{array}$ & $\begin{array}{c}B 100 \\
(\mathrm{~L} / 100 \\
\mathrm{km})\end{array}$ & $\begin{array}{c}\text { HYB } \\
(2 / 100 \\
\mathrm{km})\end{array}$ & $\begin{array}{c}\text { PHEV } \\
(\mathrm{CHJ/100} \\
\mathrm{km})\end{array}$ & \begin{tabular}{c|}
$\mathrm{EV}$ \\
$(\mathrm{NIJ/100}$ \\
$\mathrm{km})$
\end{tabular} & $\begin{array}{l}F C \\
(2 / 100 \\
\mathrm{km})\end{array}$ \\
\hline LDPV-A & 10.55 & 7.85 & 14.02 & 10.21 & 0 & 10.83 & 13.58 & 17.03 & 0 & 0 & 6.18 & 160.24 & 106.03 & 11.07 \\
\hline LDPV-T & 13.56 & 11.44 & 18.02 & 13.12 & 0 & 13.92 & 17.59 & 21.9 & 0 & 0 & 7.95 & 205.96 & 136.28 & 14.23 \\
\hline LDCV & 17.63 & 14.54 & 23.42 & 17.06 & 0 & 18.09 & 22.86 & 28.46 & 0 & 0 & 10.33 & 267.73 & 177.15 & 18.5 \\
\hline MDCV & 27.27 & 24.78 & 47.16 & 31.72 & 42.52 & 0 & 0 & 0 & 25.8 & 25.96 & 0 & 0 & 0 & 0 \\
\hline $\mathrm{HDCV}$ & 37.09 & 40.15 & 76.41 & 51.4 & 68.89 & 0 & 0 & 0 & 41.8 & 42.07 & 0 & 0 & 0 & 0 \\
\hline BUS & 36.75 & 55.15 & 104.95 & 70.6 & 94.62 & 0 & 0 & 0 & 57.41 & 57.78 & 33.41 & 0 & 0 & 79.37 \\
\hline TB & 0 & 0 & 0 & 0 & 0 & 0 & 0 & 0 & 0 & 0 & 0 & 0 & 86.64 & 0 \\
\hline LR-E & 0 & 0 & 0 & 0 & 0 & 0 & 0 & 0 & 0 & 0 & 0 & 0 & 78.49 & 0 \\
\hline LR-D & 0 & 5.64 & 0 & 0 & 0 & 0 & 0 & 0 & 0 & 0 & 0 & 0 & 0 & 0 \\
\hline SM & 0 & 0 & 0 & 0 & 0 & 0 & 0 & 0 & 0 & 0 & 0 & 0 & 58.47 & 0 \\
\hline HR & 0 & 5.03 & 0 & 0 & 0 & 0 & 0 & 0 & 0 & 0 & 0 & 0 & 0 & 0 \\
\hline
\end{tabular}

Source: See User Guide

\section{Highway Driving Conditions}

\begin{tabular}{|c|c|c|c|c|c|c|c|c|c|c|c|c|c|c|c|}
\hline $\begin{array}{l}\text { Vehicle } \\
\text { Class }\end{array}$ & $\frac{\mathrm{Q}}{(\mathrm{L} / \mathrm{100}}$ & $\begin{array}{c}\text { D } \\
(\mathrm{L} / \mathrm{100} \\
\mathrm{km})\end{array}$ & $\frac{\text { P }}{(\mathrm{L} / \mathrm{100}}$ & $\begin{array}{c}\text { CNG } \\
(\mathrm{m} 3 / 100 \\
\mathrm{km})\end{array}$ & $\begin{array}{c}\text { LNG } \\
\left(\begin{array}{l}\mathrm{L} / \mathrm{100} \\
\mathrm{km})\end{array}\right.\end{array}$ & $\begin{array}{c}\mathrm{E} 10 \\
\mathrm{CL} / 100 \\
\mathrm{~km})\end{array}$ & $\begin{array}{c}\text { E85 } \\
(\mathrm{L} / \mathrm{200} \\
\mathrm{km})\end{array}$ & $\begin{array}{c}\text { M85 } \\
\text { (L/100 } \\
\text { km) }\end{array}$ & $\begin{array}{c}\text { Eb10 } \\
(\mathrm{L} / 100 \\
\mathrm{km})\end{array}$ & $\begin{array}{c}\text { B100 } \\
(\mathrm{L} / \mathrm{100} \\
\mathrm{km})\end{array}$ & $\begin{array}{c}\text { HYB } \\
(\mathrm{L} / \mathrm{200} \\
\mathrm{km})\end{array}$ & $\begin{array}{c}\text { PHEV } \\
\text { (CMY/100 } \\
\text { km) }\end{array}$ & $\frac{\mathrm{EV}}{(\mathrm{CHJ} / 100}$ & $\begin{array}{c}\text { FC } \\
(\mathrm{L} / \mathrm{100} \\
\mathrm{km})\end{array}$ & $\begin{array}{c}\mathrm{PC} \\
(\mathrm{L} / \mathrm{100} \\
\mathrm{km})\end{array}$ \\
\hline LDPV-A & 8.12 & 6.04 & 10.78 & 7.85 & 0 & 8.33 & 0 & 10.53 & 13.1 & 0 & 0 & 6.58 & 168.38 & 108.49 & 10.42 \\
\hline LDPV-T & 10.43 & 8.8 & 13.86 & 10.1 & 0 & 10.71 & 0 & 13.53 & 16.84 & 0 & 0 & 8.46 & 216.43 & 139.44 & 13.39 \\
\hline LDCV & 13.56 & 11.19 & 18.02 & 13.12 & 0 & 13.92 & 0 & 17.59 & 21.89 & 0 & 0 & 11 & 281.33 & 181.26 & 17.41 \\
\hline MDCV & 20.98 & 19.06 & 36.27 & 24.4 & 32.7 & 0 & 19.97 & 0 & 0 & 19.84 & 19.97 & 0 & 0 & 0 & 0 \\
\hline $\mathrm{HDCV}$ & 28.53 & 30.89 & 58.78 & 39.54 & 52.99 & 0 & 32.36 & 0 & 0 & 32.15 & 32.36 & 0 & 0 & 0 & 0 \\
\hline BUS & 28.27 & 42.42 & 80.73 & 54.31 & 72.79 & 0 & 44.45 & 0 & 0 & 44.16 & 44.45 & 35.56 & 0 & 0 & 75.32 \\
\hline TB & 0 & 0 & 0 & 0 & 0 & 0 & 0 & 0 & 0 & 0 & 0 & 0 & 0 & 86.64 & 0 \\
\hline LR-E & 0 & 0 & 0 & 0 & 0 & 0 & 0 & 0 & 0 & 0 & 0 & 0 & 0 & 78.49 & 0 \\
\hline LR-D & 0 & 5.64 & 0 & 0 & 0 & 0 & 0 & 0 & 0 & 0 & 0 & 0 & 0 & 0 & 0 \\
\hline SM & 0 & 0 & 0 & 0 & 0 & 0 & 0 & 0 & 0 & 0 & 0 & 0 & 0 & 58.47 & 0 \\
\hline HR & 0 & 5.03 & 0 & 0 & 0 & 0 & 0 & 0 & 0 & 0 & 0 & 0 & 0 & 0 & 0 \\
\hline
\end{tabular}

Source: (Transport Canada, 2008c).

*Note: $\mathrm{G}=$ Gasoline; $\mathrm{D}=$ Diesel.

LDPV-A = Light Duty Passenger Vehicle - Automobile

LDPV-T $=$ Light Duty Passenger Vehicle - Truck / Sports Utility Vehicle 
Table F-2: 2030 Fuel Efficiency by Vehicle Class Used in the UTEC Model Fuel Efficiency by Vehicle Class

2031

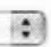

\section{City Driving Conditions}

\begin{tabular}{|c|c|c|c|c|c|c|c|c|c|c|c|c|c|c|}
\hline $\begin{array}{l}\text { Yehicle } \\
\text { Clans }\end{array}$ & $\begin{array}{c}\mathrm{G} \\
(\mathrm{L} / 100 \\
\mathrm{km})\end{array}$ & $\begin{array}{c}D \\
(L / 100 \\
\mathrm{km})\end{array}$ & $\underset{\substack{(\mathrm{L} / 100 \\
\mathrm{~km})}}{P}$ & $\begin{array}{c}\text { CNG } \\
(\mathrm{m} 3 / 100 \\
\mathrm{km})\end{array}$ & $\begin{array}{c}\text { LNG } \\
\left(\begin{array}{c}\text { L/100 } \\
\mathrm{km})\end{array}\right.\end{array}$ & $\begin{array}{c}E 10 \\
(L / 100 \\
(\mathrm{km})\end{array}$ & $\begin{array}{c}E 35 \\
(L / 100 \\
\mathrm{km})\end{array}$ & $\begin{array}{c}\text { M85 } \\
(\mathbf{L} / 100 \\
\mathrm{lm})\end{array}$ & $\begin{array}{c}\begin{array}{c}E 010 \\
(L / 100 \\
(\mathrm{km})\end{array} \\
\end{array}$ & $\begin{array}{c}\text { B100 } \\
\left(\begin{array}{c}\mathrm{L} / 100 \\
\mathrm{~km})\end{array}\right.\end{array}$ & $\begin{array}{c}\text { HYB } \\
(L / 100 \\
\mathrm{km})\end{array}$ & $\begin{array}{l}\text { PHEY } \\
(\mathrm{M} / 1 \mathrm{100} \\
\mathrm{km})\end{array}$ & $\begin{array}{c}\mathrm{EV} \\
(\mathrm{NH} / 100 \\
\mathrm{km})\end{array}$ & $\begin{array}{c}\text { FC } \\
(\text { L//100 } \\
\text { km) }\end{array}$ \\
\hline LDPV-A & 9.21 & 5.85 & 11.72 & 8.47 & 0 & 9.42 & 11.63 & 14.48 & 0 & 0 & 5.1 & 132.17 & 87.57 & 9.19 \\
\hline LDPV-T & 11.99 & 10.04 & 15.27 & 11.03 & 0 & 12.27 & 15.16 & 18.87 & 0 & 0 & 6.64 & 172.18 & 114.08 & 11.97 \\
\hline LDCV & 15.62 & 13.02 & 19.9 & 14.37 & 0 & 15.99 & 19.75 & 24.58 & 0 & 0 & 8.65 & 224.32 & 148.62 & 15.59 \\
\hline MDCV & 22.37 & 19.65 & 36.63 & 24.64 & 33.21 & 0 & 0 & 0 & 20.46 & 20.59 & 0 & 0 & 0 & 0 \\
\hline $\mathrm{HOCV}$ & 31.89 & 34.79 & 64.84 & 43.61 & 58.78 & 0 & 0 & 0 & 36.21 & 36.44 & 0 & 0 & 0 & 0 \\
\hline BUS & 32.14 & 46.78 & 87.19 & 58.65 & 79.05 & 0 & 0 & 0 & 48.69 & 49.01 & 26.76 & 0 & 0 & 64.16 \\
\hline TB & 0 & 0 & 0 & 0 & 0 & 0 & 0 & 0 & 0 & 0 & 0 & 0 & 86.64 & 0 \\
\hline LR-E & 0 & 0 & 0 & 0 & 0 & 0 & 0 & 0 & 0 & 0 & 0 & 0 & 78.49 & 0 \\
\hline$L R \cdot D$ & 0 & 5.64 & 0 & 0 & 0 & 0 & 0 & 0 & 0 & 0 & 0 & 0 & 0 & 0 \\
\hline SM & 0 & 0 & 0 & 0 & 0 & 0 & 0 & 0 & 0 & 0 & 0 & 0 & 58.47 & 0 \\
\hline HR & 0 & 5.03 & 0 & 0 & 0 & 0 & 0 & 0 & 0 & 0 & 0 & 0 & 0 & 0 \\
\hline
\end{tabular}

Source: See User Guide

Highway Driving Conditions

\begin{tabular}{|c|c|c|c|c|c|c|c|c|c|c|c|c|c|c|c|}
\hline $\begin{array}{l}\text { Yehicle } \\
\text { Class }\end{array}$ & $\begin{array}{c}\mathrm{g} \\
(\mathrm{L} / 100 \\
\mathrm{km})\end{array}$ & $\begin{array}{c}D \\
(L / 100 \\
\mathrm{km})\end{array}$ & $\underset{\substack{(L / 100 \\
\mathrm{~km})}}{P}$ & $\begin{array}{c}\text { CNG } \\
(\mathrm{m} 3 / 100 \\
\mathrm{km})\end{array}$ & $\begin{array}{c}\text { LNG } \\
(\mathrm{L} / 100 \\
\mathrm{km})\end{array}$ & $\begin{array}{l}\text { E10 } \\
(\mathrm{L} / 100 \\
\mathrm{km})\end{array}$ & $\begin{array}{c}E B 5 \\
(L / 100 \\
\mathrm{km})\end{array}$ & $\begin{array}{c}M 85 \\
(L / 100 \\
\mathrm{km})\end{array}$ & $\begin{array}{c}\text { ED10 } \\
(L / 100 \\
\mathrm{km})\end{array}$ & $\begin{array}{c}\text { B100 } \\
(L / 100 \\
\mathrm{km})\end{array}$ & $\begin{array}{l}\text { HYB } \\
(L / 100 \\
\mathrm{km})\end{array}$ & $\begin{array}{c}\text { PHEV } \\
(\mathrm{MJ} / 100 \\
\mathrm{km})\end{array}$ & $\begin{array}{c}E \mathrm{~V} \\
(\mathrm{MJ} / \mathrm{100} \\
\mathrm{km})\end{array}$ & $\begin{array}{c}F C \\
(L / 100 \\
\mathrm{km})\end{array}$ & $\begin{array}{c}\text { FC } \\
(L / 100 \\
\mathrm{km})\end{array}$ \\
\hline LDPV -A & 7.08 & 5.27 & 9.02 & 6.51 & 0 & 7.25 & 0 & 8.95 & 11.14 & 0 & 0 & 5.34 & 138.09 & 91 & 8.42 \\
\hline LDPV-T & 9.22 & 7.72 & 11.75 & 8.48 & 0 & 9.44 & 0 & 11.66 & 14.51 & 0 & 0 & 6.95 & 179.89 & 118.54 & 10.97 \\
\hline LDCV & 12.02 & 10.02 & 15.3 & 11.05 & 0 & 12.3 & 0 & 15.19 & 18.91 & 0 & 0 & 9.06 & 234.36 & 154.44 & 14.3 \\
\hline MDCV & 17.21 & 15.12 & 28.18 & 18.96 & 25.55 & 0 & 15.84 & 0 & 0 & 15.74 & 15.84 & 0 & 0 & 0 & 0 \\
\hline $\mathrm{HDCV}$ & 24.53 & 26.76 & 49.87 & 33.55 & 45.22 & 0 & 28.03 & 0 & 0 & 27.85 & 28.03 & 0 & 0 & 0 & 0 \\
\hline BUS & 24.72 & 35.98 & 67.07 & 45.11 & 60.8 & 0 & 37.7 & 0 & 0 & 37.46 & 37.7 & 28.04 & 0 & 0 & 59.19 \\
\hline TB & 0 & 0 & 0 & 0 & 0 & 0 & 0 & 0 & 0 & 0 & 0 & 0 & 0 & 86.64 & 0 \\
\hline LR-E & 0 & 0 & 0 & 0 & 0 & 0 & 0 & 0 & 0 & 0 & 0 & 0 & 0 & 78.49 & 0 \\
\hline LR-D & 0 & 5.64 & 0 & 0 & 0 & 0 & 0 & 0 & 0 & 0 & 0 & 0 & 0 & 0 & 0 \\
\hline SM & 0 & 0 & 0 & 0 & 0 & 0 & 0 & 0 & 0 & 0 & 0 & 0 & 0 & 58.47 & 0 \\
\hline HR & 0 & 5.03 & 0 & 0 & 0 & 0 & 0 & 0 & 0 & 0 & 0 & 0 & 0 & 0 & 0 \\
\hline
\end{tabular}

Source: (Transport Canada, 2008d).

*Note: $\mathrm{G}=$ Gasoline; $\mathrm{D}=$ Diesel.

LDPV-A = Light Duty Passenger Vehicle - Automobile

LDPV-T $=$ Light Duty Passenger Vehicle - Truck / Sports Utility Vehicle 


\section{GLOSSARY OF TERMS}

AQBAT: Air Quality Benefit Assessment Tool

CAC: Criteria Air Contaminants

CBD: $\quad$ Central Business District

CMA: Census Metropolitan Area

CMHC: Canadian Mortgage and Housing Corporation

CO: $\quad$ Carbon Monoxide

COPD: $\quad$ Chronic Obstructive Pulmonary Disease

EAA: Environmental Assessment Act, 1990

GGH: Greater Golden Horseshoe

GHG: $\quad$ Greenhouse Gas

GTA: $\quad$ Greater Toronto Area

LDPV: Light-duty Personal Vehicle

$\mathrm{N}_{2} \mathrm{O}: \quad$ Nitrous Oxide

$\mathrm{NH}_{3}: \quad$ Ammonia

NO: $\quad$ Nitric Oxide

$\mathrm{NO}_{2}: \quad$ Nitrogen Dioxide

$\mathrm{NO}_{\mathrm{x}}: \quad$ Nitrogen Oxide Gases

NPRI: National Pollutant Release Inventory

$\mathrm{O}_{3}: \quad$ Ozone

OMB: $\quad$ Ontario Municipal Board

PM: $\quad$ Particulate Matter

$\mathrm{PM}_{10}$ : Particulate Matter under $10 \mu \mathrm{m}$ 
$\mathrm{PM}_{2.5}: \quad$ Particulate Matter under $2.5 \mu \mathrm{m}$

PPS: $\quad$ Provincial Policy Statement

$\mathrm{SO}_{2}: \quad$ Sulphur Dioxide

$\mathrm{SO}_{\mathrm{x}}: \quad$ Sulphur Oxides

TENS: $\quad$ Tool for Evaluating Neighbourhood Sustainability

TPM: Total Particulate Matter

TTC: Toronto Transit Commission

TTS: $\quad$ Transportation Tomorrow Study

UTEC: Urban Transportation Emissions Calculator

VHT: Vehicle Hours Traveled

VKT: $\quad$ Vehicle Kilometers Traveled

VOC: $\quad$ Volatile Organic Compounds 